Florida International University FIU Digital Commons

$11-7-2008$

\title{
Melanocytes in the developing and adult atrioventricular valves of the murine heart
}

Flavia Carneiro Brito

Florida International University

DOI: $10.25148 /$ etd.FI14051843

Follow this and additional works at: https://digitalcommons.fiu.edu/etd

Part of the Biology Commons

\section{Recommended Citation}

Brito, Flavia Carneiro, "Melanocytes in the developing and adult atrioventricular valves of the murine heart" (2008). FIU Electronic Theses and Dissertations. 2246.

https://digitalcommons.fiu.edu/etd/2246

This work is brought to you for free and open access by the University Graduate School at FIU Digital Commons. It has been accepted for inclusion in FIU Electronic Theses and Dissertations by an authorized administrator of FIU Digital Commons. For more information, please contact dcc@fiu.edu. 
FLORIDA INTERNATIONAL UNIVERSITY

Miami, Florida

\title{
MELANOCYTES IN THE DEVELOPING AND ADULT ATRIOVENTRICULAR
} VALVES OF THE MURINE HEART

\author{
A dissertation submitted in partial fulfillment of the \\ requirements for the degree of \\ DOCTOR OF PHILOSOPHY \\ in \\ BIOLOGY \\ by
}

Flavia Carneiro Brito 


\section{To: Dean Kenneth Furton}

\section{College of Arts and Sciences}

This dissertation, written by Flavia Carneiro Brito, and entitled Melanocytes in the Developing and Adult Atrioventricular Valves of the Murine Heart, having been approved in respect to style and intellectual content, is referred to you for judgment.

We have read this dissertation and recommend that it be approved.

Fatma Huffman

Leung Kim

Fernando Noriega

Ophelia Weeks

Lidia Kos, Major Professor

Date of defense: November 7, 2008

The dissertation of Flavia Carneiro Brito is approved.

Dean Kenneth Furton
College of Arts and Sciences

Florida International University, 2008 
(C) Copyright 2008 by Flavia Carneiro Brito

All rights reserved. 


\section{DEDICATION}

I dedicate this dissertation to my parents, grandparents and my friends. Without their support, patience and love, the completion of this work would not have been possible. 


\section{ACKNOWLEDGMENTS}

This work could not have been done if it were not for some very special people.

First, I want to thank my parents and grandparents for believing in me and supporting me when I decided to move to the USA. Their love, support and understanding were essential for every step I took. My husband and his family embraced me and their love was fundamental to the completion of my work.

Very special thanks to my aunt, Mara Carneiro and my uncle, Ronaldo Carneiro, who gave me a home to live during the first years. If it was not for them, I would not be here today. Thank you very much!

There are two people that inspired me at the beginning of my trajectory at FIU: Lidia Kos and Rita Patel. I want to thank them for all their help and especially, friendship. Lidia was a great professor and I learned so much from her that I would have to write another dissertation to explain it. Rita became one of my best friends here and she is one of the best persons I ever met.

During this time, I met some wonderful people that made the transition from Brazil to USA easier and worth it. I want to thank Beth, Ernesto and Gustavo Oliveira for their support, friendship, and for embracing me as a member of their family in Miami.

I also made some very good friends here. I want to thank Kim Brothers, Sylvia Donna, Veronica Jubera, Sophie Pino, Matt Weidinger, Varee Poochareon, Megan McDonalds and her family for being there for me and cheer me up when I needed it. My friends in Brazil were also very important and their support via email and phone calls 
helped me. Thanks Barbara Alvarenga, Rafael Maurer, Lizandra e Gabriel Moreira, Francisco Silva, Gabriela Volpe, and Graziela Volpe.

Graduate school gave me the chance to meet amazing people and share great moments with them. I would not graduate if it was not for my FIU friends and classmates. This group was so important to get me through that I am sure without them I would have failed. Much love and thanks to Amy Arent, Ana Paula Benaduce, Bryan Dewsburry, Adam Edwards, Anya Goldina, Matt Graham, Liz Harrison, Greg Koch, Marcy Lowenstein, Jay Munyon, Tom Pitzer, Sergio Ruiz, Vielka Salazar, Ralph Saporito, James Valdez, Josh Voss, and Clay Williams. It is impossible to describe how much they were and are important to me.

Very special thanks to Dr. Kruithof who taught me my first lessons on atrioventricular valve development and helped me with thoughts and ideas. I also want to thank some ex and current labmates for all their insights and help during those years. Thanks to Denisse Diaz, Natasha Fernandez, Roman Garcia, Avner Ittah, Sean Mandat, and Amy Saldana.

Thanks to Dr. Mo Donnelly who was the graduate program director during most of my time as a graduate student. The staff from the Department of Biological Sciences was very helpful. Thanks to Ingrid Asencio, Erin Dowd, Helen Forlong, Carola Martinez, and Evonne Palomino.

My committee members, Dr. Huffmann, Dr. Kim, Dr. Noriega and Dr. Weeks deserve very special thanks for their guidance and bright insights during the development of my dissertation. 
Without the support, love and guidance of all the persons mentioned, this work could not be completed. Thank you all. 


\section{ABSTRACT OF THE DISSERTATION \\ VALVES OF THE MURINE HEART \\ by \\ Flavia Carneiro Brito \\ Florida International University, 2008 \\ Miami, Florida \\ Professor Lidia Kos, Major Professor}

MELANOCYTES IN THE DEVELOPING AND ADULT ATRIOVENTRICULAR

The Neural Crest (NC) is a multipotential group of cells that arises from the dorsal aspect of the neural tube early in development. It is well established that a group of NC cells named Cardiac Neural Crest (CNC) migrates to the heart and plays a critical role in the remodeling of the aortic arch arteries and septation of the outflow tract. In this study, using the mouse mutant $P a x 3^{\text {sp/sp }}$ that has $\mathrm{CNC}$ deficits I have identified a putative novel role for the $\mathrm{CNC}$ in regulating apoptosis in the atrioventricular (AV) endocardial cushion. The AV endocardial cushion undergoes remodeling to give rise to the cardiac AV valves. Using a transgenic mouse that carries the $\mathrm{LacZ}$ reporter gene under the control of the Dopachrome tautomerase promoter (Dct-LacZ), I found that another NC derived population, melanocyte precursors, also contribute to the AV endocardial cushion and developing AV valves. The analysis of Dct-LacZ embryos at different stages showed that NC cells already committed to the melanocytic fate migrate to the heart along the same initial pathway taken by those that will populate the skin. Hypopigmented mice carrying mutations in the Kit and Endothelin receptor $b$ genes, that are critical for the proper development of skin melanocytes, do not have cardiac melanocytes indicating that 
cardiac and skin melanocyte precursors share the same initial signaling requirements. The analysis of murine adult hearts showed that melanocytes are mostly found in the atrial sides of the tricuspid and mitral valve leaflets. The distribution of melanocytes in the AV valves corresponds exactly to areas of high Versican B expression, a proteoglycan essential for the process of $\mathrm{AV}$ valve remodeling. To evaluate a potential role for melanocytes in the AV valves, a nanoindentation analysis of the tricuspid valves of wild type, hypopigmented and hyperpigmented mice was performed. The storage modulus, a measure of stiffness, for the leaflets obtained from hyperpigmented mice was considerably higher $(10.5 \mathrm{GPa})$ than that for the leaflets from wild type $(7.5 \mathrm{GPa})$ and hypopigmented animals (between 3.5 and $5.5 \mathrm{GPa}$ ) suggesting that melanocytes may contribute to the mechanical properties of the AV valves. 


\section{TABLE OF CONTENTS}

CHAPTER

PAGE

I. RESEARCH OVERVIEW ...............................................

1. Neural Crest Cells........................................................2

2. Melanocytes........................................................ 3

3. Cardiac Neural Crest Cells...............................................8

4. Heart Development.....................................................11

5. Research questions..................................................16

5.1 Do cardiac neural crest cells contribute to the proper development of the mammalian heart? .........................................17

5.2 When do NC derived melanocytes precursors reach the heart and what is migratory pathway they take to reach it? ....................18

5.3 Do NC derived melanocytes affect the ECM environment and mechanical properties of the AV valves? ...........................18

References

II. THE CONTRIBUTION OF NEURAL CREST DERIVED CELLS TO

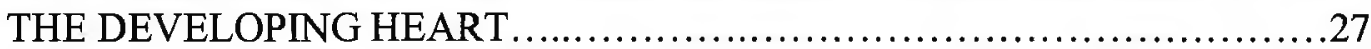

1. Cardiac Neural Crest Cells................................................28

2. The fates of Cardiac Neural Crest Cells...................................28

3. Cardiac Neural Crest Cells Markers....................................... 30

4. Alternative Roles for Cardiac Neural Crest Cells............................36

4.1 In the Myocardium...............................................36

4.2 In the Conduction System and AV Valves.........................37

4.3 As Stem Cells................................................41

References.

III. TIMELINE AND DISTRIBUTION OF MELANOCYTE PRECURSORS

IN THE MOUSE HEART ...............................................50

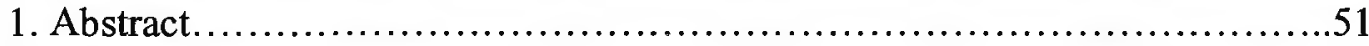

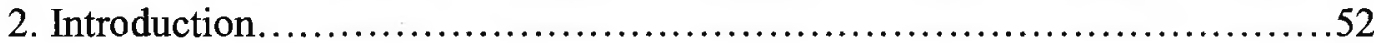

3. Results........................................................... 54

3.1 NC cells reach the heart already committed to the melanocytic fate...54

3.2 Cardiac melanocytes depend on Ednrb and Kit signaling.............59

3.3 Cardiac melanocytes are only found in four-chambered hearts........60

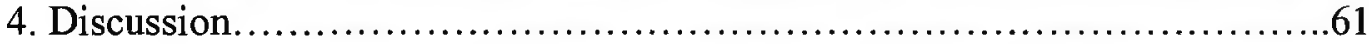

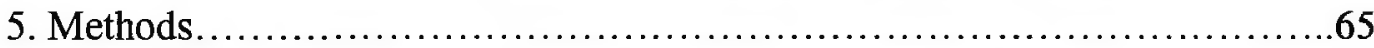

5.1 Mice..........................................................65

5.2 Semi-quantitative Reverse Transcription Polymerase Chain Reaction (RT-PCR) ......................................66

$5.3_{\mathrm{L}}$ - Dopa, $\beta$-galactosidase staining and in situ hybridization..........66

References. 
IV. THE LOCALIZATION OF MELANOCYTES AND ITS CO-EXPRESSION WITH ECM PROTEINS IN THE ATRIOVENTRICULAR VALVES ..........72

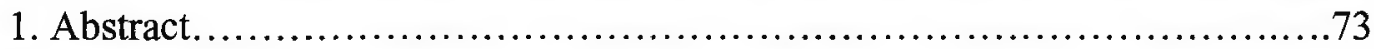

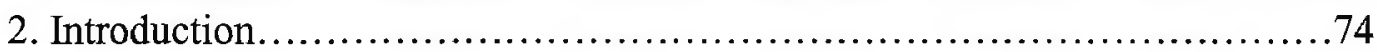

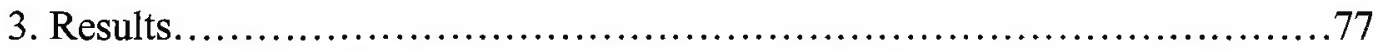

3.1 The localization of melanocytes in the valves.....................77

3.2 Correlation between melanocytes localization and extracellular matrix expression in the AV valves.................................84

3.3 Mechanical properties of the AV leaflets.........................86

4. Discussion............................................................ 91

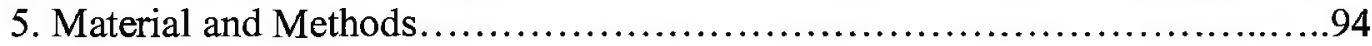

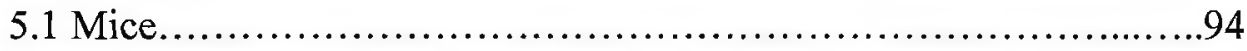

$5.2_{\mathrm{L}}$ - Dopa and antibody staining..................................94

5.3 Nanodynamic mechanical test.................................95

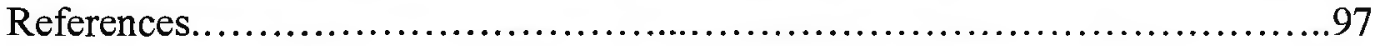

V. SUMMARY AND FUTURE DIRECTIONS ....................................100

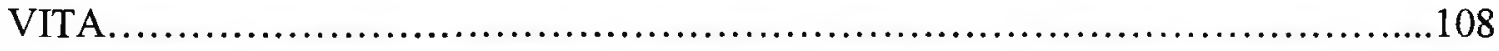




\section{LIST OF FIGURES}

FIGURE

PAGE

1. The four main regions of the chicken neural crest migration sites................... 3

2. Dct-LacZ transgenic mouse demonstrating melanocytes in the embryo..............5

3. Diagram of the cardiac neural crest cells in a chick embryo........................8

4. Electron micrographs of whole hearts from wild type and $\mathrm{Sp}$ at E13.5.............11

5. Proposed model of the development of the AV valves........................... 15

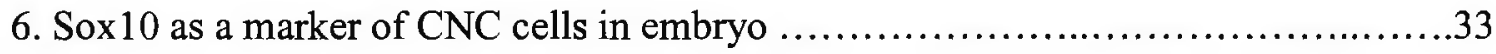

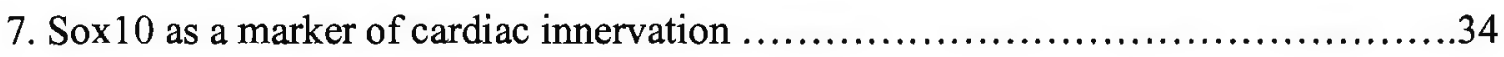

8. Dct as a marker for $\mathrm{NC}$ derived cardiac melanocytes................................ 36

9. Cryosection of an E12.5 wild type heart......................................40

10. E12.5 Wild type and splotch $\left(\mathrm{Sp}^{2 \mathrm{H}}\right)$ hearts.................................. 40

11. Melanocyte precursors are found in the heart as early as E14.5 $\ldots \ldots \ldots \ldots \ldots \ldots \ldots . . . .55$

12. The earliest time melanocyte precursors were found in the heart was E12.5 $\ldots . \ldots . . .57$

13. Melanocyte precursors have not yet reached the heart or outflow tract at E10.5.....58

14. Cardiac melanocytes depend on Edn3/Ednrb and Kit signaling..................60

15. Melanocytes are only found in four-chambered hearts..........................61

16. Schematic diagram of the leaflets of a valve.................................. 77

17. Distribution of melanocytes in post-natal AV valve development..................79

18. Distribution of melanocytes in post-natal SL valve development..................81

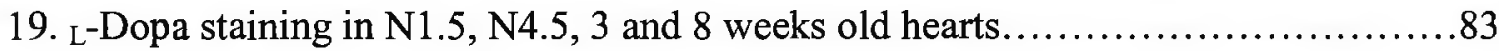

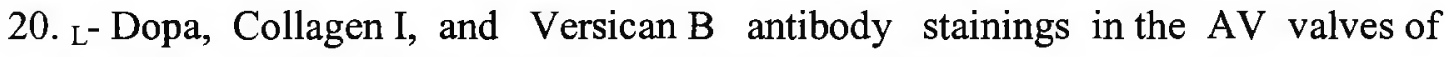
hypopigmented wild type and hyperpigmented hearts............................ 85 
21. L- Dopa, Collagen I, and Versican B antibody stainings in the pulmonary valves of wild type and hyperpigmented hearts........................................... 86

22. Load displacement curve on tricuspid leaflet and corresponding SPM image of

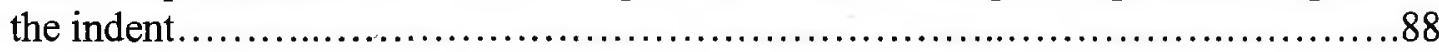

23. Modulus Variation with Contact Depth of the tricuspid leaflet......................89

24. Modulus Variation with Contact Depth of the tricuspid leaflet of hypopigmented $\left(\mathrm{Kit}^{\mathrm{W}-\mathrm{v} / \mathrm{W}-\mathrm{v}}\right.$ and $\left.\mathrm{EdnrB}^{\mathrm{s}-\mathrm{s}-\mathrm{s}}\right)$ (red line), wild type (green line) and hyperpigmented (K5tTA;TRE-Edn3) (blue line), hearts.................................................99 


\section{ABBREVIATIONS}

\section{ABBREVIATIONS}

FULL NAME

AV

$D c t$

cDNA

CCS

$\mathrm{CNC}$

CRABPI

DNA

E

E3

ECM

$E d n 3^{l s / s}$

Ednra

Ednrb

$E d n r b^{s-l / s-l}$

EMT

End1

End2

End3

FGF

GFP
Atrioventricular

Dopachrome tautomerase

Complementary Deoxyribonucleic acid Cardiac Conduction System Cardiac Neural Crest Cellular Retinoic Acid Binding protein I Deoxyribonucleic acid Embryonic day Endothelin 3 transgene Extracellular Matrix Lethal spotting Endothelin receptor $A$ Endothelin receptor $B$ Piebald Lethal

Epithelial Mesenchymal Transformation Endothelin 1 Endothelin 2 Endothelin 3 Fibroblast Growth Factors Green Fluorescent protein 
$\mathrm{K} 5-t T A$

Kitl

$K i t^{W v}$

$K i t^{W-v / W-v}$

$\mathrm{LacZ}$

L- Dopa

$M i$

mRNA

$\mathrm{NC}$

OFT

PBS

PCR

RNA

RT-PCR

$S l$

SMCs

$S p$

$\operatorname{Trp} 2$

UV

$\mu 1$

$W$

Wt
Keratin $5 t T A$ transgene

Kit- ligand

Tyroninase kinase receptor

Viable Dominant Spotting

$\beta$ - galactosidase

3,4- dihydroxy- L- phenylalanine Microphthalmia

Messenger Ribonucleic acid Neural Crest

Outflow tract

Phosphate Buffered Saline

Polymerase Chain Reaction

Ribonucleic acid

Reverse transcriptase PCR

Steel

Smooth Muscle Cells

Splotch

Tyrosinase related protein 2

Ultra violet

Microliter

Dominant White Spotting

Wild type 
CHAPTER I: RESEARCH OVERVIEW 


\section{Neural Crest cells}

The neural crest (NC) cells are derived from an epithelial lineage arising from the dorsal part of the ectoderm. They emerge from the junction of the dorsal part of the neural tube and the future epidermis (Schoenwolf and Nichols, 1984). NC cells leave the neural tube at all axial levels and contribute a variety of cell types. The crest is divided into four main regions. The cranial NC provides cells that migrate dorsolateraly to produce the craniofacial mesenchyme which will differentiate into cartilage, bone, cranial nerves, glia, and connective tissue of the face. Part of the cranial NC cells also invade the pharyngeal arches and pouches to give rise to the odontoblasts of the tooth primordia, thymic cells, and the bones of the jaw and middle ear. The trunk NC cells undertake two major pathways, namely, ventromedial and dorsolateral. Those cells that take the ventromedial pathway give rise to neurons and glia of the peripheral nervous system as well as some endocrine cells (Gilbert, 2006). The later-migrating trunk NC cells migrate between the surface ectoderm and the somites (dorsolateral pathway) and give rise to the pigment cell precursors, the melanoblasts, which will eventually populate the skin (Le Douarin and Kalcheim, 1999). The cells that originate from the vagal and sacral regions of the NC generate the parasympathetic ganglia of the gut. The absence of peristaltic movement in the bowels of the colon is caused by failure in the migration of the NC cells from those two regions (Le Douarin and Teillet, 1973). Cells that originate from the first to the third somite of the vagal NC are called cardiac neural crest (CNC) cells (Kirby, 1987; Kirby and Waldo, 1990) which can develop into melanocytes, cartilage, neurons, or connective tissue. Additionally, those cells can give rise to the entire muscular- 
connective tissue wall of the large arteries (outflow tract) and contribute to the septation of the pulmonary circulation from the aorta (Le Lièvre and Le Douarin, 1975).

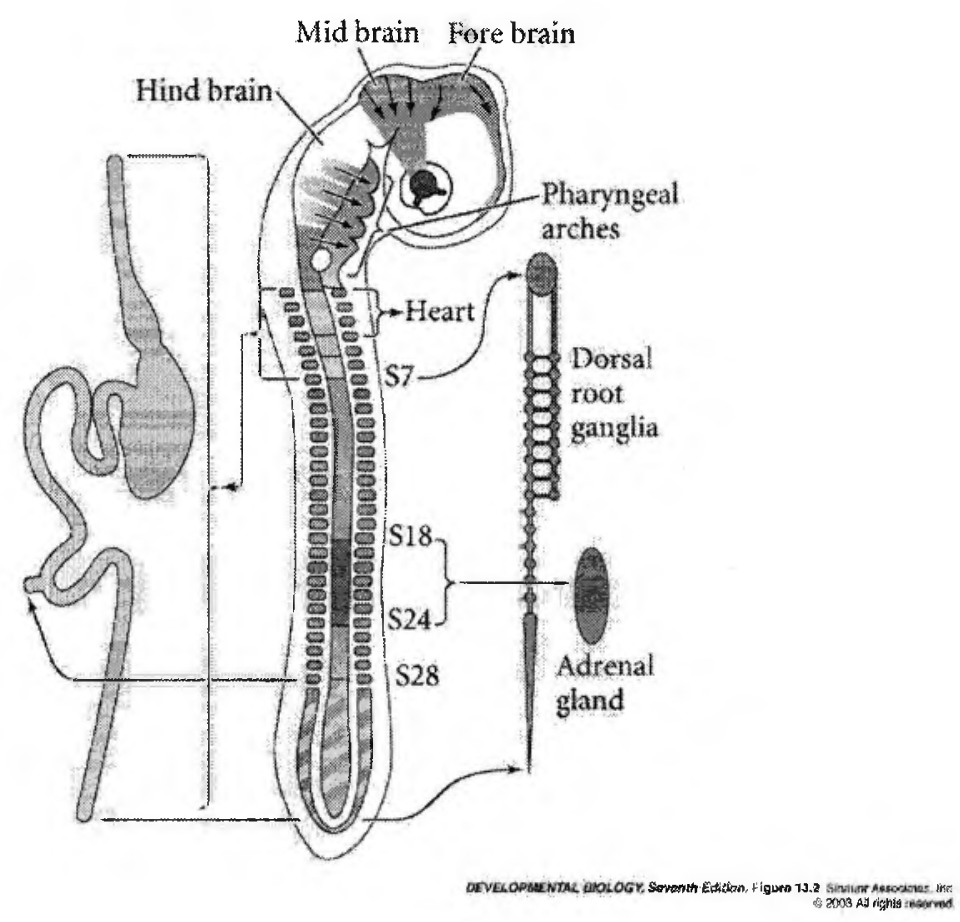

Figure 1. The four main regions of the chicken neural crest (NC) migration sites. The cranial NC migrates into the face of the embryo to form bones and cartilage, and into the pharyngeal arches and it is also responsible for the cranial nerves. The vagal NC (near somites 1-7) and the sacral NC (posterior to somite 28) are responsible for the formation of the parasympathetic nerves of the gut. The NC cells of the trunk, which arise around somite 6 until the tail, make sympathetic neurons, melanocytes, and a subset of these (between somites 18 and 24) form the mesulla portion of the adrenal gland. The cardiac neural crest (CNC) cells arise near somites 1-3 and are critical for the division of between the aorta and pulmonary artery being essential for the proper development of the outflow tract of the heart (Gilbert, 2006).

\section{Melanocytes}

In the mouse embryo, melanoblasts leave the dorsal part of the neural tube at embryonic day 9-9.5 (E9- 9.5) and at this developmental stage they are found in the olfactory placode, otic vesicle, optic cup, optic eminence, and telencephalon (MacKenzie 
et al., 1997; Steel et al., 1992; Yoshida et al., 1996). By E10.5, the melanoblasts are located over the mesencephalon extending forward towards the eyes and are lightly scattered over the dorsolateral aspect of the trunk and tail neural tube (MacKenzie et al., 1997) (Figure 2A). At E11 this group of cells can be found throughout the trunk and sacral regions (Lee et al., 2003). At E11.5, the melanoblasts persist in the trunk with a non-uniform pattern along the anterior- posterior axis, with the premier densities around the base of the tail, hindlimbs, and head (Pavan and Tilghman, 1994). By E12.5 melanoblasts are found surrounding the eyes, in a broad band curving back beyond the ear to the shoulder region, and in the spinal cord wall into the tail (MacKenzie et al., 1997). At this stage, an increased number of melanoblasts are found caudal to the hindlimbs and at (as well as rostral to) the forelimbs. A day or two later, these cells start entering the hindlimbs (MacKenzie et al., 1997). Between E12.5 and E14.5, melanoblasts start accumulating in the pinna. These cells have been shown to contribute to the stria vascularis of the inner ear (MacKenzie et al., 1997). At El3.5 almost the entire surface of the embryo is covered by melanoblasts (Figure 2B). 


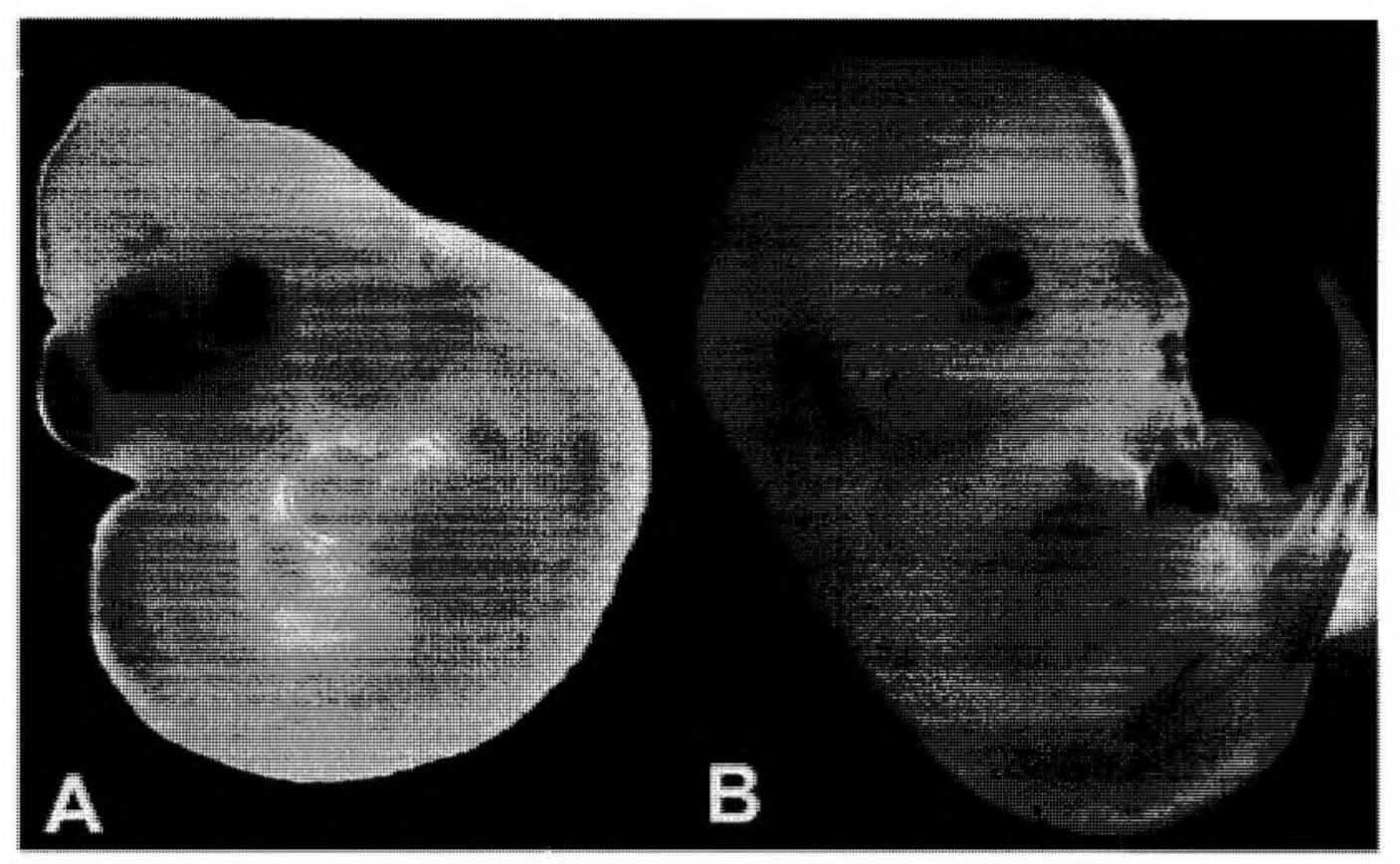

Figure 2. Dct-LacZ transgenic mouse demonstrating melanocytes in the embryo. (A) Whole mount E10.5 embryo from a Dct-LacZ transgenic mouse showing the presence of most melanoblasts in the post-otic area. Few melanoblasts are found more ventrally at the level of somites. (B) Whole mount E13.5 Dct-LacZ embryo demonstrating the number of melanocytes on the surface of the embryo.

The analysis of mutations associated with pigment abnormalities have contributed to the elucidation of various genetic pathways involved in melanocyte biology and development. In the mouse alone, more than 100 different loci have been described that either affect the generation of pigment cells or the quality of their pigment. About a quarter of these loci have now been analyzed molecularly, and it has become apparent that melanocyte development is controlled by a variety of transcription factors and signaling systems, in addition to proteins involved in melanin synthesis and processing. For instance, mutations in melanogenic enzymes such as tyrosinase cause albinism in mice. Mutations in the tyrosine kinase receptor Kit and its ligand Kitl (also known as mast cell growth factor/Steel factor) are responsible for the hypopigmentation, fertility 
and hematopoetic defects in Dominant white spotting $(W)$ and Steel $(S l)$ mice, respectively. Naturally occurring mutations in the transcription factors Pax3 and Mitf have been shown to be responsible for the hypopigmentation, deafness, skeletal muscle and neural tube defects of Splotch mice $(S p)$ or hypopigmentation, deafness, and retinal defects of Microphthalmia (Mi) mice, respectively (reviewed by Barsh, 1996; Jackson, 1997). The hypopigmentation phenotype of these mutants has been attributed to disruptions in the normal development of melanocytes. They affect melanoblasts during their very early steps of migration from the neural tube to the dermis. Since the pigmentation defect in these mutants is accompanied by disruptions in the development of other $\mathrm{NC}$ derived or non $\mathrm{NC}$ derived cell lineages, the analysis of pigment loci is thus important far beyond the narrow goal of understanding pigmentation.

Mutations in the piebald and lethal spotting loci produce similar phenotypes characterized by varying degrees of pigment loss and aganglionic megacolon owing to lack of NC derived enteric ganglion cells in the hindgut. The gene affected in piebald mice encodes the Endothelin receptor $b(E d n r b)$, a G-coupled seven transmembrane receptor (Hosoda et al., 1994), whose human homolog, EDNRB, is mutated in approximately $5 \%$ of cases with Hirschsprung disease (Chakravarti, 1996; Puffenberger et al., 1994). Ednrb mutations have also been identified at the spotting lethal locus in the rat (Ceccherini et al., 1995; Gariepy et al., 1996; Shin et al., 1997) and in horses with the lethal white foal syndrome (Santschi et al., 1998). The murine lethal spotting locus encodes the Ednrb ligand, Endothelin 3 (End3) (Baynash et al., 1994). End3 is a member of a group of three related peptides, End1, End2, and End3, each encoded by a separate 
gene. The peptides are produced as inactive pre-proendothelins that undergo successive proteolytic cleavages to generate the 22 amino acid active endothelins.

The developmental expression patterns of Ednrb and End3 have been analyzed mostly in avian embryos. These studies showed that End3 is expressed in the environment through which NC cells migrate while $E d n r b$ is expressed by the NC cells themselves (Nataf et al., 1996, 1998). A recent study in using a targeted mouse mutant in which the LacZ reporter gene was inserted into the Ednrb locus has shown that the mammalian pattern of expression is very similar to that of avians (Lee et al., 2003). In both quail and mouse the effects of End 3 on in vitro NC development has been studied in some detail. End 3 markedly increases the proliferation of pluripotent neural crest cells and eventually stimulates dramatic increases in the number of melanocytes (Lahav et al., 1996; Stone et al., 1997). This has been confirmed by an in vivo study using transgenic mice in which End3 has been put under the control of the keratin 5 promoter. These transgenic mice show an increase in the number of melanoblasts during embryonic development and adults show a hyperpigmentation phenotype due to the accumulation of melanocytes in the skin (Garcia et al., 2008).

In mice homozygous for Ednrb (piebald lethat), in which the Ednrb gene is deleted (Hosoda et al., 1994), there is a drastic reduction in the number of melanocyte precursors from the time they can be detected by the expression of the Dopachrome tautomerase marker (Dct, also referred to as tyrosinase related protein 2, $\operatorname{Trp} 2) . D c t$ is first detected at E10.5 as melanoblasts have already undertaken the dorsolateral migratory pathway. This suggests that the expression of functional $E d n r b$ is important for the proper development of melanocytes before or just at E10.5 (Pavan and Tilghman, 1994). A study 
in which $E d n r b$ was expressed at different stages of embryogenesis under the control of the tetracycline inducible system showed that its expression is required from E10.5 to 12.5 (Shin et al., 1999).

\section{Cardiac Neural Crest cells}

The CNC cells are derived from NC cells that contribute to the development of the outflow tract (OFT). For decades, the importance of $\mathrm{NC}$ derived cells in the creation of the pharyngeal arches and the remodeling of the OFT in the avian system has being recognized (Kirby et al., 1983; Le Douarin, 1980). In the mouse, CNC cells leave the dorsal part of the neural tube between the post-otic area and the first four somites at E9.510 (Chan et al., 2004) and migrate through branchial arches 3,4 and 6 towards the OFT of the heart.

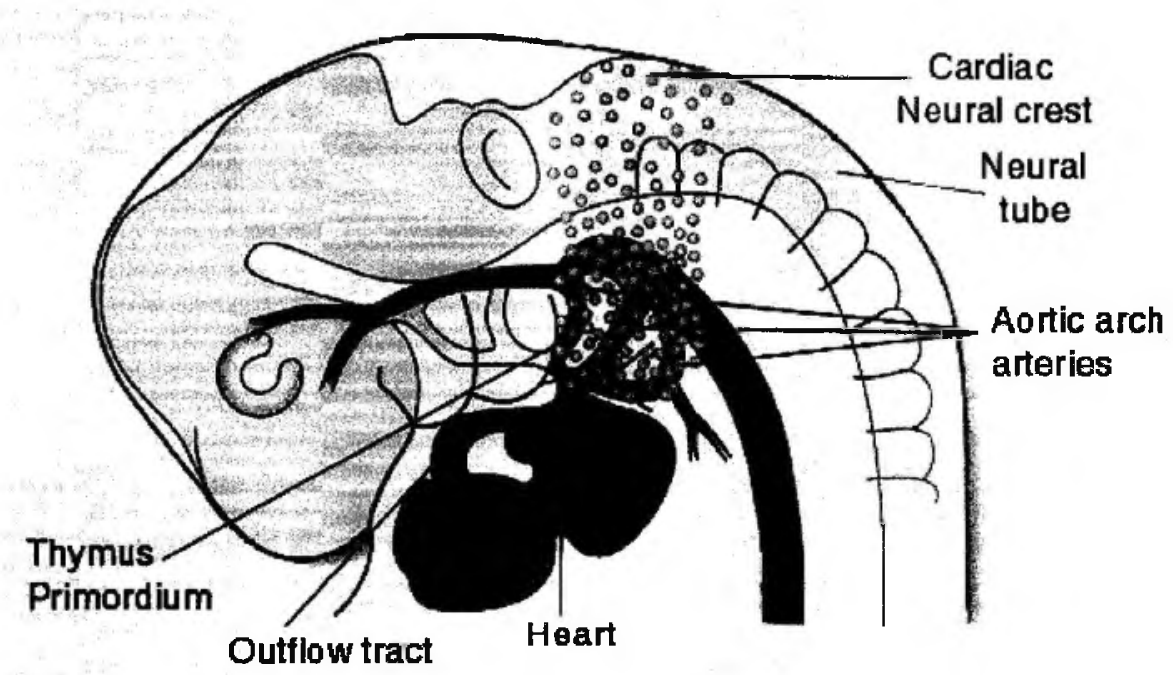

Figure 3. Diagram of the cardiac neural crest (CNC) cells in a chick embryo migrating through the ventromedial pathway to form the outflow tract (OFT) of the heart (Harvey and Rosenthal, 1999). 
At the OFT, the CNC cells contribute to the mesenchymal cells that are critical for the remodeling of the arch arteries and the septation of the OFT. Furthermore, CNC cells represent the major source of postganglionic neural progenitors that innervate the heart (reviewed in Snider et al., 2007). Studies in avian embryos showed that only CNC cells, but not NC cells from other axial levels, are capable of contributing to accurate truncal septation (Kirby, 1989). Elegant experiments using lineage tracing with double transgenic systems with LacZ or GFP reporter mice and lines carrying NC-specific Cre recombinase activity such as $P O$ (Yamauchi et al., 1999), Wntl (Jiang et al., 2000), and Pax3 (Epstein et al., 2000) have confirmed the original CNC cell fate mapping.

During development, part of the $\mathrm{CNC}$ cells will grow to be smooth muscle cells (SMCs) which will contribute to the creation of the outflow valves (Jiang et al., 2000). The differentiation of CNC cells into specified SMCs is a fundamental step for the formation of the cardiac OFT and the great arteries (Li et al., 2005) and the Notch pathway has been considered critical for this process. Experiments in vitro showed that when the Notch pathway is inhibited, the differentiation of CNC cells into SMCs can not occur (High et al., 2007). More recently, experiments using the Cre-lox fate mapping technique confirmed that the inactivation of Notch2 in CNC cells cause a decline in the proliferation rate of the SMCs resulting in abnormal narrow aortas and pulmonary arteries (Varadkar et al., 2008). Human congenital diseases, such as aortic valve defects and Alagille syndrome, have been connected with mutations in the Notch pathway, underscoring the relevance of this pathway and SMCs as fundamental players in the proper development of the cardiac OFT and great vessels. 
The Splotch $(S p)$ mutant has been used to show that Pax3, which encodes a transcription factor expressed during early to midgestation in the dorsal neural tube and somite (Goulding et al., 1991), is required for proper formation of the OFT. The pigmentation defect (white belly spot) that characterizes the Pax3 heterozygote has been originally attributed to a defect in early NC migration (Auerbach, 1954). Pax3 homozygous deficient embryos die in utero $(\sim \mathrm{E} 14.5)$ because of muscular and cardiac abnormalities. The cardiac defects are analogous to those showed in chicken embryos after ablation of premigratory NC cells (Kirby et al., 1983). Sp embryos also show defects in neural tube closure, myogenesis and other NC derived cells such as Schwann cells and mesenchymal cells in the OFT (Auerbach, 1954; Conway et al., 2000; Franz et al., 1993). Around E8.5, the expression pattern of $\operatorname{Pax3}$ coincides with the region which NC cells emerge at the dorsal part of the neural tube (Goulding et al., 1991) and the expression diminishes as the cells populate arches 3,4 and 6 , and the cardiac OFT (Conway et al., 1997). Previous studies suggested that Pax3 was required for NC cell migration (Conway et al., 1997; Moase and Trasler, 1990) but more recent studies using Cre-lox technology, showed that Pax3 is related to the survival, proliferation and differentiation of the NC cells (Conway et al., 2000; Epstein et al., 2000). 

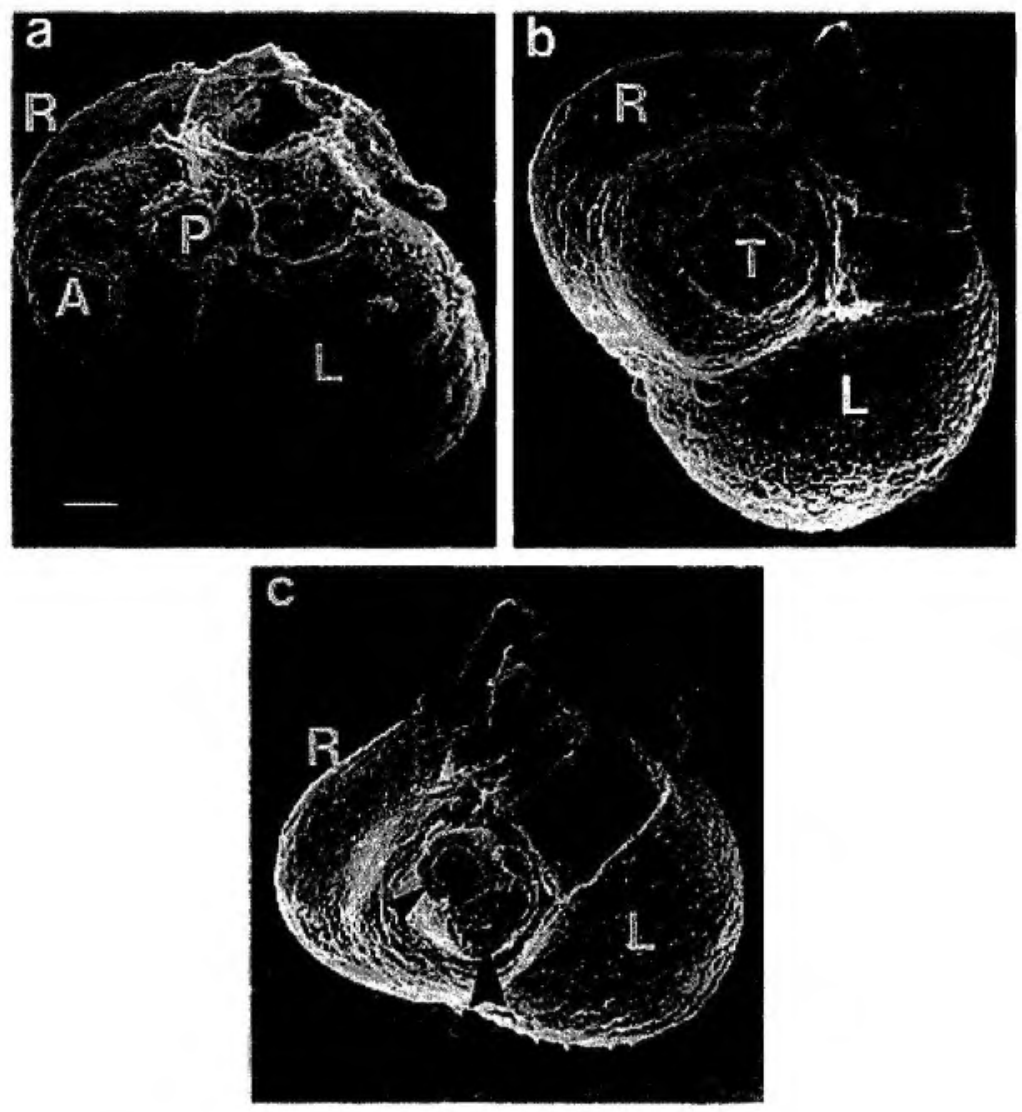

Figure 4. Electron micrographs of whole hearts from wild type and $S p$ at E13.5. The atria have been removed to illustrate better the arrangement of ventricular OFT and the arterial trunks. (a) Normal wild-type heart demonstrating the appearance of the aorta (A) and pulmonary trunk $(\mathrm{P})$ as clearly separate vessels. Serial sectioning confirms that the aorta connects solely with the left ventricle and the pulmonary trunk with the right ventricle (data not shown). (b) Splotch $\left(S p^{2 H}\right)$ heart with common arterial trunk. The undivided arterial trunk arises exclusively from the right ventricle. (c) Splotch $\left(S p^{2 H}\right)$ heart with double outlet right ventricle. The aorta (small arrowhead) and pulmonary trunk (large arrowhead) are clearly demarcated, yet serial sectioning demonstrates that both trunks arise exclusively from the right ventricle. Scale bar represents $0.1 \mathrm{~mm}$. (Conway et al., 1997).

\section{Heart Development}

The heart is the first organ to be formed and to start functioning during vertebrate development. In all vertebrates from fish to humans the heart follows the same general pattern of development which includes the fusion of the myocardium and 
endocardium in the ventral midline to form a tubular heart. The early stages of heart development are very complex processes that involve several cell lineages. The progenitors of the heart are located in bilateral paired cardiogenic fields in which, after fusion, will form the initial heart tube (Kirby, 2007). In mice at E8.5 the heart is tubular. At E9.5 during looping, the tubular structure is lengthened by the addition of myocardium from the secondary heart field. The secondary heart field not only provides myocardium to the cardiac OFT but also generates prospective smooth muscle that forms the proximal walls of the pulmonary trunk and aorta in the arterial pole of the tubular heart (Waldo et al., 2005). The arterial pole is the area where myocardium and smooth muscle are connected at the ventriculoarterial region in the embryo and at the semilunar valves in the adult heart. The venous pole of the embryo is the point of connection of the sinus venosus and atria to the body. Near to the venous pole of the embryonic heart, there is a transient extracellular group of cells that invade the heart and protrudes to the pericardial cavity to form the epicardium. The epicardium contributes to the formation of vascular mural cells which migrate to associate with endothelial cells and form the vessel wall. Epicardial derived cells also have an inductive role in differentiation of cardiac myocytes into conductive tissue of the heart. Mutant animals that lack epicardium show hypoplastic myocardial wall, ventricular septal defects, and cardiac failure (Gittenbergerde Groot et al., 2000; Kreidberg et al., 1993; Kwee et al., 1995; Männer et al., 2001; Moore et al., 1999; Ratajska et al., 2008; Yang et al., 1995).

The first signs of chamber septation are visible at E10.5. At E13.5, the four distinct chambers can be seen and the separation of the ventricles is complete. In the murine system, a slow peristaltic wave can be observed around E8 (Myers and Fishman, 
2003). When the cardiac conduction system (CCS) is totally formed, it is constituted by a variety of cells that conduct electrical impulses responsible for coordinating atrial and ventricular cardiac contraction. The pacemaker cells located in the sino atrial (SA) node generate the electrical impulses and send the stimulus to the atrioventricular (AV) node that, after a short delay, transmit these impulses along the His bundle, left and right bundle branches to the terminal Purkinje fibers which are components of the CCS. The Purkinje fibers are specialized fibers located in the subendocardial region of the ventricular myocardium and their functional importance is to allow the ventricles to contract at the same time pumping blood to the pulmonary and systemic systems. Because of the similarity of the eletrophysiological properties of the CCS cells with those of neurons, NC cells were taken as their potential progenitors (Gorza et al., 1988). However, a series of studies have identified the early cardiomyocytes as the precursors of the ventricular CCS (Cheng et al., 1999; Patel and Kos, 2005). It is important to point out that there is recent accumulating evidence that $\mathrm{NC}$ cell derivatives are found in close association with CCS cells and may induce their proper differentiation and maintain some of their functional properties (Gurjarpadhye et al., 2007; Nakamura et al., 2006; Poelmann et al., 2004; St. Amand et al., 2006).

An essential contributor for a functioning heart is its valves. The adult valves consist of the leaflets, the fibrous annulus, and the supporting tension apparatus which includes the papillary muscles, and tendinous cords. The development of the valves at the $\mathrm{AV}$ junction is a complex event that originates from the endocardium, a single layer of squamous epithelial cells that line the heart. Those cells give rise to all of the cushion mesenchyme in the AV canal and proximal OFT by transformation of cells from 
epithelial to mesenchymal (Kirby, 2007). The semilunar valves are the pulmonary and aortic valves, which separate the ventricles from the major arteries. They originate from the mesenchyme in the OFT of a variety of cushion mesenchyme derived cells from the epithelial-mesenchymal transformation (EMT), pharyngeal mesenchyme and NC.

The AV valves are located between atria and ventricles, the tricuspid valve separates the right chambers and the bicuspid valve separates the left chambers. The proper development of these valves requires different cell types and a complex sequence of events. Around E9.5, at the AV canal, endocardial cells form the endocardial cushions by EMT leading to the appearance two AV cushions by E10.5 (Delot, 2003; Kirby, 2007). The central fusion of the AV endocardial cushions form the AV septum, which divides the AV canal into separates right and left chambers (Person et al., 2005). The septation allows the formation of posterior- inferior and septal leaflets of the tricuspid valves and the aortic leaflet of the bicuspid valve. On the lateral sides of both right and left AV canals, a second set of smaller cushions will form and give rise to the remaining leaflets during fusion (Kirby, 2007). At E14.5, the remodeling of AV cushions will form mesenchymal leaflets (de Lange et al., 2004; Gitler et al., 2003). After birth, the heart continues developing by cellular proliferation to adjust to the increasing body mass and changes in vascular pressures (Leu et al., 2001). The maturation of the AV valves from embryonic cushion-like leaflets into adult stress-resistant valves is acquired post-nataly by different processes. At embryonic stages in the mouse, between E15.5 and E18.5, the mesenchymal cell density in the valves increases significantly in a process called condensation. Elongation of the leaflets of the valves occurs from E18.5 onwards and at three weeks after birth, this increase is by 8.0 fold. From 1 to 8 weeks of age, there is a 
modification in the pattern of expression of extracellular matrix (ECM) proteins which promotes a postnatal remodeling of leaflets of the valves. The nodular thickenings, which are irregular structures on the atrial surface of the adult AV valves, develop after birth and are remodeled at E11.5 (Kruithof et al., 2006).

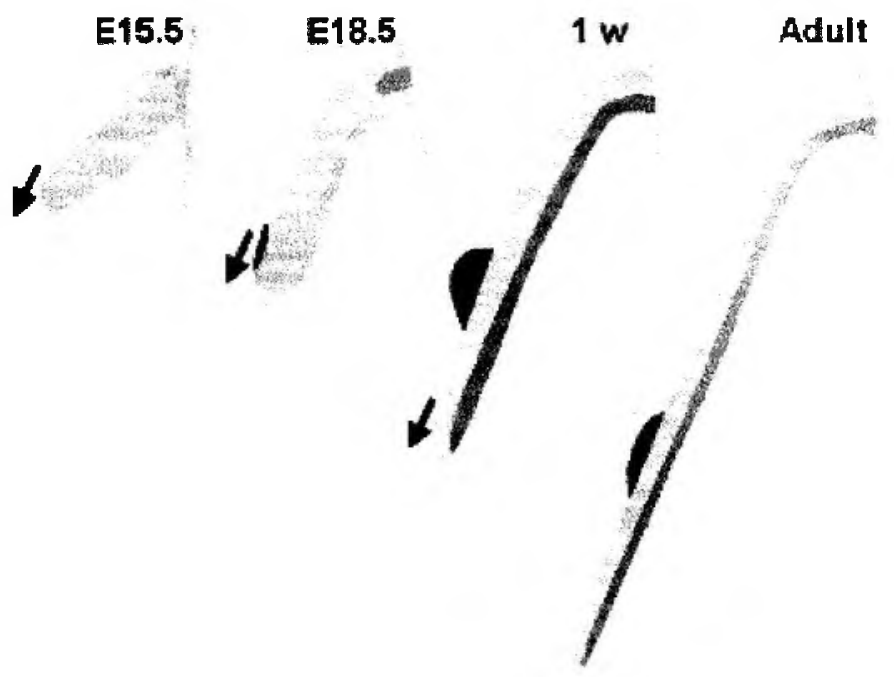

Figure 5. Proposed model of the development of the AV valves. The condensation of the mesenchymal cells (yellow) starts at E15.5 and expands throughout the leaflet at E18.5. Cellular proliferation contributes to the elongation of the leaflets (arrow) before N4.5. After N4.5, the leaflet elongation may occur by physical pulling at the level of the papillary muscles by the growing heart. Masson's trichrome staining (blue) is first detected at the anchoring point of the leaflets at E18.5 and spans the entire ventricular side of the leaflet 1 week after birth. ECM remodeling along the AV axis is achieved 1 week after birth, with the differentiation of two reciprocal structural regions, with glycosoaminoglycans, stained with alcian blue, and versican at the atrial side (orange) and densely packed collagen fibers at the ventricular side. The formation and remodeling of the nodular thickenings (red) at the closure points of the leaflets occur between N4.5 and N11.5 (Kruithof et al., 2006).

Mature AV valves separate the atria from the ventricles allowing blood flow from atria to ventricles and prevent blood flow on the opposite direction. The sounds of the heart are associated with the opening and closing of the valves, which depends on the 
pressure differences between chambers. Abnormalities in AV valve formation can lead to genetic conditions, such as Noonan syndrome which is the most common condition associated with congenital heart defects (Kirby, 2007). Another cardiac defect associated with $A V$ valves is tricuspid atresia, characterized by agenesis of the tricuspid valve and atrial and ventricular septal defects (Rao, 1980). Around 36,000 children are born with some kind of heart defect every year (www.americanheart.org). Because of the high incidence of heart malformations, a full understanding of the lineages which contribute to the heart, their specific roles and interactions is essential for the development of strategies to address these disorders.

\section{Research questions}

The critical contribution of NC cells to the OFT and innervation of the heart have long been recognized and accepted. In the last decade, experiments performed mostly in avians and zebrafish have suggested that NC cells may have a more substantial effect on heart development and function, indirectly by mediating inductive interactions between OFT cells and cardiomyocytes or directly, by giving rise to the latter (Sato and Yost, 2003; Waldo et al., 1999). Most lineage studies performed in mouse embryos have asserted the presence of $\mathrm{NC}$ derived cells only in the OFT. Those studies that have reported a more extensive contribution of $\mathrm{NC}$ cells to the heart, suggested that they undergo apoptosis and are not present in the adult organism (Poelmann et al., 2004). One recent analysis, however, has claimed the presence of $\mathrm{NC}$ derived cells in the proximal CCS and AV valves that remain into adulthood (Nakamura et al., 2006). They showed that some of these NC derived cells differentiated as neurons, glia and melanocytes and 
others maintained a somewhat undifferentiated state by expressing various precursor markers.

The idea that $\mathrm{NC}$ derived cells have a more extensive distribution in the heart was further supported by the description of pigmented cells in the adult valvuloseptal apparatus of black mice (Mjaatvedt et al., 2005). The origin of these pigmented cells was not analyzed but it is reasonable to speculate that they should be derived from NC cells. Of all the cell lineages that have been described to contribute to the heart, the NC cells are the only ones that have been shown to have the potential to differentiate as melanocytes. In vitro experiments demonstrated that $\mathrm{CNC}$ cells can develop into pigmented melanocytes (Baroffio et al., 1991; Sieber-Blum and Cohen, 1980; SieberBlum et al., 2004). In addition, when quail CNC cell cultures were treated with leukemia inhibitory factor and transplanted to chickens, they were able to form pigmented cells on the surface of arteries and at the base of the heart (Kirby et al., 1993), suggesting that pigmented cells in the heart might be produced by CNC cells.

The still controversial nature of the participation of NC cells in the mammalian embryonic and adult heart, as well as the possibility of unraveling a novel role played by melanocytes in the organism, have led me to the formulation of three major questions:

5.1 Do cardiac neural crest cells contribute to the proper development of the mammalian heart?

In Chapter II, I will provide more detailed information on what is known about the roles played by $\mathrm{NC}$ cells in heart development and show novel data regarding its 
importance in the AV endocardial cushion and ventricular CCS of the mammalian embryonic heart.

5.2 When do NC-derived melanocyte precursors reach the heart and what is the migratory pathway they take to reach it?

In Chapter III, I will describe the timeline and distribution of melanoblasts in the mammalian embryonic heart. I will also evaluate whether they depend on the same signaling mechanisms involved in the proper development of those melanoblasts destined to the skin.

5.3 Do NC derived melanocytes affect the ECM environment and mechanical properties of the AV valves?

In Chapter IV, I will provide a detailed description of the localization of melanocytes in the AV valves of the mammalian post-natal heart. I will compare their spatial distribution with that of ECM known to be important for valve remodeling and function. Finally, I will use state of the art technology to evaluate the mechanical properties of $\mathrm{AV}$ valves with differing amounts of melanocytes. 


\section{REFERENCES}

Auerbach R (1954) Analysis of the development effects of a lethal mutation in the house mouse. J. Exp. Zool. 127:305-329.

Baroffio A, Dupin E, Le Douarin NM (1991) Common precursors for neural and mesectodermal derivatives in the cephalic neural crest. Development 112:301-305.

Barsh GS (1996) The genetics of pigmentation: from fancy genes to complex traits. Trends Genet. 12:299-305.

Baynash AG, Hosoda K, Giaid A, Richardson JA, Emoto N, Hammer RE, Yanagisawa M (1994) Interaction of endothelin-3 with endothelin-B receptor is essential for development of epidermal melanocytes and enteric neurons. Cell 79:1277-1285.

Bloch KD, Eddy RL, Shows TB, Quertermous T (1989) cDNA cloning and chromosomal assignment of the gene encoding endothelin 3.J Biol Chem. 264:18156-18161.

Brito FC, Kos L (2008) Timeline and distribution of melanocyte precursors in the mouse heart. Pigment Cell Melanoma Res. 21:464-470.

Chakravarti A (1996) Endothelin receptor-mediated signaling in hirschsprung disease. Hum Mol Genet. 5:303-307.

Chan WY, Cheung CS, Yung KM, Copp AJ (2004) Cardiac neural crest of the mouse embryo: axial level of origin, migratory pathway and cell autonomy of the splotch (Sp2H) mutant effect. Development 131:3367-3379.

Ceccherini I, Zhang AL, Matera I, Yang G, Devoto M, Romeo G, Cass DT (1995) Interstitial deletion of the endothelin-B receptor gene in the spotting lethal (sl) rat. Hum Mol Genet. 4:2089-2096.

Cheng G, Litchenberg WH, Cole GJ, Mikawa T, Thompson RP, Gourdie RG (1999) Development of the cardiac conduction system involves recruitment within a multipotent cardiomyogenic lineage. Development 126:5041-5049.

Conway SJ, Bundy J, Chen J, Dickman E, Rogers R, Will BM (2000) Decreased neural crest stem cell expansion is responsible for the conotruncal heart defects within the splotch $(\mathrm{Sp}(2 \mathrm{H})) / \mathrm{Pax} 3$ mouse mutant. Cardiovasc Res. 47:314-28.

Conway SJ, Henderson DJ, Copp AJ (1997) Pax3 is required for cardiac neural crest migration in the mouse: evidence from the splotch $(\mathrm{Sp} 2 \mathrm{H})$ mutant. Development 124:505514.

de Lange FJ, Moorman AF, Anderson RH, Männer J, Soufan AT, de Gier-de Vries C, 
Schneider MD, Webb S, van den Hoff MJ, Christoffels VM (2004) Lineage and morphogenetic analysis of the cardiac valves. Circ Res. 95:645-654.

Delot EC, Bahamonde ME, Zhao MX, Lyons KM (2003) BMP signaling is required for septation of the outflow tract of the mammalian heart. Development 130:209- 220.

Epstein JA, Li, J, Lang D, Chen F, Brown CB, Jin F, Lu MM, Thomas M, Liu E, Wessels A, Lo CW (2000) Migration of cardiac neural crest cells in Splotch embryos. Development 127:1869-1878.

Erickson CA, Goins TL (1995) Avian neural crest cells can migrate in the dorsolateral path only if they are specified as melanocytes. Development 121:915-924.

Franz T (1993) The Splotch (Sp1H) and Splotch-delayed (Spd) alleles: differential phenotypic effects on neural crest and limb musculature. Anat Embryol (Berl) 187:371-7.

Garcia RJ, Ittah A, Mirabal S, Figueroa J, Lopez L, Glick AB, Kos L (2008) Endothelin 3 induces skin pigmentation in a keratin-driven inducible mouse model. $J$ Invest Dermatol. 128:131-142.

Gariepy CE, Cass DT, Yanagisawa M (1996) Null mutation of endothelin receptor type B gene in spotting lethal rats causes aganglionic megacolon and white coat color. Proc Natl Acad Sci USA 93:867-872.

Gilbert SF (2006) Developmental Biology Sunderland Associates, Inc.: Massachusetts

Gitler AD, Zhu Y, Ismat FA, Lu M, Yamauchi Y, Parada LF, Epstein JA (2003) Nfl has an essential role in endothelial cells. Nat. Genet. 33:75- 79.

Gittenberger-de Groot AC, Vrancken Peeters MP, Bergwerff M, Mentink MM, Poelmann RE (2000) Epicardial outgrowth inhibition leads to compensatory mesothelial outflow tract collar and abnormal cardiac septation and coronary formation. Circ Res. 87:969971.

Gorza L, Schiaffino S, Vitadello M (1988) Heart conduction system: A neural crest derivative? Brain Res 457:360-366.

Goulding MD, Chalepakis G, Deutsch U, Erselius JR, Gruss P (1991) Pax-3, a novel murine DNA binding protein expressed during early neurogenesis. EMBO J. 10:11351147.

Gourdie RG (1995) A map of the heart: gap junctions, connexin diversity and retroviral studies of conduction myocyte lineage. Clin Sci (Colch) 88:257-262. 
Gourdie RG, Wei Y, Kim D, Klatt SC, Mikawa T (1998) Endothelin-induced conversion of embryonic heart muscle cells into impulse-conducting Purkinje fibers. Proc Natl Acad Sci USA 95:6815-6818.

Gurjarpadhye A, Hewett KW, Justus C, Wen X, Stadt H, Kirby ML, Sedmera D, Gourdie RG (2007) Cardiac neural crest ablation inhibits compaction and electrical function of conduction system bundles. Am J Physiol Heart Circ Physiol. 292:1291-1300.

Harvey Richard P, Navia Rosenthal Heart Development (1999) Academic Press, San Diego, CA.

High FA, Zhang M, Proweller A, Tu L, Parmacek MS, Pear WS, Epstein JA (2007) An essential role for Notch in neural crest during cardiovascular and smooth muscle differentiation. $J$ Clin Invest. 117:299-302.

Hildreth V, Webb S, Bradshaw L, Brown NA, Anderson RH, Henderson DJ (2007) Cells migrating from the neural crest contribute to the innervation of the venous pole of the heart. J Anat. 212:1-11.

Hosoda K, Hammer RE, Richardson JA, Baynash AG, Cheung JC, Giaid A, Yanagisawa M (1994) Targeted and natural (piebald-lethal) mutations of endothelin-B receptor gene produce megacolon associated with spotted coat color in mice. Cell 79:1267-1276.

Jackson IJ (1997) Homologous pigmentation mutations in human, mouse and other model organisms. Hum Mol Genet. 6:1613-1624.

Jiang X, Rowicth DH, Soriano P, McMahon AP, Sucov HM (2000) Fate of the mammalian cardiac neural crest. Development 127:1607-1616.

Kirby LM (2007) Cardiac Development Oxford University Press, Inc.: New York.

Kirby LM (1987) Cardiac morphogenesis--recent research advances. Pediatr Res. 21:219-224.

Kirby ML (1989) Plasticity and predetermination of mesencephalic and trunk neural crest transplanted into the region of the cardiac neural crest. Dev Biol. 134:402-412.

Kirby ML, Gale TF, Stewart DE (1983) Neural Crest cells contribute to aorticopulmonary septation. Science 220:1059-1061.

Kirby ML, Kumiski DH, Myers T, Cerjan C, Mishima N (1993) Backtransplantation of chick cardiac neural crest cells cultured in LIF rescues heart development. Dev Dyn. 198:296-311. 
Kirby ML, Waldo KL (1990) Role of neural crest in congenital heart disease. Circulation 82:332-340.

Kreidberg JA, Sariola H, Loring JM, Maeda M, Pelletier J, Housman D, Jaenisch R (1993) WT-1 is required for early kidney development. Cell 74:679-691.

Kruithof BP, Krawitz SA, Gaussin V (2007) Atrioventricular valve development during late embryonic and postnatal stages involves condensation and extracellular matrix remodeling. Dev Biol. 302:208-217.

Kunisada T, Yoshida H, Yamazaki H, Miyamoto A, Hemmi H, Nishimura E, Shultz LD, Nishikawa S, Hayashi S (1998) Transgene expression of steel factor in the basal layer of epidermis promotes survival, proliferation, differentiation and migration of melanocyte precursors. Development 125:2915-2923.

Kwee L, Baldwin HS, Shen HM, Stewart CL, Buck C, Buck CA, Labow MA (1995) Defective development of the embryonic and extraembryonic circulatory systems in vascular cell adhesion molecule (VCAM-1) deficient mice. Development 121:489-503.

Lahav R, Ziller C, Dupin E, Le Douarin NM (1996) Endothelin 3 promotes neural crest cell proliferation and mediates a vast increase in melanocyte number in culture. Proc Natl Acad Sci USA 93:3892-3897.

Le Douarin NM (1980) The ontogeny of the neural crest in avian embryo chimaeras. Nature 286:663-669.

Le Douarin NM, Kalcheim C (1999) The Neural Crest Cambridge: Cambridge Univ. Press: Cambridge.

Le Douarin NM, Teillet MA (1973) The migration of neural crest cells to the wall of the digestive tract in avian embryo. J Embryol Exp Morphol. 30(1):31-48.

Lee HO, Levorse JM, Shin MK (2003) The endothelin receptor-B is required for the migration of neural crest-derived melanocyte and enteric neuron precursors. Dev Biol. 259:162-175.

Le Lièvre CS, Le Douarin NM (1975) Mesenchymal derivatives of the neural crest: analysis of chimaeric quail and chick embryos. J Embryol Exp Morphol. 34:125-154.

Leu M, Ehler E, Perriard JC (2001) Characterisation of postnatal growth of the murine heart. Anat Embryol (Berl). 204:217-224.

Li J, Zhu X, Chen M, Cheng L, Zhou D, Lu MM, Du K, Epstein JA, Parmacek MS (2005) Myocardin-related transcription factor B is required in cardiac neural crest for 
smooth muscle differentiation and cardiovascular development. Proc Natl Acad Sci USA 102: 8916-8921.

Mackenzie MA, Jordan SA, Budd PS, Jackson IJ (1997) Activation of the receptor tyrosine kinase Kit is required for the proliferation of melanoblasts in the mouse embryo. Dev Biol. 192:99-107.

Männer J, Pérez-Pomares JM, Macías D, Muñoz-Chápuli R (2001) The origin, formation and developmental significance of the epicardium: a review. Cells Tissues Organs 169:89-103.

Matsumoto H, Suzuki N, Onda H, Fujino M (1989) Abundance of endothelin-3 in rat intestine, pituitary gland and brain. Biochem Biophys Res Commun 164:74-80.

Meyer D, Birchmeier C (1995) Multiple essential functions of neuregulin in development. Nature 378:386-390.

Mjaatvedt CH, Kern CB, Norris RA, Fairey S, Cave CL (2005) Normal distribution of melanocytes in the mouse heart. Anat. Rec. A Discov. Mol. Cell Evol. Bio. 285:748-757.

Moase CE, Trasler DG (1990) Delayed neural crest cell emigration from Sp and Spd mouse neural tube explants. Teratology 42:171-82.

Moore AW, McInnes L, Kreidberg J, Hastie ND, Schedl A (1999) YAC complementation shows a requirement for Wt1 in the development of epicardium, adrenal gland and throughout nephrogenesis. Development 126:1845-1857.

Myers DC, Fishman GI (2003) Molecular and functional maturation of the murine cardiac conduction system. Trends Cardiovasc Med. 13:289-295.

Nakamura T, Colbert MC, Robbins J (2006) Neural crest cells retain multipotential characteristics in the developing valves and label the cardiac conduction system. Circ Res. 98:1547-1554.

Nataf V, Amemiya A, Yanagisawa M, Le Douarin NM (1998) The expression pattern of endothelin 3 in the avian embryo. Mech Dev. 73(2):217-220.

Nataf V, Lecoin L, Eichmann A, Le Douarin NM (1996) Endothelin-B receptor is expressed by neural crest cells in the avian embryo. Proc Natl Acad Sci USA 93:96459650.

Onda H, Ohkubo S, Ogi K, Kosaka T, Kimura C, Matsumoto H, Suzuki N, Fujino M (1990) One of the endothelin gene family, endothelin 3 gene, is expressed in the placenta. FEBS Lett. 261:327-330. 
Patel R, Kos L (2005) Endothelin-1 and Neuregulin-1 convert embryonic cardiomyocytes into cells of the conduction system in the mouse. Dev Dyn. 23:20-28.

Pavan WJ, Tilghman SM (1994) Piebald lethal (sl) acts early to disrupt the development of neural crest-derived melanocytes. Proc. Natl. Acad. Sci. USA 91:7159- 7163.

Person AD, Klewer SE, Runyan RB (2005) Cell biology of cardiac cushion development. Int. Rev. Cytol. 243:287-335.

Pla P, Larue L (2003) Involvement of endothelin receptors in normal and pathological development of neural crest cells. Int J Dev Biol. 47:315-325.

Poelmann RE, Gittenberger-de Groot AC (1999) A subpopulation of apoptosis-prone cardiac neural crest cells targets to the venous pole: multiple functions in heart development? Dev Biol. 207:271-286.

Poelmann RE, Jongbloed MRM, Moli DGM, Fekkes ML, Wang A, Fishman GI, Doetschman T, Azhar M, Gittenberger-de Groot AC (2004) The neural crest is contiguous with the cardiac conduction system in the mouse embryo: a role in induction? Anat Embryol. 208:389-393.

Puffenberger EG, Hosoda K, Washington SS, Nakao K, deWit D, Yanagisawa M, Chakravart A (1994) A missense mutation of the endothelin-B receptor gene in multigenic Hirschsprung's disease. Cell 79:1257-1266.

Rao PS (1980) A unified classification for tricuspid atresia. Am. Heart J. 199:799-804.

Ratajska A, Czarnowska E, Ciszek B (2008) Embryonic development of the proepicardium and coronary vessels. Int J Dev Biol. 52:229-236.

Reid K, Turnley AM, Maxwell GD, Kurihara Y, Kurihara H, Bartlett PF, Murphy M (1996) Multiple roles for endothelin in melanocyte development: regulation of progenitor number and stimulation of differentiation. Development 122:3911-3919.

Rentschler S, Zander J, Meyers K, France D, Levine R, Porter G, Rivkees SA, Morley GE, Fishman GI (2002) Neuregulin-1 promotes formation of the murine cardiac conduction system. Proc Natl Acad Sci USA 99:10464-10469.

Rice J, Doggett B, Sweetser DA, Yanagisawa H, Yanagisawa M, Kapur RP (2000) Transgenic rescue of aganglionosis and piebaldism in lethal spotted mice. Dev Dyn. 217:120-132.

Santschi EM, Purdy AK, Valberg SJ, Vrotsos PD, Kaese H, Mickelson JR (1998) Endothelin receptor B polymorphism associated with lethal white foal syndrome in horses. Mamm Genome 9:306-309. 
Sato M, Yost HJ (2003) Cardiac neural crest contributes to cardiomyogenesis in zebrafish. Dev Biol. 257:127-139.

Shin MK, Levorse JM, Ingram RS, Tilghman SM (1999) The temporal requirement for endothelin receptor-B signalling during neural crest development. Nature 402:496-501.

Shin MK, Russel LB, Tilghman SM (1997) Molecular characterization of four induced alleles at the Ednrb locus. Proc Natl Acad Sci USA 94:13105-13110.

Schoenwolf GC, Nichols DH (1984) Histological and ultrastructural studies on the origin of caudal neural crest cells in mouse embryos. $J$ Comp Neurol. 222:496-505.

Sieber-Blum M, Cohen AM (1980) Clonal analysis of quail neural crest cells: they are pluripotent and differentiate in vitro in the absence of noncrest cells. Dev Biol. 80:96-106.

Sieber-Blum M, Grim M, Hu YF, Szeder V (2004) Pluripotent neural crest stem cells in the adult hair follicle. Dev Dyn. 231:258-269.

Silvers WK (1979) The coat colors of mice: a model for mammalian gene action and interaction. Springer-Verlag, Inc.: New York.

Snider P, Olaopa M, Firulli AB, Conway SJ (2007) Cardiovascular development and the colonizing cardiac neural crest lineage. Scientific World Journal 7:1090-1113.

St Amand TR, Lu JT, Zamora M, Gu Y, Stricker J, Hoshijima M, Epstein JA, Ross JJ Jr, Ruiz-Lozano P, Chien KR (2006) Distinct roles of HF-1b/Sp4 in ventricular and neural crest cells lineages affect cardiac conduction system development. Dev Biol. 291:208217.

Steel KP, Barkway C (1989) Another role for melanocytes: their importance for normal stria vascularis development in the mammalian inner ear. Development 107:453-463.

Steel KP, Davidson DR, Jackson IJ (1992) TRP-2/DT, a new early melanoblast marker, shows that stell growth factor (c-kit ligand) is a survival factor. Development 115:11111119.

Stone JG, Spirling LI, Richardson MK (1997) The neural crest population responding to endothelin-3 in vitro includes multipotent cells. J Cell Sci. 110:1673-1682.

Takebayashi-Suzuki K, Pauliks LB, Eltsefon Y, Mikawa T (2001) Purkinje fibers of the avian heart express a myogenic transcription factor program distinct from cardiac and skeletal muscle. Dev Biol. 234:390-401. 
Varadkar P, Kraman M, Despres D, Ma G, Lozier J, McCright B (2008) Notch2 is required for the proliferation of cardiac neural crest-derived smooth muscle cell. Dev Dyn. 237:1144-1152.

Waldo KL, Hutson MR, Stadt HA, Zdanowicz M, Zdanowicz J, Kirby ML (2005) Cardiac neural crest is necessary for normal addition of the myocardium to the arterial pole from the secondary heart field. Dev Biol. 281:66-77.

Waldo KL, Hutson MR, Ward CC, Zdanowicz M, Stadt HA, Kumiski D, Abu-Issa R, Kirby ML (2005) Secondary heart field contributes myocardium and smooth muscle to the arterial pole of the developing heart. Dev Biol. 281:78-90.

Waldo K, Zdanowicz M, Burch J, Kumiski DH, Stadt HA, Godt RE, Creazzo TL, Kirby ML (1999) A novel role for cardiac neural crest in heart development. $J$ Clin Invest. 103:1499-1507.

Wehrle-Haller B (2003) The role of Kit-ligand in melanocyte development and epidermal homeostasis. Pigment Cell Res. 16:287-296.

Wilson YM, Richards KL, Ford-Perriss ML, Panthier JJ, Murphy M (2004) Neural crest cell lineage segregation in the mouse neural tube. Development 131:6153-6162.

Yamauchi Y, Abe K, Mantani A, Hitoshi Y, Suzuki M, Osuzu F, Kuratani S, Yamamura $\mathrm{K}$ (1999) A novel transgenic technique that allows specific marking of the neural crest cell lineage in mice. Dev Biol. 212:191-203.

Yang JT, Rayburn H, Hynes RO (1995) Cell adhesion events mediated by alpha 4 integrins are essential in placental and cardiac development. Development 121:549-60.

Yoshida H, Kunisada T, Kusakabe M, Nishikawa S, Nishikawa SI (1996) Distinct stages of melanocyte differentiation revealed by analysis of nonuniform pigmentation patterns. Development 122:1207- 1214.

Zhao S, Overbeek PA (1999) Tyrosinase-related protein 2 promoter targets transgene expression to ocular and neural crest-derived tissues. Dev Biol. 216:154-163.

Zhou HM, Wang J, Rogers R, Conway SJ (2008) Lineage-specific responses to reduced embryonic Pax3 expression levels. Dev Biol. 315:369-82. 
CHAPTER II: THE CONTRIBUTION OF NEURAL CREST DERIVED CELLS TO

THE DEVELOPING HEART 


\section{Cardiac Neural Crest Cells}

During early vertebrate development, the neural crest (NC) cells arise from the dorsal tip of the neural epithelium and migrate extensively throughout the embryo. All organs and tissues in the adult body contain cells that are derived from the NC cells. Depending on the pathway these cells undertake and the signaling molecules they encounter during their migration, they become different kinds of cell populations. The $\mathrm{NC}$ cells derivatives include neural and glial cells of the peripheral nervous system, melanocytes in the skin, vascular smooth muscle cells (SMCs), craniofacial cartilage, adipose tissue, bone, and endocrine cells of the thyroid and adrenal glands (Le Douarin and Kalcheim, 1999). In certain cases, their fate restriction is also determined by their origin along the rostro-caudal axis of the embryo. For example, $\mathrm{NC}$ cells that contribute neurons and glia to the enteric nervous system are derived exclusively from the vagal and sacral regions of the neural tube. Some of the cells originating at the vagal region migrate to the developing heart through branchial arches 3,4 and 6 . This population of cells is called cardiac neural crest $(\mathrm{CNC})$ and provides an extracardiac source of mesenchyme to the outflow tract (OFT) as well as neural progenitors that innervate the heart. The absence or reduced number of $\mathrm{CNC}$ cells in the heart lead to a range of cardiovascular defects, such as abnormalities in the remodeling of the arteries, persistent truncus arteriosus (PTA) and ventricular septal defects (VSD) (Kirby, 2007).

\section{The fates of Cardiac Neural Crest Cells}

Most of the CNC cells will primarily differentiate as SMCs lining the blood vessels around which they assemble and contributing to the formation of the outflow 
valves (Jiang et al., 2000). One of the critical signaling pathways involved in the specification of CNC cells into SMCs is that mediated by Notch. In vitro studies showed that inhibition of Notch prevents the differentiation of CNC cells into SMCs (High et al., 2007). Recently, experiments using the Cre-lox targeting system verified that the inactivation of Notch2 in $\mathrm{CNC}$ cells cause a decrease in the proliferation rate of the SMCs resulting in unusually narrow aortas and pulmonary arteries (Varadkar et al., 2008). Some congenital heart diseases in humans, such as aortic valve defects and Alagille syndrome, have been associated with mutations in the Notch pathway (Varadkar et al., 2008) reinforcing the fact that SMCs play a fundamental role in the formation of the cardiac OFT and great vessels.

CNC cells can also differentiate into the neurons that are responsible for the innervation of the heart and its vessels. Most studies attempting to investigate the lineage, migratory route and differentiation process of the neurons that innervate the heart were initially carried out in the avian system (Kirby et al., 1980; Kirby et al., 1985; Veberne et al., 1998; Veberne et al., 2000). These studies showed that CNC cells contribute the neurons to the entire anterior and posterior plexus. The precursor cells enter the arterial pole via the arterial cardiac vagal branches and the venous pole via the sinal cardiac vagal branch without intermixing. There is also some evidence that some of the $\mathrm{CNC}$ differentiate as glia or remain undifferentiated cells along the nerve fibers.

More recent studies in the mouse using the Cre-lox technology have corroborated the results obtained in avians. Transgenic mice in which the regulatory regions of Wnt1, HtPA or PO driving the expression of Cre recombinase were crossed into the ROSA26LacZ reporter mice showed the presence of cardiac neurons derived from the NC at the 
arterial pole (Yamauchi et al.., 1999; Jiang et al., 2000; Pietri et al., 2003). Part of the autonomic nerves and ganglia innervating the venous pole has also been shown to be NC derived. (Hildreth et al., 2007). Nerve growth factor (NGF) and Platelet derived growth factor beta (PDGF- $\beta$ ) seem to control the amount of cardiac innervation. Transgenic over-expression of NGF in the heart causes sympathetic hyperinnervation (Hassankhani et al., 1995) while targeted deletion of PDGF- $\beta$ or its receptor lead to hypoplasia of cardiac nerves (Van den Akken et al., 2008). The pathway mediated by retinoic acid has an important role in CNC cells (Li et al., 2001) and has been shown to affect the differentiation of these precursors into neurons destined to contribute to the parasympathetic innervations of the heart by regulating the expression of the transcription factors Phox2a and Phox2b (Shoba et al., 2002).

\section{Cardiac Neural Crest Cells Markers}

The study of particular cell lineages is facilitated by the availability of markers that are restricted to that specific group of cells. Unfortunately, to date, a $\mathrm{CNC}$ restricted marker has not been identified. The markers that are currently used, such as Wnt1, Pax3, $C R A B P I$, and $P 0$, label cranial, cardiac and trunk NC progenitors. Additionally, they are downregulated in post-migratory $\mathrm{NC}$ cells. Only through transgenic methodologies in mice employing the Cre-lox system the cells can be permanently marked with reporters such as $\beta$-galactosidase or green fluorescent protein (Yamauchi et al., 1999; Jiang et al., 2000; Epstein et al., 2000; Nakamura et al., 2006).

One of the most used CNC markers is the transcription factor Pax3. It is expressed during early to mid stages of gestation in the somites, dorsal neural tube and 
most or all migrating NC cells (Goulding et al., 1991). The splotch $(S p)$ spontaneous mouse mutant carries a mutation in $P a x 3$ and has been critical to show that $\mathrm{CNC}$ cells are required for proper formation of the OFT. The Pax3 heterozygote $\left(\operatorname{Pax}^{\mathrm{sp} /+}\right)$ is characterized by a pigmentation defect (white belly spot) that was originally attributed to defects in early NC migration (Auerbach, 1954). Pax3 homozygous deficient embryos $\left(\operatorname{Pax}^{\mathrm{Sp} / \mathrm{sp}}\right)$ display spina bifida, exencephaly, absence of limb and hypaxial muscles. In the heart, they show $100 \%$ penetrant PTA/VSD and aortic arch artery remodeling defects (Conway et a1., 2000; Epstein et a1., 2000). They die in utero by E14.5 of unknown causes since PTA/VSD alone is not sufficient to cause embryonic lethality.

The cardiac defects observed in $P a x 3^{\text {sp/sp }}$ are similar to those observed in chick embryos after the ablation of pre-migratory NC cells (Kirby et al., 1983). These defects have been shown to be due to the failure of the $6^{\text {th }}$ aortic arch artery, which normally gives rise to the pulmonary trunk to persist (Conway, 2003). In the absence of the $6^{\text {th }}$ aortic arch artery, a single OFT forms from the left $4^{\text {th }}$ aortic arch artery which normally gives rise to the aorta.

Since Pax3 is not expressed in the heart, its involvement in heart development must be indirect, most likely acting autonomously or non-autonomously in NC cells. Transgenic studies in which Pax3's expression was directed exclusively to the neural tube and migrating neural crest was sufficient to rescue the cardiac phenotype and the mice survived to birth ( $\mathrm{Li}$ et al., 1999). They died shortly after birth due to muscular defects and consequent respiratory failure. These results indicate that the action of Pax3 in the neural tube or the $\mathrm{NC}$ cells themselves is critical for proper OFT formation. Apart from its role in migration (Conway et al., 1997; Moase and Trasler, 1990), putative 
involvement in the survival, proliferation and differentiation of the $\mathrm{NC}$ cells have also been suggested (Conway et al., 2000; Epstein et al., 2000).

One of the transcription factors that interact with Pax3 during the development of certain NC lineages is Sox10 (Bondurand et al., 2000; Lang et al., 2000; Potterf et al., 2000; Lang and Epstein, 2003). Sox10 is expressed in early migrating NC cells, transiently in committed melanocyte and enteric neuronal precursors and throughout the development of Schwann cells. In the Dominant megacolon spontaneous mouse mutant that carries a mutation in the Sox 10 gene, all these NC derived lineages are affected leading to deficits in pigmentation, gut innervations and PNS development (SouthardSmith et al., 1998; Kuhlbrodt et al., 1998; Potterf et al., 2000). Homozygous mutant embryos die around E14.5, of yet unknown causes. In humans, Sox10 mutations cause Hirschsprung disease, characterized by congenital aganglionic megacolon ((Pingault et al., 1998). Certain patients also present with Waardenburg Syndrome, a hereditary disorder that involves sensorineural deafness and pigmentation disturbances of the skin, hair and eyes (Pingault et al., 1998).

In chicken embryos Sox10 transcripts can be observed in the subendothelial tissue of differentiating heart septa and atrioventricular (AV) valve leaflets during early stages of development (day 5 of incubation). Later, it is also detected in cardiac nerves (Montero et al., 2002). To date, no studies have been performed in the mouse to evaluate whether Sox10 can be use as a marker for migrating CNC cells and/or heart innervations. Taking advantage of a transgenic mouse in which the $L a c Z$ reporter gene was introduced into the Sox10 locus (Sox10 $0^{\text {thlWeg }}$; Britsch et al., 2001), I was able to trace migrating CNC cells and mark, at least, part of the heart nerves. 
At embryonic day 10.5 (E10.5), LacZ expression is observed in various NC derived structures such as trigeminal, facioacoustic, and dorsal root ganglia. It is also present in the first and second branchial arches as well as in a population of cells in the heart OFT (Figure 6). At the heart level, LacZ positive cells can be found surrounding the cardinal veins and aortic sac (Figure 6C). This population seems to overlap entirely with those marked in Wnt1CreROSA26 or Pax3CreROSA26 (Jiang et al., 2000; Epstein et al., 2000) embryos at this stage, suggesting that Sox 10 can also be used as a marker for NC cells that migrate to the heart region. Although a cardiac phenotype has not been described for Sox10 homozygous mutants, its expression in migrating CNC cells and its partnership with Pax3 in other cell type, suggest that they might present OFT defects.
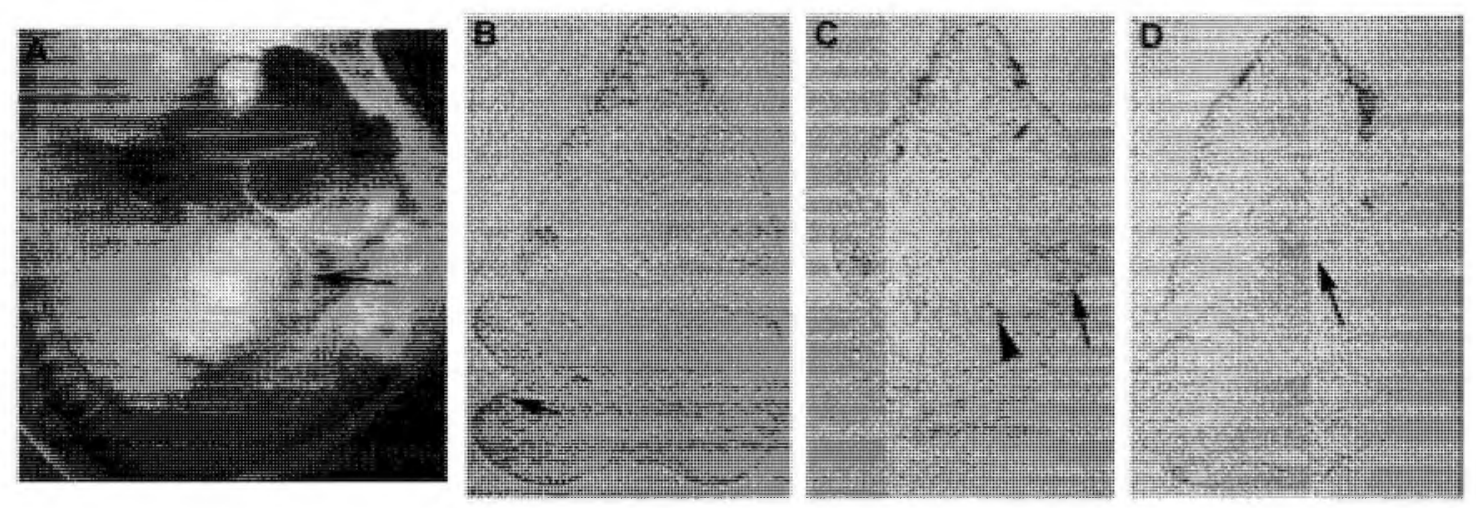

Figure 6. Sox 10 as a marker of CNC cells in embryo. Sox $10^{\text {tmllweg }}$ E10.5 embryos were stained for LacZ as whole mounts (A) and cryosectioned (B, C, D). In the whole mount preparation $\mathrm{LacZ}$ positive cells are found in the OFT (arrow) (A). In cryosections, LacZ positive cells can be detected in the branchial arches (arrow) (B), surrounding the cardinal veins (arrow) and aortic sac (arrow head) (C) as well as in the OFT (arrow) (D). Magnification: (A) 3x; (B, C and D) 6x.

At E12.5, most of the LacZ expression was no longer detected in the OFT or inside the heart (data not shown). However, at E15.5, considerable expression was found in cells surrounding the OFT and the heart itself (Figure 7A). In cryosections, no 
expression was seen in side the heart. The expression pattern and localization suggest that that the LacZ positive cells are from a neuronal or glial lineage and responsible for the innervations of the heart. A similar pattern of LacZ expression was observed in adult hearts (Figure 7B). Inside the adult heart, LacZ expression was observed in the proximity to the attachment site of the AV valves to the cardiac muscle and the interventricular septum (IVS) (Figure 7C). These data suggested that Sox10 can be used not only as a marker for early $\mathrm{CNC}$ cell migration, but also for cells that will promote the innervations of the heart. It will be interesting to evaluate how Sox10 might interact with signaling pathways such as those mediated by NGF, PDGF and retinoic acid that control proper heart innervations.
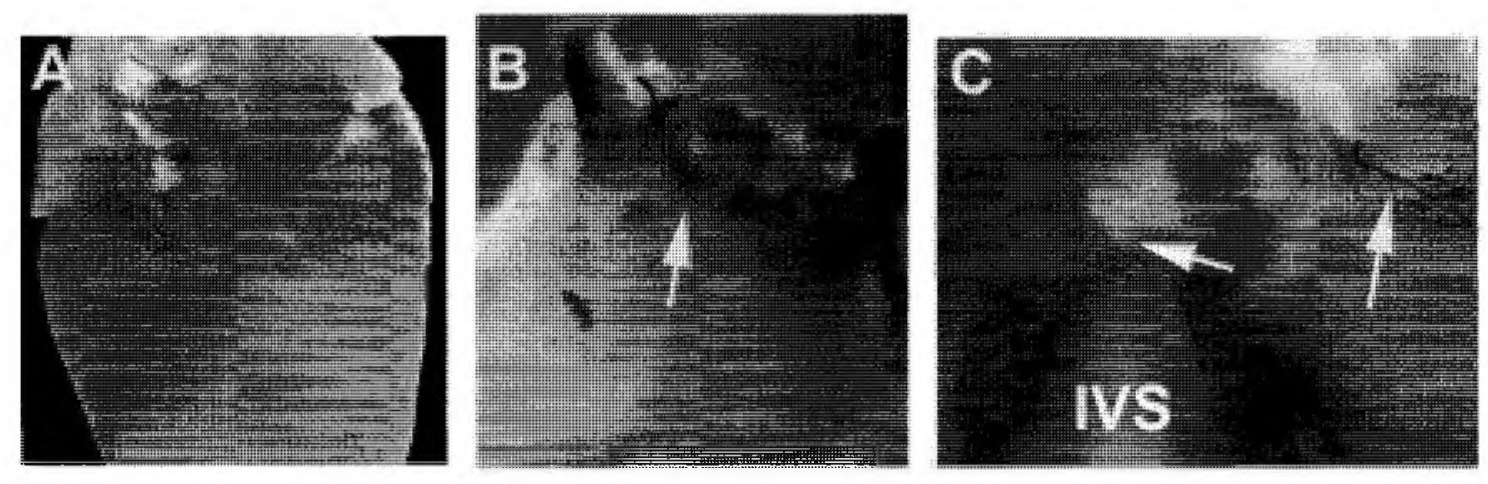

Figure 7. Sox 10 as a marker of cardiac innervation. Sox $10^{\text {tmlWeg }}$ E15.5 and adult hearts were stained for LacZ. (A) LacZ expression was detected in the outermost layer of the heart and OFT promoting its innervations at E15.5. (B and C) In adult hearts, a similar pattern is observed; however noticeable expression was detected inside the heart around the area where the AV valves connect to the cardiac muscle and interventricular septum (IVS) (arrows). Magnification: (A) 1.7x; (B) 4x; and (C) 3.7x.

Although Sox 10 is critical for melanocyte development, its expression is transient in these cells and can only be detected until E11.5. NC-derived melanocytes have been described in the AV valves of the adult and embryonic mouse heart (Brito and Kos, 2008; 
Mjaatvedt et al., 2005; Nakamura et al., 2006). The analysis of embryonic AV valves of

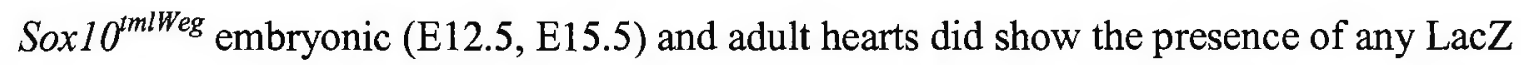
positive cells. It is still possible that some of those LacZ positive cells migrating into the heart at earlier stages will become differentiated melanocytes in the AV valves.

A melanocyte marker that is expressed as soon as precursor cells leave the neural tube is the enzyme Dopachrome tautomerase $(D c t)$. A transgenic mouse in which the $D c t$ promoter drives expression of $\mathrm{LacZ}$ has been extensively used in studies of cutaneous melanocyte development (Hornyak et al., 2001; McKenzie et al., 1997; Zhao and Overbeek, 1999). Using the same Dct-LacZ mice, LacZ positive cells can be detected in whole mount preparations and cryosections of E13.5 to E18.5 hearts in a pattern that overlaps with the AV endocardial cushion and valves (Figure 8). It is interesting to note that none of the other transgenic mice (Wnt1-Cre, Pax3-Cre, P0-Cre) that have been used to map CNC cells have shown such a robust pattern in these areas. Either these markers do not encompass the whole population of NC cells that contribute the heart or have differential expressivity in the various cell lineages. 

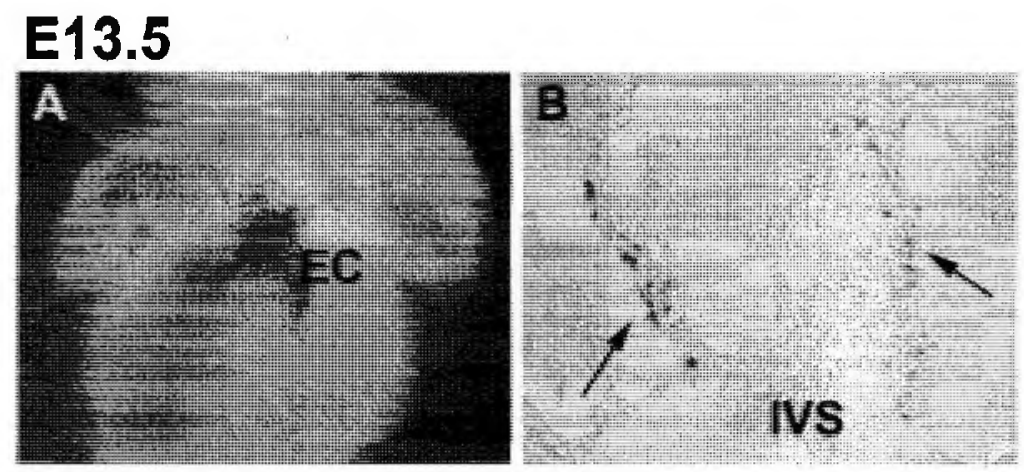

\section{E15.5}
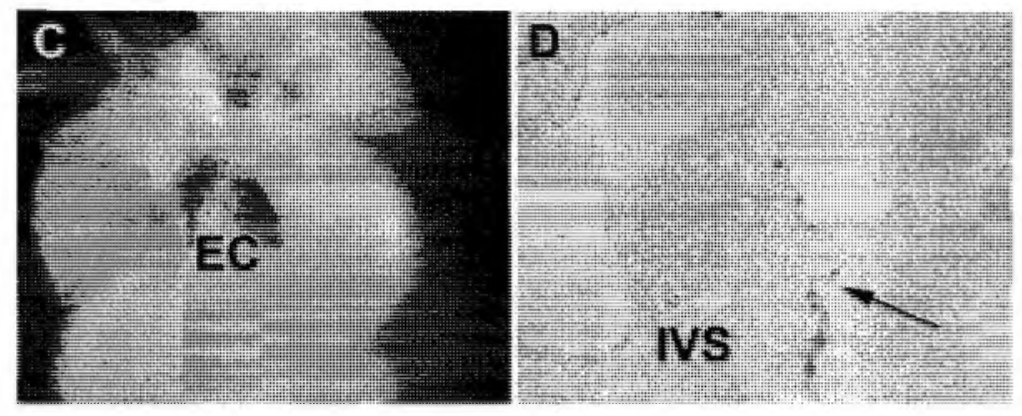

\section{E18.5}
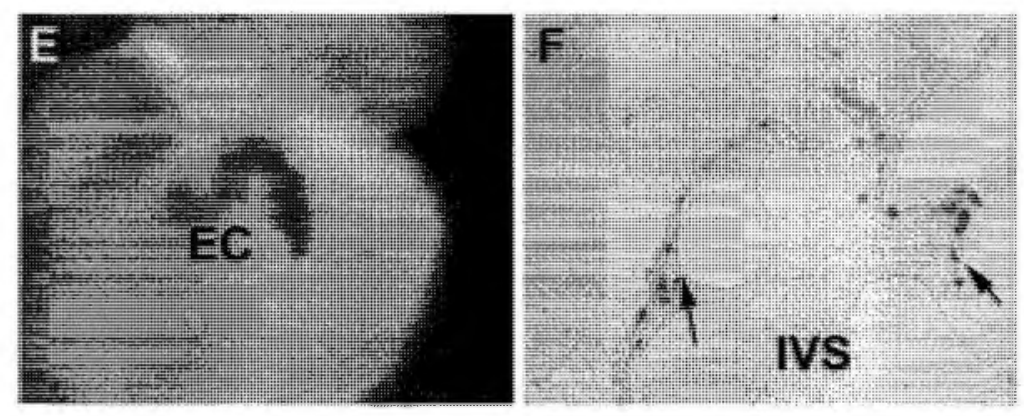

Figure 8. Dct as a marker for NC derived cardiac melanocytes. E13.5, E15.5 and E18.5 hearts from Dct-LacZ embryos were subjected to whole mount LacZ staining and cryosectioned. LacZ expression is detected in the endocardial cushion (EC) and AV leaflets (arrow), IVS: interventricular septum. Magnification (A, C and E): 6x; (B, D and F): 20x.

\section{Alternative Roles for Cardiac Neural Crest Cells}

\subsection{In the Myocardium}

Pre-migratory $\mathrm{CNC}$ cells ablation in the chick results in myocardial defects that is detected prior to the arrival of CNC cells to the OFT cushions (Waldo et al., 1999). These 
deleterious effects have been attributed to an indirect effect of $\mathrm{CNC}$ by preventing the prolonged release of Fibroblast Growth Factors (FGFs) from the pharyngeal endoderm. FGFs control myocardial proliferation, differentiation and contraction (Farrell et al., 2001). $P a x 3^{\text {sp } / \mathrm{sp}}$ embryonic hearts exhibit a thinned myocardium and absence of the compact zone (Li et al., 1999). Since this phenotype can be rescued by the expression of Pax3 exclusively in CNC cells, it is probably associated with the absence of these cells in the mutant embryos. Thus, as in the chick, it is possible that CNC cells regulate paracrine factors, secreted either by themselves or other tissues, which control myocardial development. Other than the pharyngeal endoderm, the epicardium has been shown to play a critical role in regulating myocardial maturation (Lavine et al., 2005). Interestingly, one study using the $W n t 1-\mathrm{Cre}$, Rosa26 reporter mice have described a small population of marked cells in the epicardium (Stottmann et al., 2004). Thus, in the mouse CNC cells may directly contribute to the epicardium and participate in the maturation of the adjacent myocardium.

\subsection{In the Conduction System and AV Valves}

Apart from our demonstration that NC derived melanocyte precursors can populate deeper areas in the heart, a few other studies in chick and mouse have demonstrated the presence of $\mathrm{CNC}$ cells in proximity to the proximal cardiac conduction system (CCS) and AV valves. Retroviral labeling of pre-migratory NC cells in the chick has shown that they can enter the heart via both the arterial and venous poles (Poelmann and Gittenberger de Groot, 1999). The cells entering via the venous pole can be found close to the AV node area, the retroaortic root bundle, the bundle of His, the left and right 
bundle branches, and the right $\mathrm{AV}$ ring bundle. The AV ring bundle connects the AV node area with the retroaortic bundle, which is populated by $\mathrm{CNC}$ cells that enter via the arterial pole. Most of the $\mathrm{CNC}$ cells entering via the venous pole seem to undergo apoptosis and, thus, are not direct contributors to the CCS. However, their time of arrival and death correspond to critical changes in the eletrophysiological behavior of the heart and could possibly participate in the differentiation and maturation processes of the CCS. Experiments with transgenic mice in which the $\mathrm{CNC}$ cells were indelibly marked have corroborated these findings and have shown $\mathrm{CNC}$ cells entering the heart via both the arterial and venous poles and contributing to areas adjacent to the CCS and AV valves (Poelmann et al., 2004; Nakamura et al., 2006). One of the studies has clearly shown that at least part of these cells do not undergo apoptosis, instead, they persist in the heart and exhibit neuronal, melanocytic and glial markers (Nakamura et al., 2006). This is further supported by the demonstration of melanin producing cells in the valvuloseptal apparatus of mouse adult hearts (Mjaatvedt et al., 2005).

An interesting recent study has provided evidence to suggest a putative novel role for these CNC cells that surround the proximal CCS (Gurjarpadhye et al., 2007). Optical mapping of voltage sensitive dye in $\mathrm{CNC}$-ablated chick embryos demonstrated that the ventricular CCS does not mature properly. His bundle cells were not able to electrically uncouple from the adjacent myocytes resulting in a delay in the normal apex-to-base activation that occurs during CCS differentiation. This was attributed to the lack of a lamellar organization in the His bundle or failure to undergo compaction. Thus, it is possible that $\mathrm{CNC}$ cells aid in the organization and insulation of the CCS cells from the myocardium. 
In order to identify other possible roles for the CNC cells in CCS and AV valve development, I used the $P a x 3^{\text {sp/sp }}$ embryonic hearts which lack CNC cells. A change in the proliferation rate of myocytes has been reported in the trabeculae of these mutant hearts when compared to controls (Kochilas et al., 1999). However, an evaluation of alterations in apoptotic rates has not been investigated. Lyso Tracker red staining of E12.5 control and $P a x 3^{\text {sp/sp }}$ hearts showed a dramatic increase in the numbers of dying cells in the latter (Figure 10A and B). These dying cells were concentrated in the AV endocardial cushion area, the anlagen of the AV valves. The lineage of these cells in unknown at this time, but they are most likely of endocardial origin. This result suggest that $\mathrm{CNC}$ cells might also directly or indirectly regulate the survival of endocardial cushion cells and contribute to the remodeling required for AV valve formation.

Immunofluorescence staining of control and mutant hearts with the ventricular CCS specific marker Connexin 40 (Cx40; Delorme et al., 1995) indicated that Cx40 positive cells are present in both genotypes (Figure 10C and D). Despite the thinned ventricular myocardium of $P a x 3^{\text {sp/sp }}$ hearts, CCS cells are still capable of undergoing differentiation in the absence of CNC cells. It is likely that those CNC cells that contribute to the epicardium and regulate myocardial proliferation are not required for CCS development. Alternatively, the use of other CCS ventricular markers might indicate that these cells are affected in the absence of CNC cells. For example, in chick embryos with epicardial ablation, the ventricular CCS fails to differentiate properly as shown by EAP-300 (a chick ventricular CCS marker) immunohistochemistry (Eralp et al., 2006). Thus, a more detailed histological and molecular analysis of $P a x 3^{\text {sp/sp }}$ hearts might unravel even more novel functions for $\mathrm{CNC}$ cells. 


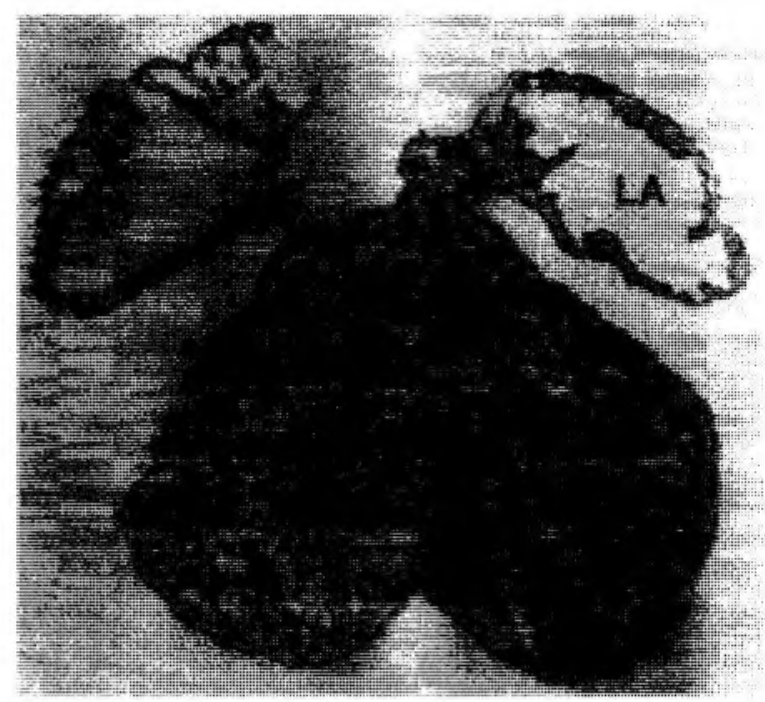

Figure 9. Cryosection of an E12.5 wild type heart. EC: endocardial cushion; IVS: interventricular septum; LA: left atroa; LV: left ventricle; RA: right atria; RV: right ventricle; T: trabeculae. Magnification: $4 \mathrm{x}$.
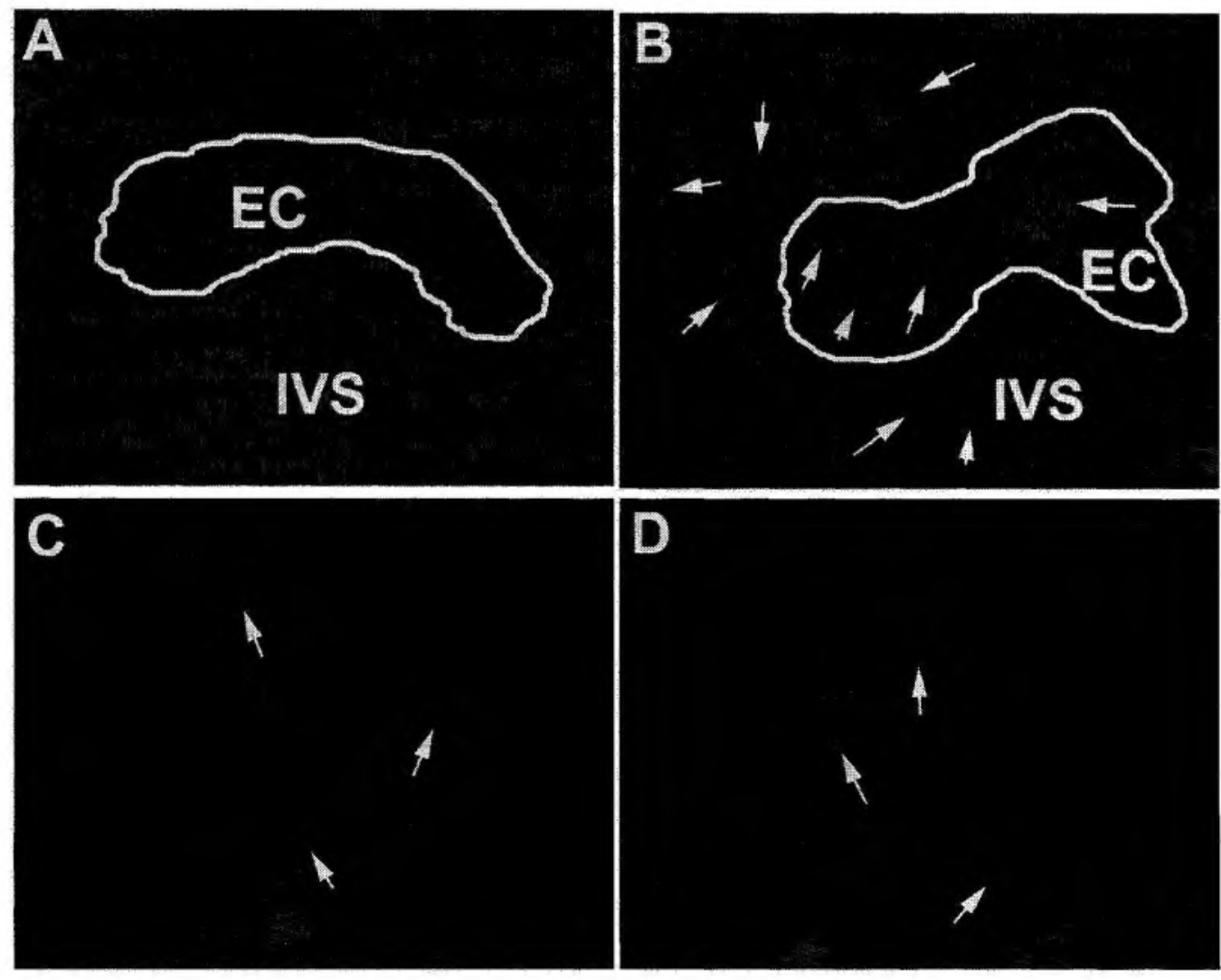
Figure 10. E12.5 wild type and splotch $\left(S p^{2 H}\right)$ hearts. E12.5 cryosections of wild type $(\mathrm{A}, \mathrm{C})$ and $\mathrm{Pax}^{\mathrm{sp} / \mathrm{sp}}(\mathrm{B}, \mathrm{D})$ hearts. Lyzo Tracker red staining $(\mathrm{A}, \mathrm{B})$ indicates higher numbers of apoptotic cells (arrows) in Pax ${ }^{\mathrm{sp} / \mathrm{sp}}$ hearts. Cx40 immunofluorecence (C, D) shows positive cells (arrows) in the trabeculae in controls and mutants. EC: endocardial cushion; IVS: intraventricular septum. Magnification: (A and B) 40x; (C and D) 100x.

\subsection{As Stem Cells}

The initial pluripotentiality of $\mathrm{NC}$ cells is well established and various recent studies have indicated their plasticity even after acquiring specific fates (reviewed in Dupin, 2007). For example, the small signaling molecule Endothelin 3 can convert Schwann cells into melanocytes and vice - versa in vitro. During this process, an intermediate cell type that expresses specific markers for both cell lineages was identified (Dupin et al., 2000; Dupin et al., 2003). These experiments showed that different lineages of NC cells might go through phenotype conversion during development to support instability of $\mathrm{NC}$ phenotypes.

The fate mapping study using the Wnt1-Cre, Rosa26 transgenic mouse that showed the presence and persistence of $\mathrm{CNC}$ cells in the proximal CCS and AV valves found that some of these CNC cells expressed a combination of differentiation markers or none at all (Nakamura et al., 2006). Based on the characteristics of these cells, the suggestion was made that multipotent NC derived cells may remain dormant in the heart and differentiate into various cell types when needed.

A few other studies have also claimed that $\mathrm{CNC}$ cells contribute to a small stemcell like population that resides in the myocardium. Lineage studies using the $\mathrm{P} 0$-Cre mouse crossed to the Floxed-EGFP indicator mouse identified a small number of marked 
cells in the fetal myocardium. Some of these cells expressed the stem cell markers GATA-binding protein 4 and nestin and were considered undifferentiated. Another group of cells showed cardiomyocyte differentiation markers. Under culture conditions the undifferentiated cells were able to form spheres and upon serum exposure, differentiate into neurons, glia, and smooth muscle (Tomita et al., 2005). Nestin expressing cells have also been identified in the rat heart and shown to migrate to the infarct region after induced ischemic insult. There, they seem to function as a substrate for de novo angiogenesis. Similar observations were made in infracted human hearts, where nestin positive cells were found in the viable myocardium and scar tissue (El-Helou et al., 2008).

The multipotentiality and plasticity exhibited by $\mathrm{NC}$ cells is an intriguing and fascinating subject that should be further explored. The manipulation of NC cells using the mechanisms underlying these processes could be used for therapeutic purposes and offer alternative approaches to enhance the treatment of cardiac conditions such as those that result from ischemic injuries. 


\section{REFERENCES}

Auerbach R (1954) Analysis of the development effects of a lethal mutation in the house mouse. J. Exp. Zool. 127:305-329.

Baroffio A, Dupin E, Le Douarin NM (1988) Clone-forming ability and differentiation potential of migratory neural crest cells. Proc Natl Acad Sci USA 85:5325-5329.

Bondurand N, Pingault V, Goerich DE, Lemort N, Sock E, Le Caignec C, Wegner M, Goossens M (2000) Interaction among SOX10, PAX3 and MITF, three genes altered in Waardenburg syndrome. Hum Mol Genet. 9:1907-1917.

Brito FC, Kos L (2008) Timeline and distribution of melanocyte precursors in the mouse heart. Pigment Cell Melanoma Res. 21:464-470.

Britsch S, Goerich DE, Riethmacher D, Peirano RI, Rossner M, Nave KA, Birchmeier C, Wegner M (2001) The transcription factor Sox 10 is a key regulator of peripheral glial development. Genes Dev. 15:66-78.

Chan WY, Cheung CS, Yung KM, Copp AJ (2004) Cardiac neural crest of the mouse embryo: axial level of origin, migratory pathway and cell autonomy of the splotch (Sp2H) mutant effect. Development 131:3367-3379.

Chen G, Litchenberg WH, Cole GJ, Mikawa T, Thompson RP, Gourdie RG (1999) Development of the cardiac conduction system involves recruitment within a multipotent cardiomyogenic lineage. Development 126:5041-5049.

Clouthier DE, Hosoda K, Richardson JA, Williams SC, Yanagisawa H, Kuwaki T, Kumada M, Hammer RE, Yanagisawa M (1998) Cranial and cardiac neural crest defects in endothelin-A receptor-deficient mice. Development 125:813-824.

Conway SJ, Bundy J, Chen J, Dickman E, Rogers R, Will BM (2000) Decreased neural crest stem cell expansion is responsible for the conotruncal heart defects within the splotch $(\mathrm{Sp}(2 \mathrm{H})) / \mathrm{Pax} 3$ mouse mutant. Cardiovasc Res. 47:314-28.

Conway SJ, Henderson DJ, Copp AJ (1997) Pax3 is required for cardiac neural crest migration in the mouse: evidence from the splotch $(\mathrm{Sp} 2 \mathrm{H})$ mutant. Development 124:505514.

Delorme B, Dahl E, Jarry-Guichard T, Marics I, Briand JP, Willecke K, Gros D, Théveniau-Ruissy M (1995) Developmental regulation of connexin 40 gene expression in mouse heart correlates with the differentiation of the conduction system. Dev Dyn. 204:358-371. 
Dupin E, Calloni G, Real C, Gonçalves-Trentin A, Le Douarin NM (2007) Neural crest progenitors and stem cells. C R Biol. 330:521-529.

Dupin E, Glavieux C, Vaigot P, Le Douarin NM (2000) Endothelin 3 induces the reversion of melanocytes to glia through a neural crest-derived glial-melanocytic progenitor. Proc Natl Acad Sci USA 97:7882-7887.

Dupin E, Real C, Glavieux-Pardanaud C, Vaigot P, Le Douarin NM (2003) Reversal of developmental restrictions in neural crest lineages: transition from Schwann cells to glialmelanocytic precursors in vitro. Proc Natl Acad Sci USA 100:5229-5233.

El-Helou V, Beguin PC, Assimakopoulos J, Clement R, Gosselin H, Brugada R, Aumont A, Biernaskie J, Villeneuve L, Leung TK, Fernandes KJ, Calderone A (2008) The rat heart contains a neural stem cell population; Role in sympathetic sprouting and angiogenesis. J Mol Cell Cardiol. [Epub ahead of print]

Epstein JA, Li, J, Lang D, Chen F, Brown CB, Jin F, Lu MM, Thomas M, Liu E, Wessels A, Lo CW (2000) Migration of cardiac neural crest cells in Splotch embryos. Development 127:1869-1878.

Eralp I, Lie-Venema H, Bax NA, Wijffels MC, Van Der Laarse A, Deruiter MC, Bogers AJ, Van Den Akker NM, Gourdie RG, Schalij MJ, Poelmann RE, Gittenberger-De Groot AC (2006) Epicardium-derived cells are important for correct development of the Purkinje fibers in the avian heart. Anat Rec A Discov Mol Cell Evol Biol. 288:1272-1280.

Erickson CA, Goins TL (1995) Avian neural crest cells can migrate in the dorsolateral path only if they are specified as melanocytes. Development 121:915-924.

Farrell MJ, Kirby ML (2001) Cell biology of cardiac development. Int Rev Cytol. 202:99158.

Franz T (1993) The Splotch (Sp1H) and Splotch-delayed (Spd) alleles: differential phenotypic effects on neural crest and limb musculature. Anat Embryol (Berl) 187:371-7.

Garcia RJ, Ittah A, Mirabal S, Figueroa J, Lopez L, Glick AB, Kos L (2008) Endothelin 3 induces skin pigmentation in a keratin-driven inducible mouse model. $J$ Invest Dermatol. 128:131-142.

Goulding MD, Chalepakis G, Deutsch U, Erselius JR, Gruss P (1991) Pax-3, a novel murine DNA binding protein expressed during early neurogenesis. EMBO J. 10:11351147.

Gourdie RG (1995) A map of the heart: gap junctions, connexin diversity and retroviral studies of conduction myocyte lineage. Clin Sci (Colch) 88:257-262. 
Gourdie RG, Wei Y, Kim D, Klatt SC, Mikawa T (1998) Endothelin-induced conversion of embryonic heart muscle cells into impulse-conducting Purkinje fibers. Proc Natl Acad Sci USA 95:6815-6818.

Gurjarpadhye A, Hewett KW, Justus C, Wen X, Stadt H, Kirby ML, Sedmera D, Gourdie RG (2007) Cardiac neural crest ablation inhibits compaction and electrical function of conduction system bundles. Am J Physiol Heart Circ Physiol. 292:H1291-1300.

Hassankhani A, Steinhelper ME, Soonpaa MH, Katz EB, Taylor DA, Andrade-Rozental A, Factor SM, Steinberg JJ, Field LJ, Federoff HJ (1995) Overexpression of NGF within the heart of transgenic mice causes hyperinnervation, cardiac enlargement, and hyperplasia of ectopic cells. Dev Biol. 169:309-321.

High FA, Zhang M, Proweller A, Tu L, Parmacek MS, Pear WS, Epstein JA (2007) An essential role for Notch in neural crest during cardiovascular and smooth muscle differentiation. J Clin Invest. 117:299-302.

Hildreth V, Webb S, Bradshaw L, Brown NA, Anderson RH, Henderson DJ (2007) Cells migrating from the neural crest contribute to the innervation of the venous pole of the heart. $J$ Anat. 212:1-11.

Hornyak TJ, Hayes DJ, Chiu LY, Ziff EB (2001) Transcription factors in melanocyte development: distinct roles for Pax-3 and Mitf. Mech Dev. 101:47-59.

Jiang X, Rowicth DH, Soriano P, McMahon AP, Sucov HM (2000) Fate of the mammalian cardiac neural crest. Development 127:1607-1616.

Kirby ML (2007) Cardiac Development Oxford University Press, Inc.: New York

Kirby ML (1989) Plasticity and predetermination of mesencephalic and trunk neural crest transplanted into the region of the cardiac neural crest. Dev Biol. 134:402-412.

Kirby ML, Gale TF, Stewart DE (1983) Neural Crest cells contribute to aorticopulmonary septation. Science 220:1059-1061.

Kirby ML, Turnage KL 3rd, Hays BM (1985) Characterization of conotruncal malformations following ablation of "cardiac" neural crest. Anat Rec. 213:87-93.

Kirby ML, Weidman TA, McKenzie JW (1980) An ultrastructural study of the cardia ganglia in the bulbar plexus of the developing chick heart. Dev Neurosci. 3:174-184.

Kochilas LK, Li J, Jin F, Buck CA, Epstein JA. (1999) p57Kip2 expression is enhanced during mid-cardiac murine development and is restricted to trabecular myocardium. Pediatr Res. 45:635-642. 
Kruithof BP, Krawitz SA, Gaussin V (2007) Atrioventricular valve development during late embryonic and postnatal stages involves condensation and extracellular matrix remodeling. Dev Biol. 302:208-217.

Kuhlbrodt K, Schmidt C, Sock E, Pingault V, Bondurand N, Goossens M, Wegner M (1998) Functional analysis of Sox10 mutations found in human WaardenburgHirschsprung patients. J Biol Chem. 273:23033-23038.

Kurihara Y, Kurihara H, Oda H, Maemura K, Nagai R, Ishikawa T, Yazaki Y (1995) Aortic arch malformations and ventricular septal defect in mice deficient in endothelin-1. J Clin Invest. 96, 293-300.

Lang D, Chen F, Milewski R, Li J, Lu MM, Epstein JA (2000) Pax3 is required for enteric ganglia formation and functions with Sox 10 to modulate expression of c-ret. $J$ Clin Invest. 106:963-971.

Lang D, Epstein JA (2003) Sox 10 and Pax3 physically interact to mediate activation of a conserved c-RET enhancer. Hum Mol Genet. 12:937-945.

Lavine KJ, Yu K, White AC, Zhang X, Smith C, Partanen J, Ornitz DM (2005) Endocardial and epicardial derived FGF signals regulate myocardial proliferation and differentiation in vivo. Dev Cell. 8:85-95.

Le Douarin NM, Creuzet S, Couly G, Dupin E (2004) Neural crest cell plasticity and its limits. Development 131:4637-4650.

Le Douarin NM, Kalcheim C (1999) The Neural Crest Cambridge: Cambridge Univ. Press: Cambridge.

Le Douarin NM (1980) The ontogeny of the neural crest in avian embryo chimaeras. Nature 286:663-669.

Li J, Liu KC, Jin F, Lu MM, Epstein JA (1999) Transgenic rescue of congenital heart disease and spina bifida in Splotch mice. Development 126:2495-2503.

Li J, Molkentin JD, Colbert MC (2001) Retinoic acid inhibits cardiac neural crest migration by blocking c-Jun N-terminal kinase activation. Dev Biol. 232:351-361.

Li J, Zhu X, Chen M, Cheng L, Zhou D, Lu MM, Du K, Epstein JA, Parmacek MS (2005) Myocardin-related transcription factor B is required in cardiac neural crest for smooth muscle differentiation and cardiovascular development. Proc Natl Acad Sci USA 102: $8916-8921$. 
Mackenzie MA, Jordan SA, Budd PS, Jackson IJ (1997) Activation of the receptor tyrosine kinase Kit is required for the proliferation of melanoblasts in the mouse embryo. Dev Biol. 192:99-107.

Mjaatvedt CH, Kern CB, Norris RA, Fairey S, Cave CL (2005) Normal distribution of melanocytes in the mouse heart. Anat. Rec. A Discov. Mol. Cell Evol. Bio. 285:748-757.

Montero JA, Giron B, Arrechedera H, Cheng YC, Scotting P, Chimal-Monroy J, GarciaPorrero JA, Hurle JM (2002) Expression of Sox8, Sox9 and Sox10 in the developing valves and autonomic nerves of the embryonic heart. Mech Dev. 118:199-202.

Morrison SJ, White PM, Zock C, Anderson DJ (1999) Prospective identification, isolation by flow cytometry, and in vivo self-renewal of multipotent mammalian neural crest stem cells. Cell 96:737-749.

Nakamura T, Colbert MC, Robbins J (2006) Neural crest cells retain multipotential characteristics in the developing valves and label the cardiac conduction system. Circ Res. 98:1547-1554.

Patel R, Kos L (2005) Endothelin-1 and Neuregulin-1 convert embryonic cardiomyocytes into cells of the conduction system in the mouse. Dev Dyn. 23:20-28.

Pietri T, Eder O, Blanche M, Thiery JP, Dufour S (2003) The human tissue plasminogen activator-Cre mouse: a new tool for targeting specifically neural crest cells and their derivatives in vivo. Dev Biol. 259:176-187.

Pingault V, Bondurand N, Kuhlbrodt K, Goerich DE, Préhu MO, Puliti A, Herbarth B, Hermans-Borgmeyer I, Legius E, Matthijs G, Amiel J, Lyonnet S, Ceccherini I, Romeo G, Smith JC, Read AP, Wegner M, Goossens M (1998) SOX10 mutations in patients with Waardenburg-Hirschsprung disease. Nat Genet. 18:171-173.

Pla P, Larue L (2003) Involvement of endothelin receptors in normal and pathological development of neural crest cells. Int J Dev Biol. 47:315-325.

Poelmann RE, Gittenberger-de Groot AC (1999) A subpopulation of apoptosis-prone cardiac neural crest cells targets to the venous pole: multiple functions in heart development? Dev Biol. 207:271-286.

Poelmann RE, Jongbloed MRM, Moli DGM, Fekkes ML, Wang A, Fishman GI, Doetschman T, Azhar M, Gittenberger-de Groot AC (2004) The neural crest is contiguous with the cardiac conduction system in the mouse embryo: a role in induction? Anat Embryol. 208:389-393. 
Potterf SB, Furumura M, Dunn KJ, Arnheiter H, Pavan WJ (2000) Transcription factor hierarchy in Waardenburg syndrome: regulation of MITF expression by SOX10 and PAX3. Hum Genet. 107:1-6.

Read AP, Newton VE (1997) Waardenburg syndrome. JMed Genet. 34:656-665.

Schoenwolf GC, Nichols DH (1984) Histological and ultrastructural studies on the origin of caudal neural crest cells in mouse embryos. J Comp Neurol. 222:496-505.

Shoba T, Dheen ST, Tay SS (2002) Retinoic acid influences Phox2 expression of cardiac ganglionic cells in the developing rat heart. Neurosci Lett. 321:41-44.

Sieber-Blum M, Cohen AM (1980) Clonal analysis of quail neural crest cells: they are pluripotent and differentiate in vitro in the absence of noncrest cells. Dev Biol. 80:96-106.

Sieber-Blum M, Grim M, Hu YF, Szeder V (2004) Pluripotent neural crest stem cells in the adult hair follicle. Dev Dyn. 231:258-269.

Snider P, Olaopa M, Firulli AB, Conway SJ (2007) Cardiovascular development and the colonizing cardiac neural crest lineage. Scientific World Journal 7:1090-1113.

Southard-Smith EM, Kos L, Pavan WJ (1998) Sox10 mutation disrupts neural crest development in Dom Hirschsprung mouse model. Nat Genet. 18:60-64.

Steel KP, Barkway C (1989) Another role for melanocytes: their importance for normal stria vascularis development in the mammalian inner ear. Development 107:453-463.

Stottmann RW, Choi M, Mishina Y, Meyers EN, Klingensmith J (2004) BMP receptor IA is required in mammalian neural crest cells for development of the cardiac outflow tract and ventricular myocardium. Development 131:2205-2218.

Trentin A, Glavieux-Pardanaud C, Le Douarin NM, Dupin E (2004) Self-renewal capacity is a widespread property of various types of neural crest precursor cells. Proc Natl Acad Sci USA 101:4495-4500.

Van den Akker NM, Winkel LC, Nisancioglu MH, Maas S, Wisse LJ, Armulik A, Poelmann RE, Lie-Venema H, Betsholtz C, Gittenberger-de Groot AC (2008) PDGF-B signaling is important for murine cardiac development: its role in developing atrioventricular valves, coronaries, and cardiac innervation. Dev Dyn. 237:494-503.

Varadkar P, Kraman M, Despres D, Ma G, Lozier J, McCright B (2008) Notch2 is required for the proliferation of cardiac neural crest-derived smooth muscle cell. Dev Dyn. 237:1144-1152. 
Verberne ME, Gittenberger-De Groot AC, Poelmann RE (1998) Lineage and development of the parasympathetic nervous system of the embryonic chick heart. Anat Embryol (Berl). 198:171-184.

Verberne ME, Gittenberger-De Groot AC, Poelmann RE (2000) Distribution of antigen epitopes shared by nerves and the myocardium of the embryonic chick heart using different neuronal markers. Anat Rec. 260:335-350.

Waldo KL, Hutson MR, Stadt HA, Zdanowicz M, Zdanowicz J, Kirby ML (2005) Cardiac neural crest is necessary for normal addition of the myocardium to the arterial pole from the secondary heart field. Dev Biol. 281:66-77.

Waldo K, Miyagawa-Tomita S, Kumiski D, Kirby ML (1998) Cardiac neural crest cells provide new insight into septation of the cardiac outflow tract: aortic sac to ventricular septal closure. Dev Biol. 196129-144.

Waldo K, Zdanowicz M, Burch J, Kumiski DH, Stadt HA, Godt RE, Creazzo TL, Kirby ML (1999) A novel role for cardiac neural crest in heart development. $J$ Clin Invest. 103:1499-1507.

Wehrle-Haller B (2003) The role of Kit-ligand in melanocyte development and epidermal homeostasis. Pigment Cell Res. 16:287-296.

Wilson YM, Richards KL, Ford-Perriss ML, Panthier JJ, Murphy M (2004) Neural crest cell lineage segregation in the mouse neural tube. Development 131:6153-6162.

Yamauchi Y, Abe K, Mantani A, Hitoshi Y, Suzuki M, Osuzu F, Kuratani S, Yamamura $\mathrm{K}$ (1999) A novel transgenic technique that allows specific marking of the neural crest cell lineage in mice. Dev Biol. 212:191-203.

Zhao S, Overbeek PA (1999) Tyrosinase-related protein 2 promoter targets transgene expression to ocular and neural crest-derived tissues. Dev Biol. 216:154-163.

Zhou HM, Wang J, Rogers R, Conway SJ (2008) Lineage-specific responses to reduced embryonic Pax3 expression levels. Dev Biol. 315:369-82. 
CHAPTER III: TIMELINE AND DISTRIBUTION OF MELANOCYTE PRECURSORS IN THE MOUSE HEART 


\section{Abstract}

Apart from the well studied melanocytes of the skin, eye and inner ear, another population has recently been described in the heart. In this study we tracked cardiac melanoblasts using in situ hybridization with a Dopachrome tautomerase $(D c t)$ probe and Dct-LacZ transgenic mice. Large numbers of melanoblasts were found in the atrioventricular (AV) endocardial cushions at embryonic day (E) 14.5 and persisted in the AV valves into adulthood. The earliest time Dct-LacZ positive cells were observed in the AV endocardial cushions was E12.5. Prior to that, between E10.5 and E11.5, small numbers of melanoblasts traveled between the post-otic area and third somite along the anterior and common cardinal veins and branchial arch arteries with other neural crest cells expressing $C R A B P I$. Cardiac melanocytes were not found in the spotting mutants $E d n r b^{s-l / s-l}$ and $K i t^{w-v / w-\nu}$, while large numbers were observed in transgenic mice that overexpress Endothelin 3. These results indicate that cardiac melanocytes depend on the same signaling molecules known to be required for proper skin melanocyte development and may originate from the same precursor population. Cardiac melanocytes were not found in zebrafish or frog but were present in quail suggesting an association between cardiac melanocytes and four-chambered hearts. 


\section{Introduction}

The neural crest (NC) constitutes a population of stem-like cells that originates at the dorsal aspect of the neural tube and is capable of giving rise to a wide variety of cell lineages. The differentiation of NC cells is highly influenced by the migratory route they undertake after leaving the neural tube and their final destination. In the trunk, cells that migrate between the neural tube and somites (ventromedial pathway) mostly give rise to neurons and glial cells of the Peripheral Nervous System. The cells that migrate between the surface ectoderm and the somites (dorsolateral pathway) become melanocytes that populate the skin (Le Douarin and Kalcheim, 1999). Along the dorsolateral pathway, melanocyte precursors, the melanoblasts, are exposed to the signaling molecules Kitligand $(K i t l)$ and Endothelin 3 (End3) that control their proliferation, survival, migration and differentiation (reviewed in Wehler-Haller, 2003; Pla and Larue, 2003).

It is generally accepted that most NC cells are pluripotent as they leave the neural tube. However, some precursors may already show some level of commitment to specific lineages prior to or as soon as they exit the neural tube. There is substantial evidence that this applies to those NC cells that give rise to melanocytes. In chicks, only those cells that have already committed to the melanocytic fate are allowed to undertake the dorsolateral pathway (Erickson and Goins, 1995). In mouse embryos, a small group of NC cells that express the tyrosine kinase receptor Kit are found on the medial aspect of the dorsal neural tube and were shown to migrate dorsolaterally and give rise only to melanocytes (Wilson et al., 2004). As soon as NC cells undertake the dorsolateral pathway they start expressing the melanocyte specific transcription factor microphthalmia (Nakayama et al., 1998), and soon after, melanogenic markers such as tyrosinase related protein 
2/Dopachrome tautomerase (Trp2/Dct) (Steel et al, 1992) and pmel17 (Baxter and Pavan, 2003).

Some NC derivatives, such as melanocytes, can be generated by NC cells found along the entire rostro-caudal axis of the embryo. Other cell lineages descend from more restricted areas. This is the case for the cardiac $\mathrm{NC}(\mathrm{CNC})$ that, in the mouse embryo, leaves the neural tube between the post-otic area and the first four somites (Chan et al., 2004). These cells migrate through branchial arches 3,4 and 6 towards the outflow tract of the heart. There, they contribute mesenchymal cells that are critical for the remodeling of the arch arteries and the septation of the outflow tract. Additionally, these cells constitute the major source of postganglionic neural progenitors that innervate the heart (reviewed in Snider et al., 2007). Transplantation experiments in avian embryos demonstrated that only CNC cells, but not NC cells from other axial levels, are capable of contributing to proper truncal septation (Kirby, 1989).

Various lineage tracing studies with double transgenic systems using LacZ or GFP reporter mice and lines carrying NC-specific Cre recombinase activity such as Wnt 1 (Jiang et al., 2000), P0 (Yamauchi et al., 1999), and $\operatorname{Pax3}$ (Epstein et al., 2000) have mostly confirmed the original $\mathrm{CNC}$ cell fate mapping. There are, however, both quantitative and qualitative discrepancies in the data obtained from these analyses, especially in regards to the contribution of $\mathrm{CNC}$ to areas other than the outflow tract and the longevity of reporter expression. For example, one study using the Wntl-Cre system described the presence of CNC in the sinoatrial and atrioventricular (AV) node areas, and bundle branches (Poelmann et al., 2004) that was not reported by Jiang et al (2000). These CNC cells destined to the proximal conduction system had been described 
previously to enter via the venous pole and to undergo apoptosis (Poelmann et al., 1999). Another study that used both $\mathrm{Wnt} 1$-Cre and $\mathrm{PO}$-Cre mice further expanded the pattern of CNC contributions showing the presence of these cells in the semilunar and AV valves that persisted into adulthood (Nakamura et al., 2006).

Recently, the presence of differentiated melanocytes was described in the heart, localized mostly to the valvuloseptal apparatus supporting the notion of a wider and more persistent contribution of NC cells in the heart (Mjaatvedt et al., 2005). However, the developmental trajectory of these cells was not analyzed. In this study, I used transgenic mice that express LacZ under the control of the Dct promoter (Dct-LacZ) (Zhao and Overbeek, 1999) to track melanoblasts entering the heart to establish whether already committed NC cells reach the heart and delineate a timeline for their migratory pathway. I also used mice with mutations that affect Kitl and End3 (Baynash et al., 1994; Geissler et al., 1988; Hosoda et al., 1994; Nocka et al., 1990) signaling to determine if cardiac melanocytes depend on the same pathways that are critical for proper cutaneous melanocyte development.

\section{Results}

3.1 NC cells reach the heart already committed to the melanocytic fate As previously described (Mjaatvedt et al., 2005), we found melanocytes in $\mathrm{L}^{-}$ Dopa stained adult mouse hearts. These melanocytes were mostly localized to the mitral (Figure 11A) and tricuspid valves. In order to determine when already committed melanocyte precursors are found in the heart, I initially performed RT-PCR with RNA obtained from embryonic hearts using primers to amplify Dct. At E10.5, little or no 
expression of Dct was seen while there was considerable expression at E14.5 (Figure 11B).

To further characterize the position of melanoblasts at earlier embryonic stages and determine when these cells reach the heart, I performed in situ hybridization with a Dct probe and traced the melanoblasts using the Dct-LacZ mouse. On whole mount preparations of Dct-LacZ embryonic hearts, the earliest time LacZ positive cells could be easily detected in the heart was E13.5 (data not shown). At E.14.5, a large number of LacZ positive cells were found inside the heart in a pattern that seemed to overlap with the AV endocardial cushions (Figure 11C), the regions where the AV valves arise from. This was confirmed by the distribution of these cells observed in sections of $\beta$ galactosidase stained hearts (Figure 11D) or labeled by in situ hybridization with the Dct probe (Figure 11E).

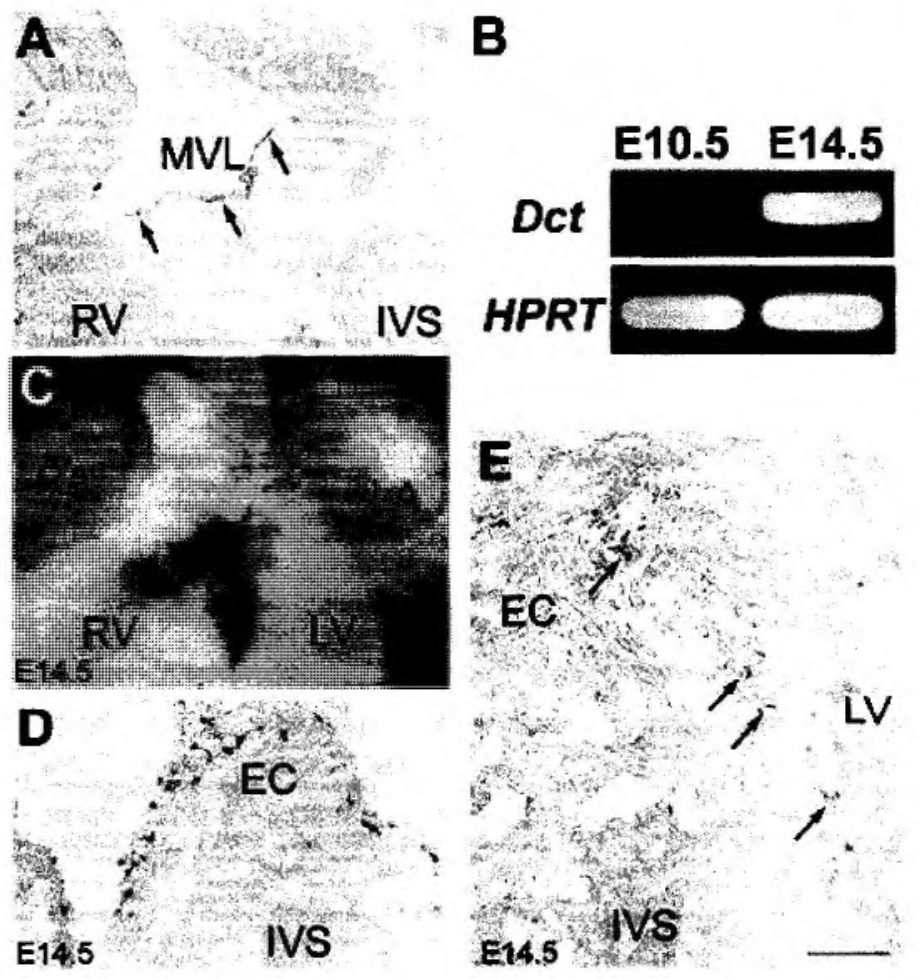


Figure 11. Melanocyte precursors are found in the heart as early as E14.5. (A) Cryosection of an adult mouse heart stained with $L_{-}$- Dopa indicating the presence of melanocytes (arrows) in the mitral valve leaflet (MVL). (B) RT-PCR with mRNA obtained from E10.5 and 14.5 hearts. Dct was not expressed at E10.5 but was highly expressed at E14.5. HPRT was used to normalize the quantities of RNA used. (C) Whole mount E14.5 heart from a Dct-LacZ transgenic mouse showing the presence of large numbers of LacZ positive cells in the region of the developing AV valves. (D) Cryosection of the heart shown in $(\mathrm{C})$ confirming the presence of LacZ positive cells in the developing AV valves. (E) In situ hybridization on cryosection of E14.5 heart with a Dct riboprobe showing many Dct positive cells (arrows) in the developing tricuspid valve. EC: endocardial cushion; IVS: interventricular septum; LA: left atrium; LV: left ventricle; RA: right atrium; RV: right ventricle. Scale bar: (A) $8 \mathrm{~mm}$, (D) $140 \mu \mathrm{m}$, (E) $100 \mu \mathrm{m}$.

Although Dct-LacZ positive cells were not readily seen in whole mount preparations of E12.5 hearts, in sections, isolated melanoblasts were found in the AV endocardial cushions (Figure 12A). Additionally, a few Dct-LacZ positive cells were found in the surroundings area of the aortic sac and common cardinal vein. Small groups also appeared on the dorsal aspect of the right atrium, apparently traveling along the anterior cardinal vein and the sixth branchial arch artery (Figures $12 \mathrm{~A}$ and $\mathrm{B}$ ).

At E11.5, large numbers of melanoblasts are seen migrating along the dorsolateral pathway from the post-otic region to the base of the forelimb. Although Dct-LacZ positive cells were not found in the endocardial cushions, few were already detected in close proximity, such as in the region surrounding the trachea and brancheal arch arteries and appeared to be entering the heart via the septum primum (Figure 12C). The distance between the melanoblasts traveling along the dorsolateral pathway and those that by this stage seem to be entering the heart, suggests that the latter emigrate from the neural tube at an earlier stage. 

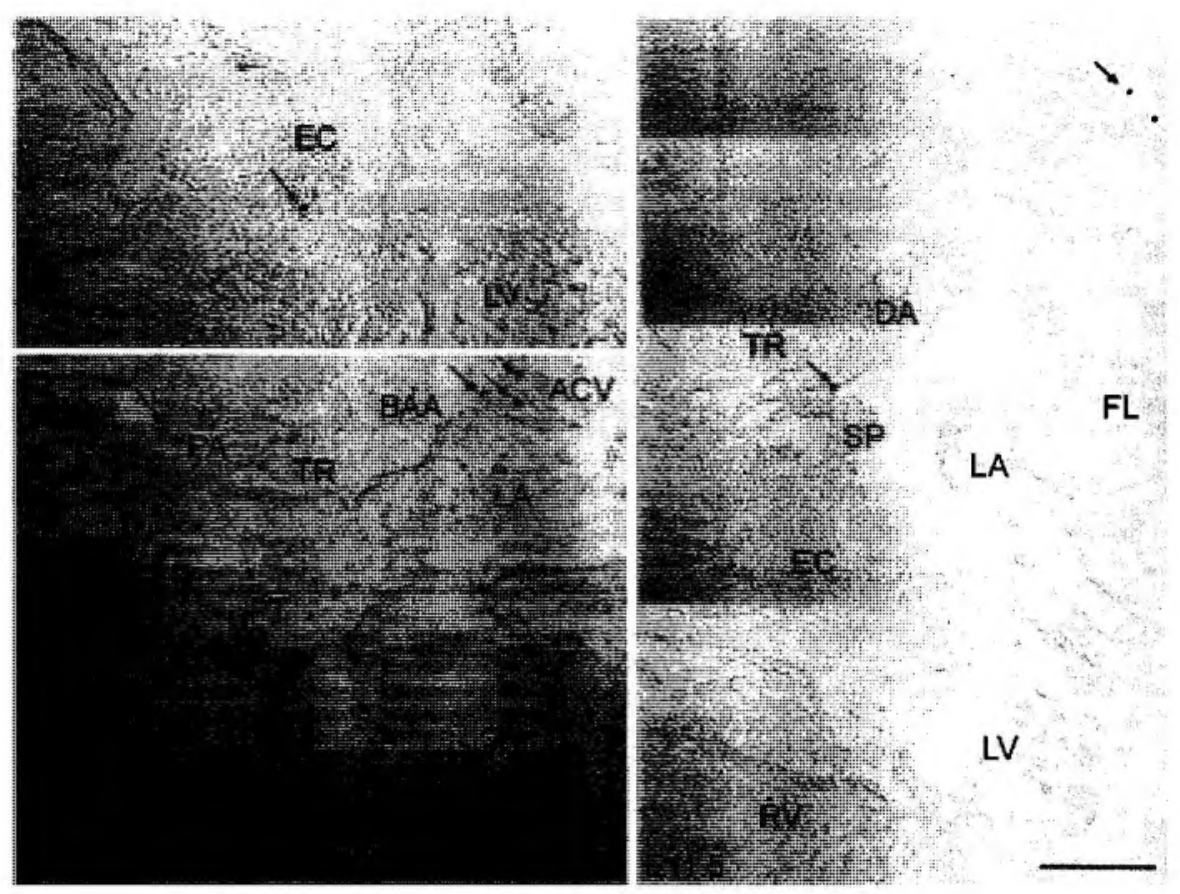

Figure 12. The earliest time melanocyte precursors were found in the heart was E12.5. (A, B) Cryosections of E12.5 hearts from Dct-LacZ embryos. Isolated Dct-LacZ positive cells (arrows) were observed in the AV endocardial cushion (EC), around the common cardinal vein (CCV) (A), anterior cardinal vein (ACV), pulmonary artery (PA) and sixth branchial arch artery (BAA) (B). (C) At E11.5, many Dct-LacZ positive cells were seen migrating along the dorsolateral pathway while only very few were found in proximity to the heart. DRG: dorsal root ganglion; LA: left atria; LV: left ventricle; NT: neural tube; PT: pulmonary trunk; RA: right atrium; $R V$ : right ventricle; $S P$ : septum primum; TR: trachea, FL: forelimb, DA: dorsal aorta. Scale bar: (A, B) $153 \mu \mathrm{m}$, (C) $180 \mu \mathrm{m}$.

At E10.5 most Dct-LacZ positive cells were localized in the post-otic area extending into the second and third branchial arches. A small group of cells were found more posterior in the region of somites 2 and 3 (Figure 13A). Since these cells occupy the most ventral positions, they might be the first to reach the heart. In order to compare the position of Dct-LacZ positive cells in relation to other NC cells, I labeled consecutive sections of $D c t$-LacZ embryos with $\beta$-galactosidase and with the neural crest marker Cellular Retinoic Acid Binding protein I (CRABPI; Figure 13B; Conway et al., 1997; Ruberte et al., 1992). At E10.5, Dct-LacZ positive cells are found in regions of CRABPI 
expression. Around the otic vesicle, Dct-LacZ positive cells seem to overlap with CRABPI expressing cells (Figures 13B and C). Although CRABPI positive cells were observed in the aortic sac (Figure 13D), no Dct-LacZ positive cells were found in the same area (data not shown) demonstrating that the cardiac melanoblasts are not part of the outflow tract population at E10.5. However, slightly more posterior, isolated DctLacZ positive cells were found traveling at a certain distance from the embryo's surface, close to the sixth branchial arch arteries in areas of CRABPI expression (Figures $13 \mathrm{E}$ and F).
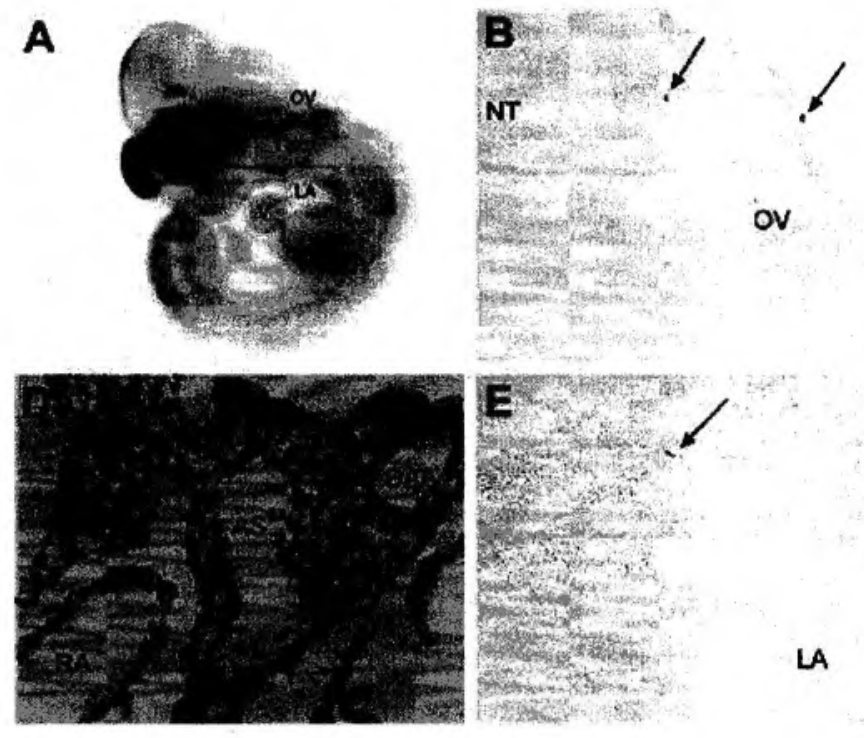

LA

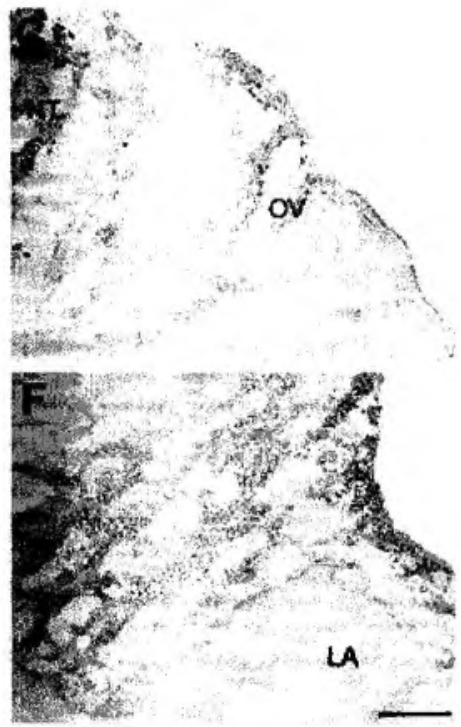

Figure 13. Melanocyte precursors have not yet reached the heart or outflow tract at E10.5. (A) Whole mount E10.5 Dct-LacZ embryo stained for $\beta$-galactosidase. Dct-LacZ positive cells are mostly located in the post-otic area. A few, are found more ventrally at the level of somites 2 and 3 (S). (B, C, E, F) Consecutive cryosections stained for Bgalactosidase (B, E) and in situ with $C R A B P I$ probe $(\mathrm{C}, \mathrm{F})$. Dct-LacZ positive cells (arrows) were found in areas of $C R A B P I$ staining around the otic vesicle (OV) (B, C) and trunk mesenchyme (E, F). (D) CRABPI positive cells (arrow), but not Dct-LacZ positive cells, were observed entering the aortic sac (AS). BAA: branchial arch artery; LA: left atrium; NT: neural tube; RA: right atrium; V: ventricle. Scale bar: (B, C, D, E, F) 125 $\mu \mathrm{m}$. 


\subsection{Cardiac melanocytes depend on Ednrb and Kit signaling}

To determine whether the melanocytes residing in the heart depend on the same signaling pathways that play a role in the early development of those destined to the skin, I looked for their presence in whole mount preparations of two months old hearts of the mutants lethal spotting $\left(E d n 3^{l s / s}\right)$, piebald lethal $\left(E d n r b^{s-l / s-l}\right)$ and viable dominant spotting $\left(K i t^{w-v / v-v}\right)$ mice. $E d n 3^{l s / s}$ mice have varying amounts of pigmented and nonpigmented areas in their coats due to an initial reduction in the number of melanocyte precursors with some subsequent correction as they migrate into the epidermis (Yoshida et al., 1996). Compared with the AV valves of wild type mouse hearts ( $n=5$; Figure $14 \mathrm{~A})$, very few $\mathrm{L}^{-}$- Dopa positive cells were detected in the area of the AV valves of $E d n 3^{l s / s}$ hearts $\left(\mathrm{n}=3\right.$; Figure 14B). The coats of $E d n r b^{s-l / s-l}$ and $K i t^{\omega-\nu / N-v}$ mutants are almost completely white as a result of a dramatic decrease in the melanocyte precursor population (Cable et al., 1995; Lee et al., 2003; Pavan and Tilghman, 1994). Accordingly, no ${ }_{\mathrm{L}}$ - Dopa positive cells were found in $E d n r b^{s-l / s-t}(\mathrm{n}=2$; Figure $4 \mathrm{C})$ and $K i t^{w-v / w-v}$ hearts $(\mathrm{n}=5$; Figure 14D).

Transgenic mice that over-express $E d n 3$ under the control of the keratin5 promoter (K5-tTA;TRE-Edn3) are hyperpigmented due to the presence of larger numbers of dermal melanocytes and an increase in pigment production (Garcia et al., 2008). Dopa staining in $\mathrm{K} 5-t T A ; T R E-E d n 3 \mathrm{AV}$ valves (n=5, Figure 14E) was more pronounced and also detected in ectopic sites such as the pulmonary valve and outflow tract (data not shown). This increase in Dopa staining could be due to the presence of larger numbers of melanocytes, more melanin production, or both. Although transgenic $E d n 3$ is capable of partially rescuing the skin pigmentation phenotype of $\mathrm{Kit}^{\mathrm{w}-\mathrm{w} / \mathrm{w}-v}$ mice, no $\mathrm{L}^{-}$- Dopa positive 
cells were found in these mutants carrying the K5-tTA;TRE-Edn3 transgene (Figure 14F). These results suggest that the $E d n r b$ and Kit signaling pathways are also involved in the proper development of melanocytes destined to the heart.
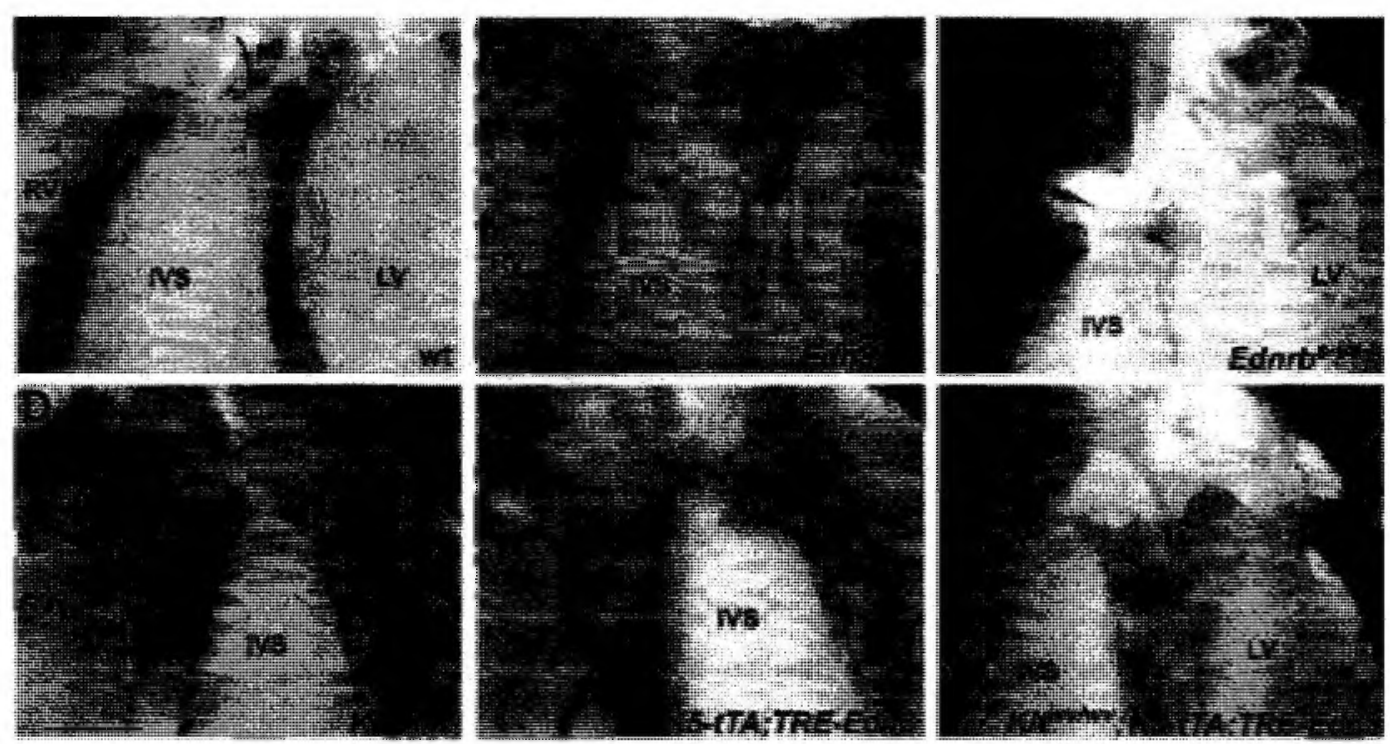

Figure 14. Cardiac melanocytes depend on $E d n 3 / E d n r b$ and Kit signaling. L- Dopa staining of whole mount 2 months old hearts. In wild type hearts, $\mathrm{L}_{-}^{-}$Dopa positive cells (arrows) were found in the AV valves (A). Very few or none were found in the same area of $E d n 3^{l s / s}(\mathrm{~B}) ; E d n r b^{s-l / s-l}(\mathrm{C})$ and $K i t^{w_{-\nu / w-v}}$ hearts (D). While large numbers of $\mathrm{L}^{-}$Dopa positive cells were found in K5-tTA;TRE-Edn 3 hearts (E), none were present in the hearts of transgenics on a $\mathrm{Kit}^{\mathrm{w}-\mathrm{v} / \mathrm{w-v}}$ background (F). RV: right ventricle, IVS: interventricular septum; LV: left ventricle.

3.3 Cardiac melanocytes are only found in four-chambered hearts

In order to determine if melanocytes are also found in other vertebrate hearts and begin to identify a putative function for these cells, I looked for their presence in the zebrafish, frog and quail hearts. Although many ${ }_{L}-$ Dopa positive cells were found in the fat and tissues surrounding the hearts of zebrafish and frog, they were not detected anywhere inside their hearts ( $n=8$, Figure $15 \mathrm{~A} ; \mathrm{n}=3$, Figure 15B, respectively). Large numbers of melanocytes were also observed in the fat tissue around the quail hearts. 
Inside the hearts, small numbers were found in the region of the AV valves ( $n=8$, Figure 15C). These results suggest that only in four chambered hearts, melanocytes populate the $\mathrm{AV}$ valves.
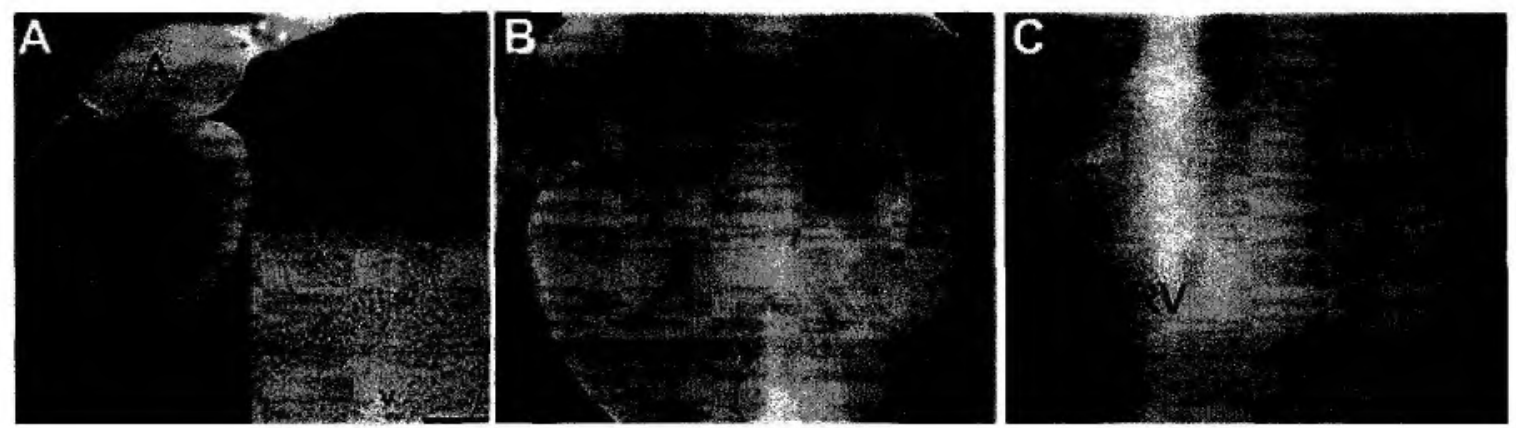

Figure 15. Melanocytes are only found in four-chambered hearts. $L^{-}$Dopa staining of

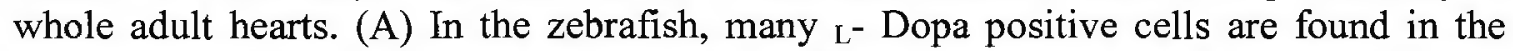
tissue surrounding the heart but not inside, as shown by their location (arrowhead) in a cryosection through the atrium and ventricle (insert, Scale bar: $50 \mu \mathrm{m}$ ). (B) In the frog, $\mathrm{L}^{-}$ Dopa positive cells were not found inside the heart. (C) In the quail, a few $L^{-}$Dopa positive cells were found in the area of the AV valves. A: atria, V: ventricle, LA: left atria, LV: left ventricle, RA: right atria.

\section{Discussion}

The presence of differentiated melanocytes in the adult heart suggested that neural crest derived cells contribute and persist in areas other than the outflow tract (Mjaatvedt et al., 2005). Lineage tracing using the Wnt1-Cre and P0-Cre systems confirmed that the melanocytes found in E17.5 AV valves were indeed of $\mathrm{NC}$ origin (Nakamura et al., 2006). Our study showed that melanocyte precursors reach the heart and can be found in AV endocardial cushion tissue as early as E12.5. These cells are already committed to the melanocytic fate as evidenced by their expression of Dct. This parallels the situation for cutaneous melanocytes, whose precursors start expressing melanogenic markers before they reach the epidermis and hair follicles. It is has not been established whether other 
$\mathrm{NC}$ cells destined to the heart or the outflow tract show any signs of lineage commitment. $\mathrm{NC}$ derived cells expressing neuronal or glial markers have also been shown to persist in the heart but have only been documented at later stages (E17.5) of gestation (Nakamura et al., 2006).

The lack of melanocytes in the AV valves of Kit and Ednrb mutants indicate that cardiac melanocytes depend on the same signaling pathways that are crucial for cutaneous melanocytes. Both Kit and Ednrb signaling are required at early stages of cutaneous melanocyte development affecting the survival and migration of precursors (reviewed in Pla and Larue, 2003; Wehler-Haller, 2003). Except for the melanoblasts, it does not seem that $\mathrm{CNC}$ cells are affected by these signaling pathways since the corresponding mouse mutants have not been shown to have the characteristic outflow tract defects. The limitation of the $D c t$-LacZ transgenic system prevents me from directly showing that those precursors found in the heart at E12.5 descend directly from the melanoblasts migrating along the dorsolateral pathway at earlier stages. However, their dependence on Ednrb and Kit signaling infers that.

There is a dramatic difference between the numbers of Dct-LacZ positive cells found in close proximity to the heart between E11.5 and E12.5 and those seen in the AV endocardial cushions and developing valves from E13.5 onwards. This difference could be due to an increase in the proliferation rate of precursors once they reach an environment rich in mitogens such as Endothelin 1 and members of the fibroblast growth factor family (Kurihara et al., 1995; Sugi et al., 2003). The apparent increase in the number of melanocytes in the AV valves of K5-tTA;TRE-Edn3 mice further supports this possibility since we found that the keratin 5 promoter drives transgene expression to 
certain areas of the heart including the developing AV valves (data not shown). It is also plausible that the $D c t$-LacZ positive cells found at later stages constitute a heterogenous population originating from those few committed melanocyte precursors as well as from other NC cells that reach the heart as uncommitted cells and differentiate in situ. This possibility is unlikely since melanocytes are not found in Kit and Ednrb mutants. Since CNC cells do not depend on Kit or Ednrb, these cells could possibly differentiate as melanocytes in the valves of the respective mutants.

Lineage tracing using DiI injections has shown that $\mathrm{CNC}$ cells that originate in the cranial region migrate dorsolaterally (Chan et al., 2004). The co-localization of DctLacZ and CRABPI positive cells in the areas around the otic vesicle support these findings. The migratory pathway of trunk CNC cells is more complex, with cells taking the dorsolateral, ventromedial and ventrolateral pathways. It is unclear whether all those cells taking the dorsolateral pathway are melanocyte precursors. It is, however, important to point out that these cells are found migrating along the dorsolateral pathway much earlier (between E8.5 and E9.5) than the cells I can detect with the Dct-LacZ transgene or any other melanocytic marker. Based on the lineage tracing studies employing transgenic mice carrying NC-specific Cre recombinase to drive LacZ expression (Epstein et al., 2000; Jiang et al., 2000; Yamauchi et al., 1999) and the presence of CRABPI expressing cells in the aortic sac at E10.5, it appears that some NC cells reach the heart one or two days earlier than the melanoblasts.

Although cardiac melanocyte precursors may originate from the same axial levels as $\mathrm{CNC}$ cells and share migratory pathways, they constitute a separate population based on their level of commitment, timing of arrival in the heart and signaling dependence. It 
would be interesting to investigate whether signaling pathways such as those mediated by Endothelin receptor a (Ednra) (Clouthier et al., 1998) and $F G F-8$ (Frank et al., 2002) that have been shown to affect CNC cells but not cutaneous melanocytes have an effect on cardiac melanocytes.

In addition to the contribution of NC derived cells to the hearts of avians and mice, recent data have shown they also play a role during Xenopus and zebrafish cardiac development. In Xenopus, ablation of premigratory NC cells lead to abnormal heart morphogenesis (Martinsen et al., 2004). In zebrafish, cranial NC cells have been found to migrate to the myocardial wall of the heart tube and acquire a myocardial phenotype. Ablation or interruption of migration of these NC cells lead to cardiac phenotypes that are much more severe than those observed in avian and mice ( $\mathrm{Li}$ et al., 2003; Sato and Yost, 2003, Sato et al., 2006). Despite the presence of NC cell derivatives in the hearts of Xenopus and zebrafish, they do not contribute cells of the melanocytic lineage. The fact that only the hearts of quail and mouse have melanocytes indicates that they may be associated with the more complex morphogenetic events involved in the formation of four-chambered hearts.

Cardiac melanocytes are not essential for gross heart morphogenesis or physiology since Kit mutants live well into adulthood with apparently normal hearts. They may, however, have a more subtle role that becomes critical in situations of stress. Cutaneous melanocytes have a protective role against UV damage (Miyamura et al., 2007). Inner ear melanocytes have a structural function and also seem to participate in controlling ionic balance for the maintenance of the endocochlear potential (Tachibana, 2001). These functions do not seem to apply to cardiac melanocytes. Rather, their 
location and timing of arrival in the heart suggest they may be involved in AV valve development from the endocardial cushions. This process requires the expression of specific extracellular matrix proteins and remodeling enzymes such as metalloproteases (Lincoln et al., 2006). NC cells that contribute to the anterior segment of the eye have been shown to secrete enzymes that participate in the remodeling of the extracellular matrix for proper corneal differentiation (Hay, 1979). The targeted deletion of the metalloprotease meltrin beta/ADAM19 exclusively in NC cells lead to ventricular septal defects and AV valve malformations (Komatsu et al., 2007). Given that melanoblasts have been shown to express and secrete metalloproteases (Lei et al., 2002), they may contribute to valve remodeling along with other $\mathrm{CNC}$ cells.

\section{Methods}

\subsection{Mice}

All animals used in this study were housed in the Animal Care Facility at Florida International University (Miami, FL). Animal work was performed according to institutional guidelines established by the National Institutes of Health. Wild type $(\mathrm{C} 57 \mathrm{BL} / 6 / \mathrm{J}), E d n r b^{s-l}(\mathrm{SSL} / \mathrm{Le}), E d n 3^{l s}$ (LS/LeJ), and $K i t^{w-v / w-v}$ were originally obtained from The Jackson Laboratory, Maine. K5-tTA;TRE-Edn3 transgenic mice were generated in our laboratory as described in Garcia et al., 2008. Dct-LacZ mice created on a FVB/N backround were provided by Dr. Paul Overbeek (Baylor College of Medicine, Houston) (Zhao and Overbeek, 1999). Noon of the day a vaginal plug was defined as embryonic day 0.5 (E0.5). Harvested embryos were subsequently staged according to standard references (Kaufman, 1995). 
Pre-hatching and adult quail (Colinus virginianus) hearts were obtained from Dr. Robert Lickliter (Department of Psychology, Florida International University, Miami). Frog (Xenopus laevis) and zebrafish (Danio rerio) hearts were obtained from Dr. Mary Lou King (University of Miami Medical School, Miami).

\subsection{Semi-quantitative Reverse Transcription Polymerase Chain Reaction (RT-PCR)}

Total RNA from E10.5 and E14.5 hearts were extracted using Trizol (Gibco BRL) and cDNA was synthesized from 1 ug of RNA using Reverse Transcriptase (RT) and oligo (dT) primers from Cells to cDNA kit (Invitrogen - Superscript first strand synthesis system for RT). PCR reactions were carried out for 35 cycles using the following Dct primers: 5'CTAACCGCAGAGCAACTTGGC3'

and 5'CCTTGAGAAGTCGCACACGA3' that yield a $303 \mathrm{bp}$ product and accompanied by controls in which RT was not added (RT-). Levels of cDNA were normalized with $H P R T$ using primers: 5'GGAGCGGTAGCACCTCCT3' and 5'GAAACGACTGGACGACCTAA3' that yield a 311 bp size product.

$5.3_{\mathrm{L}}$ - Dopa, $\beta$-galactosidase staining and in situ hybridization

Whole mount adult hearts or cryosections were subjected to the $\mathrm{L}_{\mathrm{L}}$ - Dopa reaction to stain differentiated melanocytes with tyrosinase activity according to previously described protocols (Hirobe, 1984; Hirobe et al., 2002).

Whole embryos and cryosections were stained for $\beta$-galactosidase according to standard protocols (Furth et al., 1994; Nagy et al., 2003). For the localization of embryonic $L a c Z$ positive cells migrating to or within the heart, serial cryosections (10 
$\mu \mathrm{m}$ ) were taken starting at the level of the otic vesicle and ending at the posterior most aspect of the heart.

In situ hybridization on embryonic cryosections was carried out according to standard protocols (Wilkinson and Nieto, 1993). The sections were hybridized to DIGlabeled Dct (Steel et al., 1992) or CRABPI (Image clone \# 468828) probes and visualized with alkaline phosphatase anti-DIG antibody (Roche). 


\section{REFERENCES}

Baxter LL, Pavan WJ (2003) Pmel17 expression is Mitf-dependent and reveals cranial melanoblast migration during murine development. Gene Expr Patterns 3:703-707.

Baynash AG, Hosoda K, Giaid A, Richardson JA, Emoto N, Hammer RE, Yanagisawa M (1994) Interaction of endothelin-3 with endothelin-B receptor is essential for development of epidermal melanocytes and enteric neurons: missense mutation of endothelin-3 gene in lethal spotting mice. Cell 79:1277-1285.

Cable J, Jackson IJ, Steel KP (1995) Mutations at the W locus affect survival of neural crest-derived melanocytes in the mouse. Mech Dev. 50:139-150.

Chan WY, Cheung CS, Yung KM, Copp AJ (2004) Cardiac neural crest of the mouse embryo: axial level of origin, migratory pathway and cell autonomy of the splotch (Sp2H) mutant effect. Development 131:3367-3379.

Clouthier DE, Hosoda K, Richardson JA, Williams SC, Yanagisawa H, Kuwaki T, Kumada M, Hammer RE, Yanagisawa M (1998) Cranial and cardiac neural crest defects in endothelin-A receptor-deficient mice. Development 125:813-824.

Conway SJ, Henderson DJ, Copp AJ (1997) Pax3 is required for cardiac neural crest migration in the mouse: evidence from the splotch $(\mathrm{Sp} 2 \mathrm{H})$ mutant. Development 124:505514.

Epstein JA, Li J, Lang D, Chen F, Brown CB, Jin F, Lu MM, Thomas M, Liu E, Wessels A, Lo CW (2000) Migration of cardiac neural crest cells in Splotch embryos. Development 127:1869-1878.

Erickson CA, Goins TL (1995) Avian neural crest cells can migrate in the dorsolateral path only if they are specified as melanocytes. Development 121:915-924.

Frank DU, Fotheringham LK, Brewer JA, Muglia LJ, Tristani-Firouzi M, Capecchi MR, Moon AM (2002) An Fgf8 mouse mutant phenocopies human 22q11 deletion syndrome. Development 129:4591-4603.

Furth PA, St Onge L, Böger H, Gruss P, Gossen M, Kistner A, Bujard H, Hennighausen L (1994) Temporal control of gene expression in transgenic mice by a tetracyclineresponsive promoter. Proc Natl Acad Sci USA 91:9302-9306.

Garcia RJ, Ittah A, Mirabal S, Figueroa J, Lopez L, Glick AB, Kos L (2008) Endothelin 3 induces skin pigmentation in a keratin-driven inducible mouse model. $J$ Invest Dermatol. 128:131-142. 
Geissler EN, Ryan MA, Housman DE (1988) The dominant-white spotting (W) locus of the mouse encodes the c-kit proto-oncogene. Cell 55:185-192.

Hay ED (1979) Development of the vertebrate cornea. Int Rev Cytol. 63:263-322.

Hirobe T (1984) Effects of genic substitution at the brown locus on the differentiation of epidermal melanocytes in newborn mouse skin. Anat Rec. 209:425-432.

Hirobe T, Furuya R, Akiu S, Ifuku O, Fukuda M (2002) Keratinocytes control the proliferation and differentiation of cultured epidermal melanocytes from ultraviolet radiation B-induced pigmented spots in the dorsal skin of hairless mice. Pigment Cell Res. 15:391-399.

Hosoda K, Hammer RE, Richardson JA, Baynash AG, Cheung JC, Giaid A, Yanagisawa M (1994) Targeted and natural (piebald-lethal) mutations of endothelin-B receptor gene produce megacolon associated with spotted coat color in mice. Cell 79:1267-1276.

Jiang X, Rowicth DH, Soriano P, McMahon AP, Sucov HM (2000) Fate of the mammalian cardiac neural crest. Development 127:1607-1616.

Kirby ML (1989) Plasticity and predetermination of mesencephalic and trunk neural crest transplanted into the region of the cardiac neural crest. Dev Biol. 134:402-412.

Komatsu K, Wakatsuki S, Yamada S, Yamamura K, Miyazaki J, Sehara-Fujisawa A (2007) Meltrin beta expressed in cardiac neural crest cells is required for ventricular septum formation of the heart. Dev Biol. 303:82-92.

Kurihara Y, Kurihara H, Oda H, Maemura K, Nagai R, Ishikawa T, Yazaki Y (1995) Aortic arch malformations and ventricular septal defect in mice deficient in endothelin-1. J Clin Invest. 96:293-300.

Le Douarin NM, Kalcheim C (1999) The Neural Crest. (Cambridge: Cambridge Univ. Press).

Lee HO, Levorse JM, Shin MK (2003) The endothelin receptor-B is required for the migration of neural crest-derived melanocyte and enteric neuron precursors. Dev Biol. 259:162-175.

Lei TC, Vieira WD, Hearing VJ (2002) In vitro migration of melanoblasts requires matrix metalloproteinase-2: implications to vitiligo therapy by photochemotherapy. Pigment Cell Res. 15:426-432.

Li YX, Zdanowicz M, Young L, Kumiski D, Leatherbury L, Kirby ML (2003) Cardiac neural crest in zebrafish embryos contributes to myocardial cell lineage and early heart function. Dev Dyn. 226:540-550. 
Lincoln J, Lange AW, Yutzey KE (2006) Hearts and bones: shared regulatory mechanisms in heart valve, cartilage, tendon, and bone development. Dev Biol. 294:292302.

Martinsen BJ, Frasier AJ, Baker CV, Lohr JL (2004) Cardiac neural crest ablation alters Id2 gene expression in the developing heart. Dev Biol. 272:176-190.

Mjaatvedt CH, Kern CB, Norris RA, Fairey S, Cave CL (2005) Normal distribution of melanocytes in the mouse heart. Anat. Rec. A Discov. Mol. Cell Evol. Bio. 285:748-757.

Miyamura Y, Coelho SG, Wolber R, Miller SA, Wakamatsu K, Zmudzka BZ, Ito S, Smuda C, Passeron T, Choi W, Batzer J, Yamaguchi Y, Beer JZ, Hearing VJ (2007) Regulation of human skin. pigmentation and responses to ultraviolet radiation. Pigment Cell Res. 20:2-13.

Nagy A, Gertsenstein M, Vintersten K, Behringer R (2003) Manipulating the Mouse Embryo. (New York: Cold Spring Harbor Laboratory Press).

Nakamura T, Colbert MC, Robbins J (2006) Neural crest cells retain multipotential characteristics in the developing valves and label the cardiac conduction system. Circ Res. 98:1547-1554.

Nakayama A, Nguyen MT, Chen CC, Opdecamp K, Hodgkinson CA, Arnheiter H (1998) Mutations in microphthalmia, the mouse homolog of the human deafness gene MITF, affect neuroepithelial and neural crest-derived melanocytes differently. Mech Dev. 70:155-166.

Nocka K, Tan JC, Chiu E, Chu TY, Ray P, Traktman P, Besmer P (1990) Molecular bases of dominant negative and loss of function mutations at the murine c-kit/white spotting locus: W37, Wv, W41 and W. EMBO J. 9:1805-1813.

Pavan WJ, Tilghman SM (1994) Piebald lethal (sl) acts early to disrupt the development of neural crest-derived melanocytes. Proc. Natl. Acad. Sci. USA 91:7159- 7163.

Pla P, Larue L (2003) Involvement of endothelin receptors in normal and pathological development of neural crest cells. Int J Dev Biol. 47:315-325.

Poelmann RE, Gittenberger-de Groot AC (1999) A subpopulation of apoptosis-prone cardiac neural crest cells targets to the venous pole: multiple functions in heart development? Dev Biol. 207:271-286.

Poelmann RE, Jongbloed MRM, Moli DGM, Fekkes ML, Wang A, Fishman GI, Doetschman T, Azhar M, Gittenberger-de Groot AC (2004) The neural crest is contiguous with the cardiac conduction system in the mouse embryo: a role in induction? Anat Embryol. 208:389-393. 
Ruberte E, Friederich V, Morriss-Kay G, Chambon P (1992) Differential distribution patterns of CRABP I and CRABP II transcripts during mouse embryogenesis. Development 115:973-987.

Sato M, Tsai HJ, Yost HJ (2006) Semaphorin3D regulates invasion of cardiac neural crest cells into the primary heart field. Dev. Biol. 298:12-21.

Sato M, Yost HJ (2003) Cardiac neural crest contributes to cardiomyogenesis in zebrafish. Dev Biol. 257:127-139.

Snider P, Olaopa M, Firulli AB, Conway SJ (2007) Cardiovascular development and the colonizing cardiac neural crest lineage. Scientific World Journal 7:1090-1113.

Steel KP, Davidson DR, Jackson IJ (1992) TRP-2/DT, a new early melanoblast marker, shows that stell growth factor (c-kit ligand) is a survival factor. Development 115:11111119.

Sugi Y, Sasse J, Lough J (1993) Inhibition of precardiac mesoderm cell proliferation by antisense oligodeoxynucleotide complementary to fibroblast growth factor-2 (FGF-2). Dev Biol. 157:28-37.

Tachibana M (2001) Cochlear melanocytes and MITF signaling. I Investig Dermatol Symp Proc. 6:95-98.

Wehrle-Haller B (2003) The role of Kit-ligand in melanocyte development and epidermal homeostasis. Pigment Cell Res.16:287-296.

Wilkinson DG, Nieto MA (1993) Detection of messenger RNA by in situ hybridization to tissue sections and whole mounts. Methods Enzymol. 225:361-373.

Wilson YM, Richards KL, Ford-Perriss ML, Panthier JJ, Murphy M (2004) Neural crest cell lineage segregation in the mouse neural tube. Development 131:6153-6162.

Yamauchi Y, Abe K, Mantani A, Hitoshi Y, Suzuki M, Osuzu F, Kuratani S, Yamamura $\mathrm{K}$ (1999) A novel transgenic technique that allows specific marking of the neural crest cell lineage in mice. Dev Biol. 212:191-203.

Yoshida H, Kunisada T, Kusakabe M, Nishikawa S, Nishikawa SI (1996) Distinct stages of melanocyte differentiation revealed by analysis of nonuniform pigmentation patterns. Development 122:1207- 1214.

Zhao S, Overbeek PA (1999) Tyrosinase-related protein 2 promoter targets transgene expression to ocular and neural crest-derived tissues. Dev Biol. 216:154-163. 
CHAPTER IV: THE LOCALIZATION OF MELANOCYTES AND ITS COEXPRESSION WITH ECM PROTEINS IN THE ATRIOVENTRICULAR VALVES 


\section{Abstract}

Heart valves are complex structures composed of organized layers of extracellular matrix, intersticial and overlying endothelial cells. Recently, a population of neural crest derived melanocytes has been described in the mouse atrioventricular valves. This study presents the specific localization of the melanocytes within the AV valves at ages (N1.5, N4.5, 3 and 8 weeks old) important for their embryonic and post-natal development. In all stages analyzed, melanocytes were found in high numbers populating the atrial aspect of the tricuspid septal leaflet, followed by the mitral septal leaflet. The pulmonary valve did not present melanocytes at any stage analyzed. Two of the most prominent extracellular matrix molecules in the valves are Collagen I and Versican B. Their patterns of expression accompany valve remodeling and are complementary to each other. Melanocytes were found to reside primarily in areas of Versican B expression. The patterns of expression of Collagen I and Versican B were not, however, disrupted in valves containing extra numbers of melanocytes (K5-tTA;TRE-Edn3) or no melanocytes $\left(K_{i t}{ }^{W-v / W-v}\right)$. To further characterize a putative role for melanocytes in the valves, the quasi-static and dynamic nanomechanical properties of the hypo and hyperpigmented tricuspid valve leaflets were measured. The stiffness coefficient of hyperpigmented leaflets was higher (approximately $11.5 \mathrm{GPa}$ ) when compared with the ones from wild type (approximately $7.5 \mathrm{GPa}$ ) and hypopigmented $\left(5.5 \mathrm{GPa}\right.$ for $\mathrm{Kit}^{\mathrm{W}-\mathrm{v} / \mathrm{W}-\mathrm{v}}$; and $3.5 \mathrm{GPa}$ for $\left.E d n r B^{s-l / s-l}\right)$ leaflets. These results suggest that melanocytes may contribute to the mechanical properties of the heart valves. 


\section{Introduction}

Heart valves are structures that guarantee unidirectional blood flow during the cardiac cycle. For that, they need to open and close in a coordinate fashion at least $3 \times 10^{9}$ times during a single lifetime. While they are mostly passive structures driven by forces exerted by the surrounding blood and heart, they exhibit complex biomechanical properties. The mechanical requirements for elasticity, compressibility, stiffness and strength, as well as durability throughout the lifespan of an individual are achieved primarily by their highly organized and compartmentalized extracellular matrix (ECM) composition (Rabkin-Aikawa et al., 2005; Schoen, 2005).

The semilunar valves (SL: pulmonary and aortic) of the outflow tract are composed of three cusps, whereas the atrioventricular (AV: mitral and tricuspid) of the AV canal have two or three leaflets supported by chordae tendineae that insert into the ventricular papillary muscles. Valve development starts in the embryo with the endothelial-mesenchymal transformation of the endocardium in the outflow tract and atrioventricular (AV) canal to form the endocardial cushions. Endocardial cushions then elongate due to cell proliferation and during post-natal development undergo expansion and remodeling of the ECM to form the mature SL valve cusps and AV valve leaflets as well as their supporting structures (Person et al., 2005).

The mature valve structure is composed of ECM, valvular interstitial cells and overlying endothelial cells. To achieve the demanding mechanical properties of the valves, a three-layered organization of the ECM has evolved. These layers are the fibrosa, the spongiosa, and the atrialis (AV)/ ventricularis (SL) (Rabkin-Aikawa et al., 2005). In the AV valves, the fibrosa layer is located away from the blood flow and it is 
predominantly composed of parallel, dense collagen fibers that confer stiffness and strength to the leaflets. These properties are required for the proper closing of the valve orifices preventing reflux into the adjacent chamber. The spongiosa layer is rich in proteoglycans that provide a compressible matrix and allows for changes in leaflet shape during the cardiac cycle. In the mouse, there are many proteoglycans expressed in the spongiosa layer during remodeling. Two of the most abundant components are hyaluronic acid (Camenisch et al., 2000) and Versican (Mjaatvedt et al., 1998). The atrialis layer is located adjacent to blood flow and it is mostly composed of aligned elastin fibers combined with short collagen fibers in a radial arrangement, allowing the leaflets to stretch and retract during the cardiac cycle (Rabkin-Aikawa et al., 2005).

Post-natal valve development allows for the adjustment to the increasing body mass and changes in vascular pressures (Leu et al., 2001). Different processes are responsible for AV valve maturation. For example, in the mouse, between E15.5 and E18.5, a significant increase in endocardial cushion mesenchymal cell density occurs in a process called condensation. From E18.5 onwards, valve leaflets start elongating and by 3 weeks after birth, their length has increased by 8.0 fold. Between the first and the eighth week post-natal, there is a modification in the expression pattern of ECM molecules, including Collagen I and Versican B, which promotes the remodeling of the leaflets (Kruithof et al., 2006). At E15.5 and E18.5, Collagen I expression is distributed throughout the valve. After birth it becomes restricted to the ventricular side of the leaflet while Versican B is mostly found in complementary areas in the atrial side (Kruithof et al., 2006). 
Apart from the endodermal and mesenchymal-derived cells that are present in the valves, other cell types have not been previously described to be involved in their development. The neural crest cells have long been known to participate in the formation of the outflow tract of the heart (Hutson and Kirby, 2007). Their contribution to the heart itself is still an area of much debate (Snider et al., 2007). Recently, a few studies using the Cre-Lox system to trace neural crest lineage cells in the mouse have indicated that they can be found in the proximal conduction system and AV valves (Poelmann et al., 2004; Nakamura et al., 2006). Some of these cells seem to remain undifferentiated but others show neuronal, glial and melanocytic differentiation markers (Nakamura et al., 2006). Cells of the melanocytic fate reach the developing heart already committed and persist into adulthood, particularly in the AV valves and chordae tendineae (Mjaatvedt et al., 2005; Brito and Kos, 2008; Yajima and Larue, 2008).

In an attempt to identify a putative role for melanocytes in the AV valves, I performed a systematic histological analysis during post-natal development of their localization in the leaflets in relationship to the expression of ECM molecules relevant to AV patterning. Melanocytes were found in the atrial sides of the AV valves in areas rich in the proteoglycan Versican B. To test if melanocytes could affect the AV patterning of the leaflets, ECM expression was analyzed in hypopigmented mice, in which melanocytes are completely absent, and in transgenic mice that over-express endothelin, in which there is an excessive number of melanocytes not only in the AV valves but also in ectopic locations such as the pulmonary valve. Further, I compared the dynamic mechanical properties of mitral valve leaflets with varying amounts of melanocytes using a nanoindentation approach (Ebnstein and Pruitt, 2006). This is the first time the 
mechanical properties of murine valves have been studied. I found a correlation between the number of melanocytes present in the valves and their stiffness.

\section{Results}

3.1 The localization of melanocytes in the valves

Hearts from different ages were dissected and submitted to the $\mathrm{L}_{\mathrm{L}}$ - Dopa staining technique which stains melanocytes and melanin within cells and tissues. The distribution of melanocytes was analyzed along the base-tip, ventral-dorsal, and ventricular-atrial axis of the valve (Figure 16).

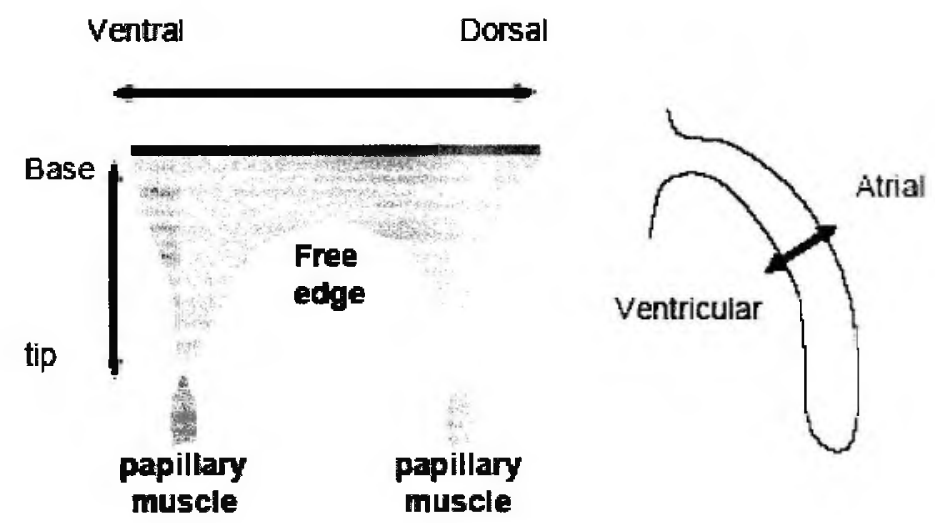

Figure 16. Schematic diagram of the leaflets of a valve (by Boudewijn Kruithof).

The mitral mural leaflet $(\mathrm{mml})$ showed few or none melanocytes throughout the stages analyzed. At N1.5, they were detected at the most ventral side close to the attachment to the mitral septal leaflet (Figure 17A). At N4.5, few cells were found at the most distal part of the tip, however this expression pattern was not seen in all leaflets analyzed (Figure 17E). The same inconsistent pattern was observed at 3 weeks of age where melanocytes were detected at the ventral side and a little broader (up to the distal 


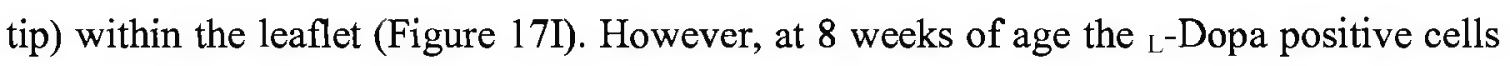
were commonly seen in the distal tip and in the ventral part of the mml (Figure 17M).

Melanocytes were also detected in the mitral septal leaflet (msl). At N1.5, they were found at the dorsal side along the atrial side of the leaflet. At the middle and more ventral areas they were located in the tip of the leaflet (Figure 17B). A similar pattern was observed at N4.5 hearts where ${ }_{L}$-Dopa positive cells were located at the tip and possibly nodular thickenings of the msl (Figure 17F). At 3 and 8 weeks old, the localization pattern of melanocytes resembles earlier stages; however at 8 weeks of age, those cells were seen more in the middle of the leaflet instead of at the dorsal side (Figures 17J and N, respectively).

The presence of melanocytes in the tricuspid mural leaflet (tml) was restricted to certain regions and ages. At N1.5, only the most ventral side of the leaflet at the atrial side showed the presence of L-Dopa positive cells (Figure 17C). At N4.5 melanocytes were observed at the tip of the tml. In addition, at the most ventral side, they were found along the down half or whole length and width of the leaflet (Figure 17G). At 3 weeks of age, almost none or none ${ }_{\mathrm{L}}$-Dopa positive cells were found in the tml (Figure 17K). However, at 8 weeks of age, melanocytes were found in the tip of the leaflet and its distribution varied from being restricted to the medial aspect to a more widespread localization along the entire tip of the tml (Figure 17O).

Most of the ${ }_{L}$-Dopa positive cells in the heart were found in the tricuspid septal leaflet (tsl). The distribution of melanocytes in the tsl throughout all stages showed certain specificity. There are patterns along the dorsal-ventral, atria-ventricular, and basetip directions. At N1.5, ${ }_{\mathrm{L}}$-Dopa positive cells were found mostly in the atrial side of the 
leaflet at the dorsal area of the heart, more ventrally their distribution becomes wider and occupies the entire width of the leaflet (Figure 17D). Between the most ventral and dorsal part of the leaflet there is a gap with no ${ }_{\mathrm{L}}$-Dopa positive cells present. Analysis of N4.5 tsl showed similar patterns, however more cells were present at the tip side of the valve (Figure 17H). The different patterns between N4.5 and 3 weeks old leaflets were clear. At N4.5 melanocytes were found along the total dorsal-ventral axis while at 3 weeks old, very little ${ }_{L}$-Dopa positive cells were found at the dorsal side (Figure $17 \mathrm{H}$ and $\mathrm{L}$, respectively). Additionally, the gap without positive cells is found along the dorsalventral axis and not only in the middle region of the leaflet. At 8 weeks of age, most melanocytes were found in the midline of the heart at the tip of the leaflet (Figure 17P).

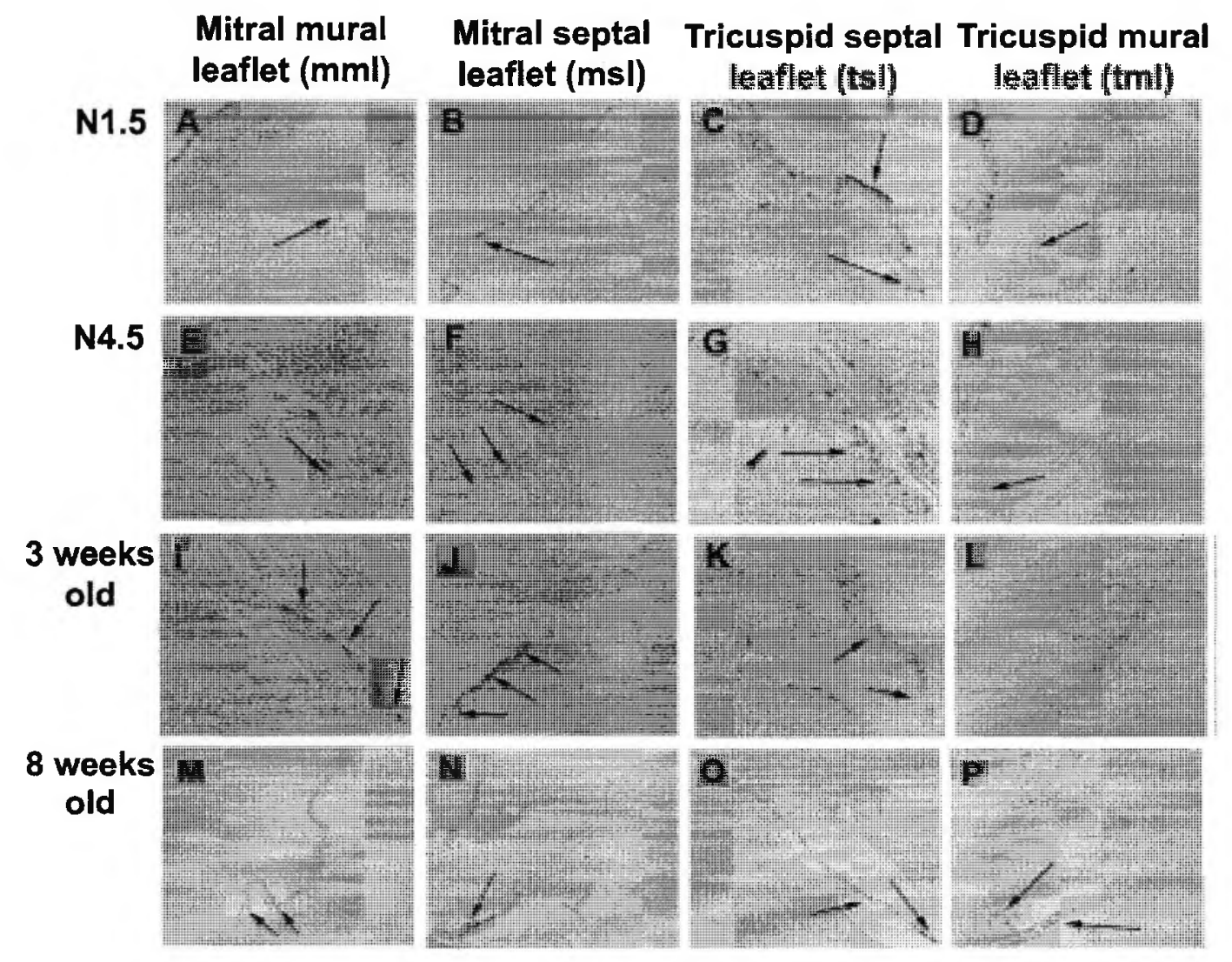


Figure 17. Distribution of melanocytes in post-natal AV valve development. L- Dopa stained sections of the mitral mural (A, E, I and M), mitral septal (B, F, J and N), tricuspid septal (C, G, K and $\mathrm{O}$ ), and tricuspid mural (D, H, L and P) leaflets showed that melanocytes are mostly localized to the atrial aspect of the valve. Magnification 10x.

The presence of melanocytes in the aortic valve was detected in all stages analyzed; however its distribution in the three cusps was not consistent. At N1.5, $\mathrm{L}$-Dopa positive cells were found in the posterior and right coronary cusps (Figure 18A). At N4.5, melanocytes were found mainly in the right cusp and few cells were observed in the left and posterior cusps (Figure 18C). At 3 and 8 weeks of age, the presence of melanocytes was constant in the right and posterior cusps, preferentially in the middle portion of the leaflet (Figure 18F and I, respectively). Interestingly, the pulmonary valve did not show ${ }_{\mathrm{L}}$-Dopa positive cells in any of the stages analyzed (Figure 18B, D, G and J).

The presence of melanocytes in the venous valves was not observed at N1.5 (data not shown). At N4.5, $\mathrm{L}$-Dopa positive cells were restricted to the tip of the valve (Figure $18 \mathrm{E}$ ) while in later stages ( 3 and 8 weeks of age), melanocytes were detected throughout the entire length of the leaflet (Figure $18 \mathrm{H}$ and $\mathrm{K}$ ). In all stages analyzed, melanocytes were detected at the dorsal right atrium and found usually in close proximity to the venous valves. At 8 weeks of age, a group of very strong L-Dopa positive cells was detected upstream of the venous valves (Figure 18K). This is the first time that the presence of neural crest derived cells has been described in the venous valves. 


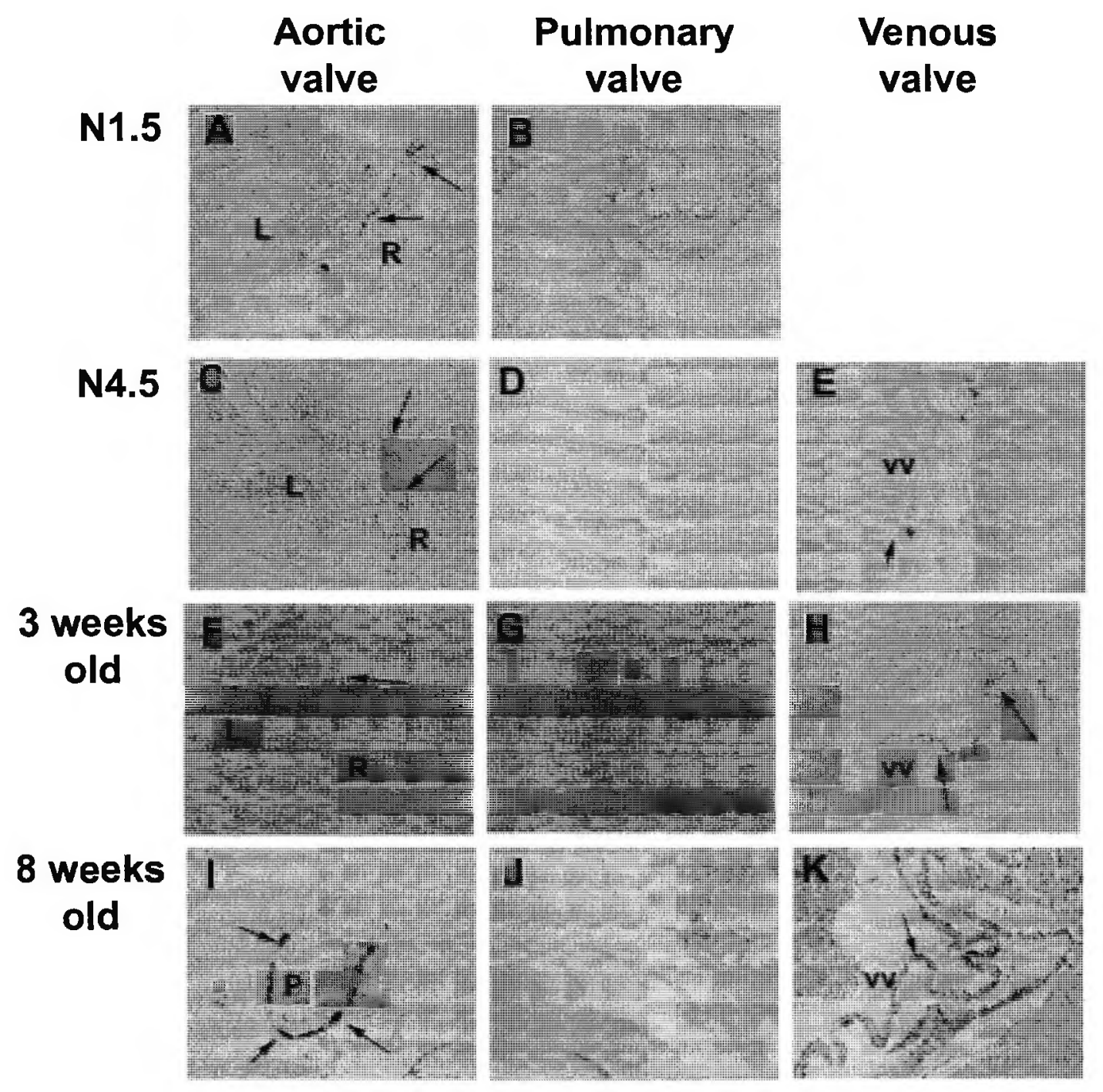

Figure 18. Distribution of melanocytes in post-natal SL valve development. L-Dopa positive cells at different stages of development in the aortic, pulmonary, and venous valves. The aortic valves ( $\mathrm{A}, \mathrm{C}, \mathrm{F}$, and $\mathrm{I})$ have melanocytes throughout all stages, especially at the right coronary cusp $(\mathrm{R})$ and at the posterior cusp $(\mathrm{P})$. No $\mathrm{No}_{\mathrm{L}}$-Dopa positive cells were detected at the pulmonary valves (B, D, G, and J). At the early stage of N1.5, the venous valves did not show the presence of melanocytes (data not shown). From N4.5 onwards, those cells were detected along the leaflets (E, H, and K). Magnification 10x.

Nevertheless, melanocytes were observed at N1.5 at the right side of the atrial septum (AS) and surrounding the IVS (Figure 19A). The cells in the central fibrous body (cfb) are contiguous with the ${ }_{\mathrm{L}}$-Dopa positive cells in the tsl (Figure 19B). In the IVS at 
N4.5, melanocytes were found in a continuous manner along its entire outer curvature (blue line) between the site of attachment of the tsl and the msl (Figure 19C). Additionally, the same pattern (orange line) was observed between the tsl and the aortic valve (av) (Figure 19D). At 3 weeks of age, melanocytes were mostly found in the AS (Figure 19E) and along the tsl (Figure 19F). At 8 weeks old heart, L-Dopa positive cells were mostly found at the left upper side of the IVS along the outer curvature (green lines) (Figure 19G and H). 


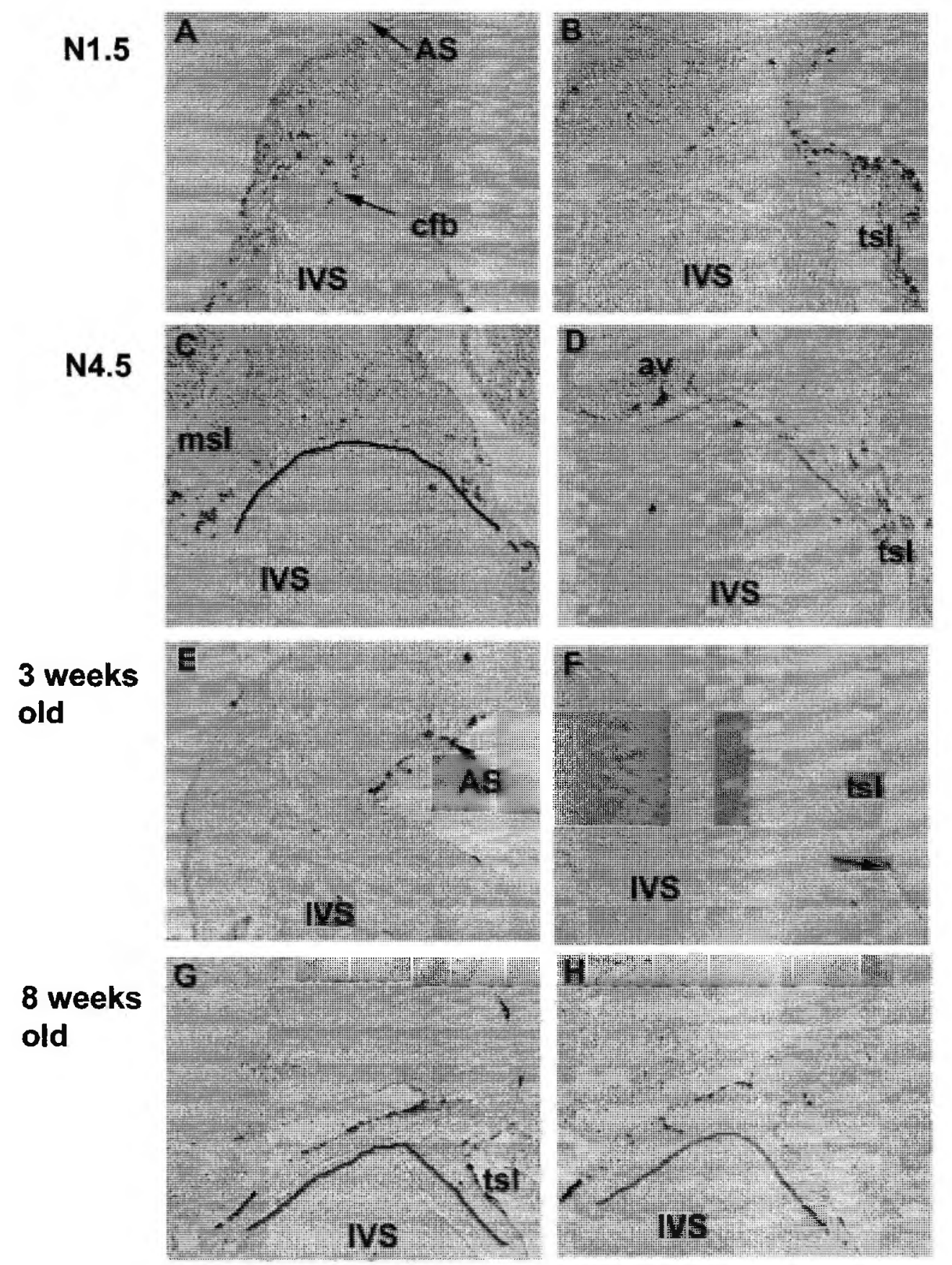

Figure 19. L-Dopa staining in N1.5, N4.5, 3 and 8 weeks old hearts. (A and B) N1.5 heart with melanocytes (black spots) in the close to the atria septum (AS), mostly in the central fibrous body (cfb) in the interventricular septum (IVS). (C and D) At N4.5, L-Dopa positive cells were localized along the IVS outer curvature (blue and orange lines). (E and F) At 3 weeks old, in the ventral aspect of the leaflet, melanocytes were mostly found in the AS (E). At a more dorsal level, they were found at the tsl (F). (G and H) At 8 weeks old, L-Dopa positive cells were mostly found at the left upper side of the IVS along 
the outer curvature (green lines). av: aortic valve; msl: mitral septal leaflet; tsl: tricuspid septal leaflet. Magnification 20x.

3.2 Correlation between melanocytes localization and extracellular matrix expression in the AV valves

Collagen I and Versican B are two of the ECM proteins involved in different stages of valve development and are important during the remodeling of the leaflets after birth. In order to identify a possible correlation between the presence of melanocytes in the valves and the pattern of expression of ECM molecules, I did ${ }_{L}$-Dopa staining and Collagen I and Versican B double antibody staining in wild type, hyperpigmented (K5$t T A ; T R E-E d n 3)$ (Garcia et al., 2008) and hypopigmented $\left(K i t^{w-v / w-v}\right)$ (Nocka et al., 1990) paraffin sections from adult hearts.

Hypopigmented animals do not have melanocytes in the leaflets of the valves (Brito and Kos, 2008) (Figure 20A). Notwithstanding, the pattern of expression of Collagen I (Figure 20B) and Versican B (Figure 20C) was similar to that found in wild type leaflets (Figures $20 \mathrm{~F}$ and G). The wild type pattern of expression was also found in the leaflets of hyperpigmented mice (Figures 20J and K). Interestingly, the localization of melanocytes in the wild type leaflet corresponded precisely to areas of Versican B expression (Figure 20H). The same pattern was noticed in the hyperpigmented leaflets (Figure 20L) demonstrating that melanocytes preferentially localize to areas where Versican B is expressed and a correlation between them should be explored. 


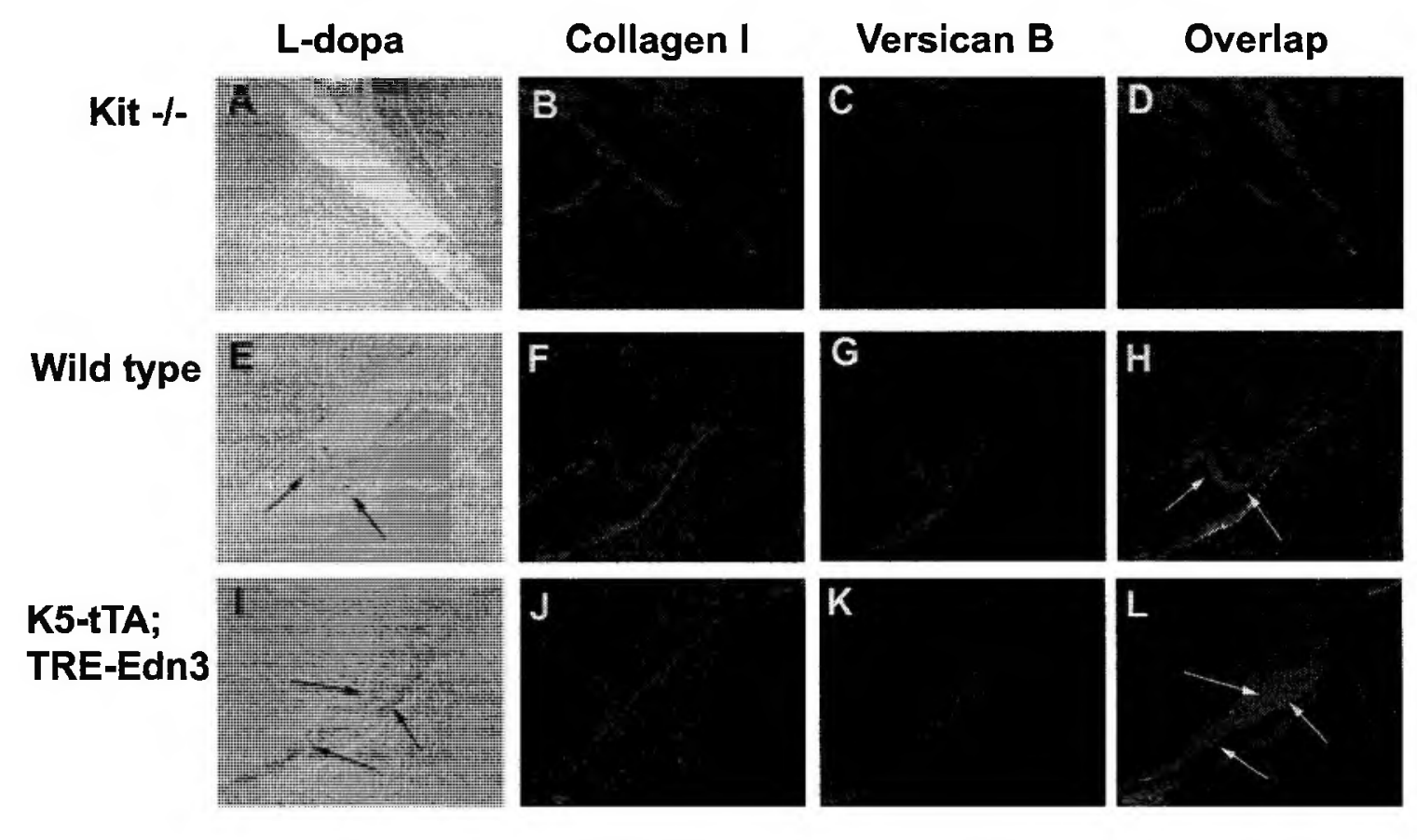

Figure 20. L- Dopa, Collagen I, and Versican B antibody stainings in the AV valves of hypopigmented $\left(\mathrm{Kit}^{-1}\right)$ wild type and hyperpigmented (K5-tTA;TRE-Edn3) hearts. (A-D) Hypopigmented leaflets showing that melanocytes are not present (A) and Collagen I (B) and Versican B (C) have a complementary expression pattern. (E-H) Wild type AV valves showing that the localization of melanocytes (black) (E) overlaps with the areas where Versican B is expressed ( $\mathrm{G}$ and $\mathrm{H}$ ) and not with Collagen I (F). (I-L) Hyperpigmented leaflets (I) and Collagen I (J), and Versican B (K) expression patterns. The melanocytes presence (dark silver) coexists with areas where Versican B is expressed (L). Magnification 20x.

Melanocytes are not normally found in the pulmonary valves of wild type animals (Figure 21A). However, a large number of ${ }_{\mathrm{L}}$-Dopa positive cells was observed in the pulmonary valve of the hyperpigmented animals (Figure 21C). As for the AV valves of hypopigmented animals, the patterns of expression of Collagen I or Versican B in the leaflet of the pulmonary valve (Figure 21D) were not different than those of the leaflets of wild type mice (Figure 21B). Together, the results indicate that melanocytes might not be responsible for regulating the expression of Collagen I and Versican B in the cardiac valves. 


\section{Wild type}
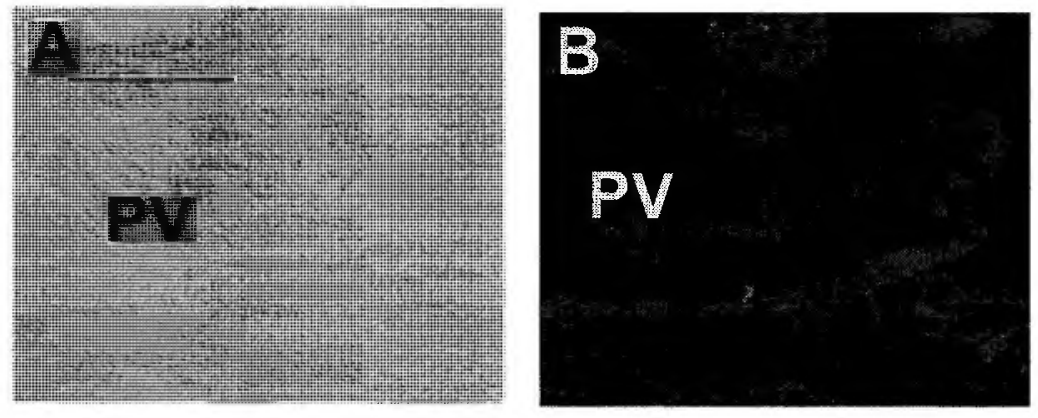

K5-tTA;TRE-Edn3
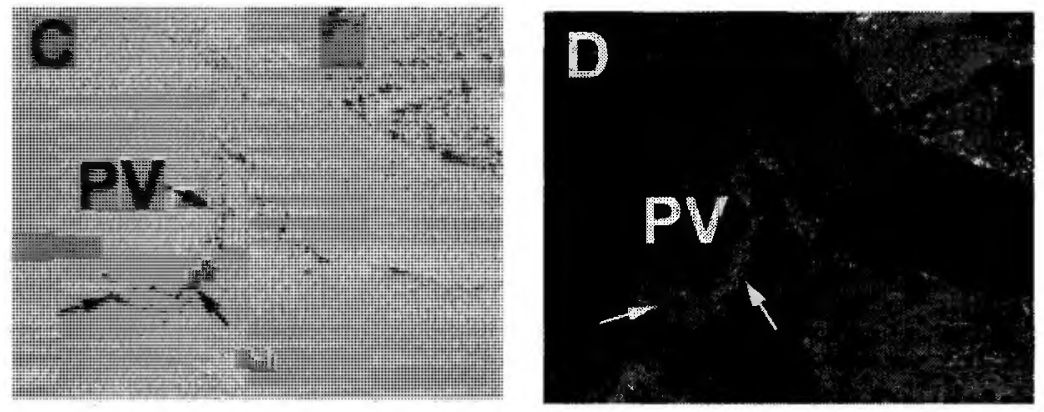

Figure 21. L- Dopa, Collagen I, and Versican B antibody stainings in the pulmonary valves of wild type and hyperpigmented (K5-tTA;TRE-Edn3) hearts. (A) There are no melanocytes present in the pulmonary valve (PV) of wild type hearts. (B) The expression pattern of Collagen I (green) and Versican B (red) are complementary in the wild type pulmonary valve. (C) In hyperpigmented animal, an ectopic expression of melanocytes (black) in the pulmonary valve was detected. (D) Versican B (red) and melanocytes (silver) co-localized in the pulmonary valve of the adult hyperpigmented mouse. Magnification 40x.

\subsection{Mechanical properties of the AV leaflets}

Even though I did not detect alterations in the expression of Collagen I and Versican B in the leaflets of hypopigmented and hyperpigmented mice, there is still the possibility that other relevant ECM molecules might be altered and affect the performance of the valves. Additionally, the simple presence of the melanocytes and/or melanin in the valves may have an effect on some of their mechanical properties. To evaluate these possibilities, I used quasi-static and dynamic nanomechanical techniques 
to measure the stiffness and hardness of the valves with or without melanocytes. Given the small size of the murine valves, a more macromechanical analysis is not possible.

In order to set up a standard for the comparisons of the valves of hypopigmented and hyperpigmented mice, a detailed analysis was initially performed on the tricuspid leaflet of the wild type mouse. A typical nanoidentation load displacement curve was obtained from the wild type leaflet of the tricuspid valve when a $30 \mu \mathrm{N}$ load was applied (Figure 22A). A corresponding scanning probe microscope (SPM) indent image of the leaflet at this load was taken (Figure 22B). A quasi-static nanoindentation of the leaflet at a depth of approximately $67 \mathrm{~nm}$ yielded an average hardness of $106.9 \pm 19.4 \mathrm{MPa}$. This test was immediately followed by the scanning of a $4 \mu \mathrm{m}$ region at a contact force of 0.5 $\mu \mathrm{N}$ and a probe scan speed of approximately $6.4 \mu \mathrm{m} / \mathrm{s}$. The restoration of indentation depth down to $20 \mathrm{~nm}$ (from $\sim 40 \mathrm{~nm}$ after indentation) as seen in the scanning probe microscopy demonstrates the viscoplasticity of the tricuspid leaflet. 

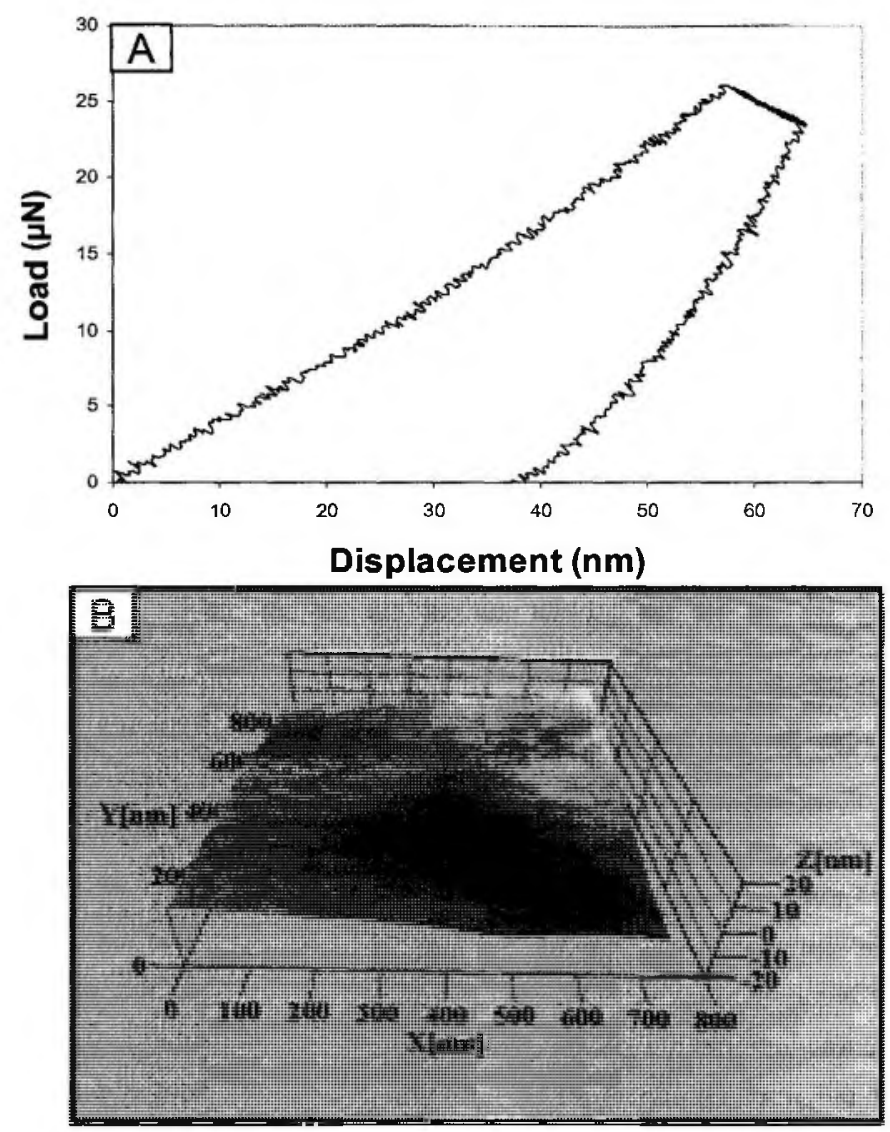

Figure 22. (A) Load displacement curve on tricuspid leaflet, and (B) corresponding SPM image of the indent.

The nanodynamic mechanical testing of various regions in the tricuspid leaflet yielded a wide distribution of storage modulus ranging between 2.5 to $10 \mathrm{GPa}$ (Figure 23). An inverted bell shape modulus distribution was observed in the near-surface region. Since the leaflet is very soft, the initial increase in the surface depth showed increased modulus. Consequently, the values reach a maximum and revert to an equilibrium value straightening the modulus plateau. The non-pigmented areas of the leaflet showed a storage modulus of $2.5-5 \mathrm{GPa}$, which increased to $7-10 \mathrm{GPa}$ in heavily pigmented regions. Areas with moderate amounts of pigmentation had a modulus of approximately 7 
$\mathrm{GPa}$ at varying indentation depths. It should be mentioned that the indentation depth for heavily pigmented regions was lower $(\sim 60 \mathrm{~nm})$ when compared to that of non-pigmented regions (approximately $75 \mathrm{~nm})$ for similar loads $(2-30 \mu \mathrm{N})$ at constant frequency $(100$ $\mathrm{Hz}$ ). For comparison purposes of the dynamic analysis, the indentation depth of $58 \mathrm{~nm}$ was selected (maximum indentation depth observed for highly pigmented areas). Under these conditions the corresponding storage modulus of non-pigmented areas was of approximately $4 \mathrm{GPa}$. The differences in storage modulus between non-pigmented and pigmented areas suggest that the presence of melanocytes in the leaflet may affect its mechanical properties.

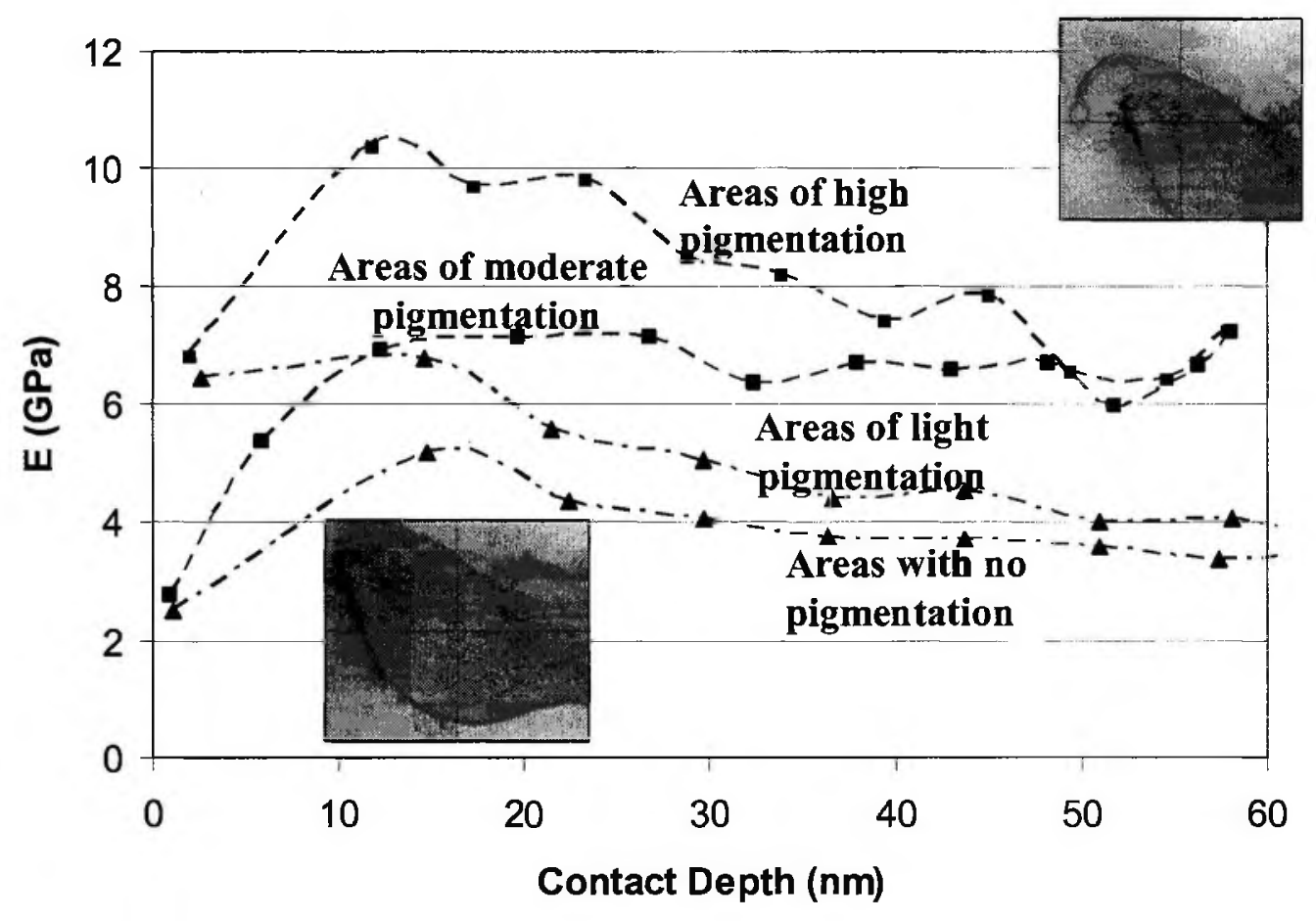

Figure 23. Modulus Variation with Contact Depth of the tricuspid leaflet. 
I further explored this correlation by measuring the storage modulus of the tricuspid leaflets of hypopigmented $\left(K i t^{W-v / W-v}\right.$ and $\left.E d n r B^{s-l / s-t}\right)$ and hyperpigmented (K5$t T A ; T R E-E d n 3$ ) mice. When compared to the average stiffness of approximately $7.5 \mathrm{GPa}$ observed for the areas of moderate pigmentation of wild type leaflets, there was a considerable difference for those obtained for the leaflets of the hypopigmented and hyperpigmented mice. The storage modulus of the hypopigmented leaflets (approximately $5.5 \mathrm{GPa}$ for $\mathrm{Kit}^{\mathrm{W}-\mathrm{v} / W-\nu}$; and $3.5 \mathrm{GPa}$ for $E d n r B^{s-l / s-l}$ ) were much smaller when compared with the wild type while for the hyperpigmented leaflet it was much higher (approximately $11.5 \mathrm{GPa}$ ) (Figure 24). These results support the notion that the presence of melanocytes in the leaflets affects their stiffness.

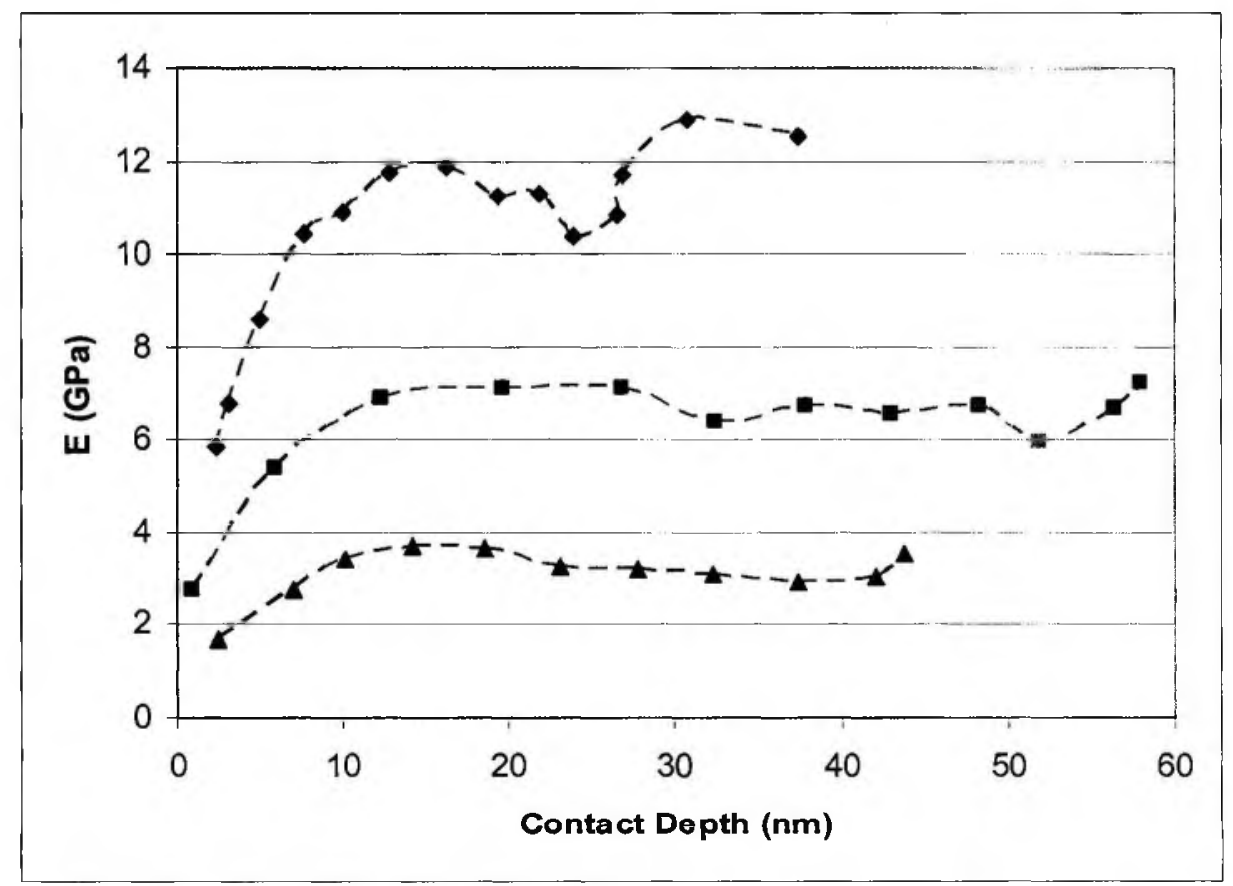

Figure 24. Modulus Variation with Contact Depth of the tricuspid leaflet of hypopigmented $\left(K i t^{W-v /} W_{-v}\right.$ and $\left.E d n r B^{s-l / s-l}\right)$ (red line), wild type (green line) and hyperpigmented (K5-tTA;TRE-Edn3) (blue line), hearts. 


\section{Discussion}

A population of neural crest cells reach the murine heart by embryonic day 11.5 already committed to the melanocytic fate (Brito and Kos, 2008). These cells differentiate and can be identified in the adult heart by their production of melanin (Mjaatvedt et al., 1998). In this study, the analysis of different stages of the post-natal development of the $\mathrm{AV}$ valves revealed that the localization of melanocytes is mostly restricted to the atrial aspect of the leaflets. Some of the melanocytes were found on the surface of the atrial aspect of the leaflets, an area that is in direct contact with blood flow and subjected to shear stress. The valvular endothelium coats the atrial aspect and has been shown to respond to shear changes (Butcher et al., 2004). These cells are thought to participate in valve remodeling and may interact with valvular interstitial cells through the release of paracrine factors (Leask et al., 2003). Although endothelium-denuded leaflets are capable of regulating the expression of collagen and proteoglycans under shear stress conditions, the presence of valvular endothelial cells alters these responses (Sacks and Yoganathan, 2008). The presence of melanocytes in the same region may contribute to these responses.

The absence of melanocytes from the pulmonary valves and presence in the AV valves may be explained by the differences in ontogeny of these valves. While the AV valves are connected to the formation of the outflow tract derived from the arterial pole of the developing heart, the pulmonary valve originates in the venous pole. There is some evidence to suggest that neural crest cells migrate through both poles to populate the heart (Nakamura et al., 2006). However, it is thought that most of the cells that reach the heart via the venous pole undergo apoptosis (Poelmann and Gittenberger-de Groot, 
1999). Some, however, do persist and contribute mostly to the parasympathetic innervations of the heart (Hildreth et al., 2007). It is interesting that in the hyperpigmented transgenic mice that over-express Endothelin 3 (ET3) and have larger numbers of melanocytes in the AV valves, the pulmonary valve is also populated by melanocytes. It is not yet clear why these mice have extra melanocytes in their valves. Preliminary data suggest that the keratin 5 promoter that drives the expression of ET3 to the skin may also direct its expression in the heart. If that is the case, the extra amounts of ET3 may be able to prevent the apoptosis of some of the neural crest cells reaching the heart via the venous pole and maintain them as differentiated melanocytes.

Melanocytes were most closely associated with areas of Versican B expression and absent from areas of Collagen I expression. Versican B is the most common proteoglycan that characterizes the spongiosa layer of the leaflets (Mjaatvedt et al., 1998). It is plausible to speculate that melanocytes might regulate the production or expression of Versican B. My data, however, contradicts this possibility. Leaflets with no melanocytes, such as those from $K i t^{W-v / W-v}$ mice, or leaflets with extra numbers of melanocytes from $\mathrm{K} 5-t T A ; T R E-E d n 3$ mice, showed the same gross pattern of expression of Versican B as that of wild type leaflets.

Another possibility is that Versican B directs the localization of melanocytes in the leaflets. This alternative is actually supported by studies that show a role for Versican in the control of neural crest cell migration. In vivo and in vitro experiments have shown that versican can act as a barrier and negatively regulate the migration of neural crest cells (Braunewell et al., 1995; Perris et al., 1996; Kerr and Newgreen, 1997; Perssinotto et al., 2000; Dutt et al., 2006). 
Interestingly, a recent report has also shown a role for Versican in melanocyte survival (Silver et al., 2008). The spontaneous mouse mutant belted carries a mutation in the ADAMTS20 metalloprotease that prevents it from properly cleaving Versican. In the absence of active Versican, melanocytes precursors undergo apoptosis and leading to a region of hypopigmentation in the trunk of mutant mice. It is therefore, possible that Versican in the spongiosa layer of the leaflets act as a stopping signal for those melanoblasts that reach the developing valves and provide the right environment for their survival.

The valves depend on their ECM organization to perform its biomechanical properties. Although the melanocytes may not contribute directly to valve remodeling through ECM regulation, they may still provide structural support that may influence the function of the valves. In the inner ear, melanocytes provide, among different roles, structural support to the stria vascularis, a membrane responsible for maintaining the endocochlear portential (Tachibana, 1999). In their absence, the cochlea eventually collapses and hearing is impaired.

The correlation between the values of the stiffness coefficients and the areas with different levels of pigmentation in the tricuspid valve leaflet suggest that the melanocytes may indeed affect the biomechanical properties of the valves. They might do so because they offer an extra amount of cellular tissue or because their specific contents, namely melanin, confer more hardness to the valvular structure. The analysis of leaflets of the hearts of albino mice, that have melanocytes but are unable to produce melanin, should discern between these two possibilities. It is important to note that the nanomechanical analysis of the leaflets of the mutant animals showed that at all indentation levels, the 
stiffness coefficients were either all higher (in the hyperpigmented leaflets) or all lower (in the hypopigmented leaflets) when compared to the wild type leaflets. These results suggest that melanocytes are regulating the overall mechanical properties of the leaflets and may be actually changing the leaflet environment. A more detailed histological analysis of the mutant leaflets, including the evaluation of other ECM molecules, will be required to identify such changes.

\section{Material and Methods}

\subsection{Mice}

The animals used in this study were housed in the Animal Care Facility at Florida International University (Miami, FL). Animal work was performed according to institutional guidelines established by the National Institutes of Health. Wild type $(\mathrm{C} 57 \mathrm{BL} / 6 / \mathrm{J}), E d n r b^{s-l}$ (SSL/Le), $E d n 3^{l s}(\mathrm{LS} / \mathrm{LeJ})$, and $K i t^{w-v / w-v}$ were originally obtained from The Jackson Laboratory, Maine. The K5-tTA;TRE-Edn3 transgenic mice were generated in our laboratory as described in Garcia et al., 2008. Noon of the day a vaginal plug was defined as embryonic day 0.5 (E0.5). Harvested embryos were subsequently staged according to standard references (Kaufman, 1995).

\section{$5.2_{L^{-}}$Dopa and antibody staining}

Embryonic and whole mount adult hearts were subjected to the ${ }_{L}$ - Dopa reaction to stain differentiated melanocytes with tyrosinase activity according to previously described protocols (Hirobe, 1984; Hirobe et al., 2002). For the localization of $L^{-}$Dopa positive cells within the heart, paraffin sections $(10 \mu \mathrm{m})$ were taken. 
Immunofluorescence was performed in the paraffin sections $(10 \mu \mathrm{m})$ with primary antibodies (1:100) directed against Collagen I (Southern Biotechnology Associates), and Versican B (Chemicon). The dilution of the antibodies was performed in PengT with $5 \%$ of goat serum and left overnight in a humid chamber. The secondary antibody (1:250) incubation was performed for 3 hours in a room temperature prior to mounting and analysis.

\subsection{Nanodynamic mechanical test}

The nanodynamic mechanical analysis (Nano-DMA) of the valves is evaluated using Hysitron's TriboIndenter (Minneapolis, MN) which uses pyramidal fluid-cell Berkovich tip of $100 \mathrm{~nm}$ radius. Nano-DMA tests were done at $100 \mathrm{~Hz}$ with load-sweep in the range of 2 to $30 \mu \mathrm{N}$ resulting in different contact depths. All the tests were conducted within one hour of the dissection of the tricuspid valves that were kept on ice until the measurement. From the principal quasi static load and much smaller dynamic load of probe tip, displacement amplitude in the range of $0.5-1.5 \mathrm{~nm}$ was maintained to achieve comparable results.

The equation of motion balances as:

$$
F_{0} \sin (\omega t)=m \ddot{x}+C \dot{x}+k x
$$

The displacement response at the same frequency oscillation is $x=X \sin (\omega t-\phi)$, $F_{0}$ is the maximum force, $m$ is the mass of center plate, $C$ and $k$ are combined damping and stiffness respectively, $X$ is the amplitude of displacement oscillation, $\omega$ is angular frequency, and $\phi$ is phase shift of displacement. Consequently, displacement and phase 
lag can be calculated from the response of cell to the loading, from which the stiffness of the cells can be evaluated by subtracting the stiffness of the instrument.

Correspondingly, storage modulus $\left(E^{\prime}\right)$ can be calculated as:

$$
E^{\prime}=\frac{k_{s} \sqrt{\pi}}{2 \sqrt{A_{c}}}
$$

The $k_{s}$ is the stiffness of cells, $A_{c}$ is the contact area, which is dependent on the contact depth. Contact depth of the indenter is described through tip area function during instrument calibration. Storage modulus relates to stiffness of cells, since it falls in direct phase with cells' response to loading. The contact depth response of same cells marginally varied with similar load cycle at varying time, hence, three times repeatable results are being reported without any statistical error analysis.

Measurements were performed at the Bioengineering Department at Florida International University. 


\section{REFERENCES}

Braunewell KH, Pesheva P, McCarthy JB, Furcht LT, Schmitz B, Schachner M (1995) Functional involvement of sciatic nerve-derived versican- and decorin-like molecules and other chondroitin sulphate proteoglycans in ECM-mediated cell adhesion and neurite outgrowth. Eur J Neurosci. 7:805-14.

Brito FC, Kos L (2008) Timeline and distribution of melanocyte precursors in the mouse heart. Pigment Cell Melanoma Res. 21:464-470.

Butcher, JT, Penrod, AM, Garcia, AJ, and Nerem, RM (2004) Unique morphology and focal adhesion development of valvular endothelial cells in static and fluid flow environments. Arterioscler. Thromb. Vasc. Biol. 24: 1429-1434.

Camenisch TD, Spicer AP, Brehm-Gibson T, Biesterfeldt J, Augustine ML, Calabro A Jr, Kubalak S, Klewer SE, McDonald JA (2000) Disruption of hyaluronan synthase-2 abrogates normal cardiac morphogenesis and hyaluronan-mediated transformation of epithelium to mesenchyme. J Clin Invest. 106(3):349-360.

Dutt S, Matasci M, Sommer L, Zimmermann DR (2006) Guidance of neural crest cell migration: the inhibitory function of the chondroitin sulfate proteoglycan, versican. ScientificWorld Journal 6:1114-1117.

Ebenstein DM, Pruitt LA (2004) Nanoindentation of soft hydrated materials for application to vascular tissues. J Biomed Mater Res A. 69:222-232.

Garcia RJ, Ittah A, Mirabal S, Figueroa J, Lopez L, Glick AB, Kos L (2008) Endothelin 3 induces skin pigmentation in a keratin-driven inducible mouse model. $J$ Invest Dermatol. 128:131-142.

Hutson MR, Kirby ML (2007) Model systems for the study of heart development and disease. Cardiac neural crest and conotruncal malformations. Semin Cell Dev Biol. 18:101-110.

Kerr RS, Newgreen DF (1997) Isolation and characterization of chondroitin sulfate proteoglycans from embryonic quail that influence neural crest cell behavior. Dev Biol. 192:108-124.

Kruithof BP, Krawitz SA, Gaussin V (2007) Atrioventricular valve development during late embryonic and postnatal stages involves condensation and extracellular matrix remodeling. Dev Biol. 302:208-217.

Leask RL, Jain N, Butany J (2003) Endothelium and valvular diseases of the heart. Microsc Res Tech. 60:129-137. 
Mjaatvedt CH, Kern CB, Norris RA, Fairey S, Cave CL (2005) Normal distribution of melanocytes in the mouse heart. Anat. Rec. A Discov. Mol. Cell Evol. Bio. 285:748-757.

Mjaatvedt CH, Yamamura H, Capehart AA, Turner D, Markwald RR (1998) The Cspg2 gene, disrupted in the hdf mutant, is required for right cardiac chamber and endocardial cushion formation. Dev Biol. 202:56-66.

Nakamura T, Colbert MC, Robbins J (2006) Neural crest cells retain multipotential characteristics in the developing valves and label the cardiac conduction system. Circ Res. 98:1547-1554.

Pavan WJ, Tilghman SM (1994) Piebald lethal (sl) acts early to disrupt the development of neural crest-derived melanocytes. Proc. Natl. Acad. Sci. USA 91:7159- 7163.

Perissinotto D, Iacopetti P, Bellina I, Doliana R, Colombatti A, Pettway Z, BronnerFraser M, Shinomura T, Kimata K, Mörgelin M, Löfberg J, Perris R (2000) Avian neural crest cell migration is diversely regulated by the two major hyaluronan-binding proteoglycans PG-M/versican and aggrecan. Development 127:2823-2842.

Perris R, Perissinotto D, Pettway Z, Bronner-Fraser M, Mörgelin M, Kimata K (1996) Inhibitory effects of PG-H/aggrecan and PG-M/versican on avian neural crest cell migration. FASEB J. 10:293-301.

Person AD, Klewer SE, Runyan RB (2005) Cell biology of cardiac cushion development. Int. Rev. Cytol. 243:287-335.

Poelmann RE, Gittenberger-de Groot AC (1999) A subpopulation of apoptosis-prone cardiac neural crest cells targets to the venous pole: multiple functions in heart development? Dev Biol. 207:271-286.

Poelmann RE, Jongbloed MRM, Moli DGM, Fekkes ML, Wang A, Fishman GI, Doetschman T, Azhar M, Gittenberger-de Groot AC (2004) The neural crest is contiguous with the cardiac conduction system in the mouse embryo: a role in induction? Anat Embryol. 208:389-393.

Rabkin E, Aikawa M, Stone JR, Fukumoto Y, Libby P, Schoen FJ (2001) Activated interstitial myofibroblasts express catabolic enzymes and mediate matrix remodeling in myxomatous heart valves. Circulation 104:2525-2532.

Rabkin-Aikawa E, Mayer JE Jr, Schoen FJ (2005) Heart valve regeneration. Adv Biochem Eng Biotechnol. 94:141-179.

Sacks MS, Yoganathan AP (2008) Heart valve function: a biomechanical perspective. Philos Trans R Soc Lond B Biol Sci. 363:2481. 
Shoen FJ (2005) Cardiac valves and valvular pathology: update on function, disease, repair, and replacement. Cardiovasc Pathol. 14:189-194.

Silver DL, Hou L, Somerville R, Young ME, Apte SS, Pavan WJ (2008) The secreted metalloprotease ADAMTS20 is required for melanoblast survival. PLoS Genet. 4:e1000003.

Snider P, Olaopa M, Firulli AB, Conway SJ (2007) Cardiovascular development and the colonizing cardiac neural crest lineage. Scientific World Journal 7:1090-1113.

Tachibana M (1999) Sound needs sound melanocytes to be heard. Pigment Cell Res. 12:344-354.

Yajima I, Larue L (2008) The location of heart melanocytes is specified and the level of pigmentation in the heart may correlate with coat color. Pigment Cell Melanoma Res. 21:471-476. 
CHAPTER V: SUMMARY AND FUTURE DIRECTIONS 
The field of heart development has seen a major explosion of novel information during the last decade. We have now started to appreciate the complexity involved in the patterning of the first organ to become functional in the organism. It was generally accepted that all cells contributing to the heart originate from the lateral plate mesoderm. It is now clear that this is not the case. Apart from this group of cells, the primary heart field, other groups of cells such as those that constitute the secondary heart field and the epicardium are also critical during heart development. Although it has been well accepted that neural crest $(\mathrm{NC})$ cells are essential for the proper formation of the outflow tract, their contribution to the heart per se has been a source of constant debate. In this dissertation I have provided evidence that $\mathrm{NC}$ cells and their derivatives contribute cells to the heart, specifically to the atrioventricular (AV) endocardial cushion and the valves that originate from this region. At least part of these cells reach the heart already committed to the melanocytic fate and display a stereotypical distribution in the developing and adult AV valves. There, they may regulate the mechanical properties that are so critical for the control of blood flow in the heart.

In Chapter II, I suggested that the transcription factor Sox10 that has been used as marker for early migrating $\mathrm{NC}$ cells can also be used to label the cardiac neural crest (CNC) cells. As all other markers so far described for CNC cells, Sox10 is downregulated as these cells reach the outflow tract. In contrast to others, Sox10 is subsequently upregulated and marks at least part of the cardiac nerves. It will be interesting to determine if Sox10 is expressed by the neurons of the cardiac ganglia and their axons or the glial cells that surround them. The latter is most likely given that Sox10 is also a marker for Schwann cells in other areas of the PNS. Sox10 homozygous embryos die 
around embryonic day 13.5 (E13.5) of unknown causes. The expression of Sox10 in CNC cells and cardiac nerves suggest that they may die from cardiac failure.

In Chapter II, I have also described a putative new role for $\mathrm{CNC}$ cells in heart development. My experiments showed that in E12.5 Pax3 homozygous embryos, which are deficient in $\mathrm{CNC}$ cells, there is a high number of apoptotic cells in the $\mathrm{AV}$ endocardial cushion. These findings support the idea of a broader role for $\mathrm{CNC}$ cells during development. Most lineage tracing experiments performed in chick or mice have not shown CNC cells reaching as far as the AV endocardial cushion. The few studies that have claimed the presence of CNC cells in this area, describe the existence of very few. Thus, it is very likely that the cells undergoing apoptosis in the AV endocardial cushion in the Pax3 homozygous embryos are not CNC cell derived. Instead, the CNC cells that contribute to the outflow tract or those few cells that reach deeper into the AV endocardial cushion are likely to provide survival factors for other mesenchymal cells. The determination of the lineage of these apoptotic cells and the identification of the factor(s) secreted by $\mathrm{CNC}$ cells that control their survival will further our understanding of the roles played by $\mathrm{CNC}$ cells during heart development.

In Chapter III, I showed that NC-derived melanocytes contribute and persist in areas of the heart other than the OFT. Using the Dct-LacZ mouse model I identified the first day (E12.5) in which melanoblasts can be found within the heart, mostly localized in the AV endocardial cushion. Interestingly, their timing of arrival in the heart coincides with the time when cutaneous melanoblasts populate almost the entire surface of the embryo. Earlier at E10.5, melanoblasts and CNC are co-localized at the otic vesicle level of the embryo. However, the data presented indicates that these are two different cell 
populations based on their level of commitment, signaling dependence and timing of arrival in the heart. Future experiments to investigate whether signaling pathways such as those mediated by Endothelin receptor a and $F G F-8$, which affect $\mathrm{CNC}$ cells but not skin melanocytes, have an effect on cardiac melanocytes will help to clarify if there is a signaling overlap requirement between these two populations of cells.

In hypopigmented mouse mutants (Kit and $E d n r b$ ) no pigmented cells were found in the heart demonstrating that the same signaling pathways are involved in the proper development of melanocytes destined to the skin and the heart. Although the Dct-LacZ transgenic system is inadequate to show that that those melanoblasts found in the heart at E12.5 descend directly from the melanoblasts migrating through the dorsolateral pathway, their reliance on $E d n r b$ and Kit signaling infers that.

In the Dct-LacZ mouse, the dramatic increase in the number of melanoblasts found close to the heart at E11.5 and those seen in the AV endocardial cushions at E13.5 suggests that after the melanoblasts reach the heart, they increase their proliferation rate. This can be due to an environment that is rich in mitogens such as Endothelin 1 and members of the fibroblast growth factor family. In hyperpigmented mice (K5-tTA;TRE$E d n 3$ ), in which the keratin 5 promoter drives transgene expression to certain areas of the heart including the developing AV valves, the higher number of melanocytes in this location reinforces the idea that the cardiac melanocytes respond to the same environmental signaling molecules as the ones that populate the skin. In these animals, melanocytes were also found in ectopic areas surrounding the heart, such as the OFT.

The fact that cardiac melanocytes are absent in Kit mutants and these animals live well into adulthood with an apparent normal heart, showed that those cells are not 
essential for heart morphogenesis or physiology, at least when animals are kept in captivity. They may, however, have a slighter role that becomes critical in stress situations or the presence of melanocytes in the AV valves might give a mechanical support to the valves to avoid reflux of the blood. Although cutaneous melanocytes protect against UV damage and inner ear melanocytes seem to participate in controlling ionic balance for the maintenance of the endocochlear potential, these functions do not seem applicable to those that reside in the heart. The location and timing of arrival of cardiac melanocytes in the heart suggest that they may be involved in AV valve development from the endocardial cushions. They may, for example, be involved in the regulation of ECM remodeling. Additionally, they may play a role in the modulation of the mechanical properties of the leaflets that are critical for the functionality. These possibilities were explored in Chapter IV.

In Chapter IV, I described the localization of melanocytes within the AV valves during post-natal stages of development. There is a possibility that melanocytes are populating these areas because it is the region in direct contact with blood flow and subjected to shear stress. The localization of melanocytes was mostly restricted to the atrial aspect of the leaflets which is coated by a vascular endothelium that responds to shear changes. The vascular endothelium participates in the remodeling of the valve and may interact with valvular interstitial cells through the release of paracrine factors. Melanocytes might be populating the $\mathrm{AV}$ valves to contribute to these responses.

In wild type mice, only the AV valves present melanocytes. This fact might be explained because of the different ontogeny between the AV and pulmonary valves. During development, the AV valves are connected to the formation of the outflow tract 
which is derived from the arterial pole. On the other hand, the pulmonary valve originates in the venous pole. Although there is some evidence suggesting that $\mathrm{NC}$ cells migrate through both poles to populate the heart, the fact that only the AV valves have melanocytes supports the idea that the point of entrance for them is from the arterial pole only. Additionally, there is evidence that most of the cells that reach the heart via the venous pole undergo apoptosis after arrival. Hyperpigmented transgenic mice that overexpress Endothelin 3 (ET3) have melanocytes in their pulmonary valves. It is still unclear the reason for such an ectopic expression but my preliminary data suggested that this might be due to the keratin 5 promoter driving expression of ET3 not only in the skin, but in this case, in the heart. The extra amount of ET3 signal may prevent the apoptosis of NC derived cells arising from the venous pole of the heart.

In order to determine if melanocytes are involved in the regulation or associated with any of the ECM proteins, I analyzed their localization in relationship to the expression pattern of Versican B and Collagen I. These are two important ECM proteins for post-natal valve development. Interestingly, melanocytes were co-localized with areas of Versican B expression, which is the most common proteoglycan that characterizes the spongiosa layer of the leaflets. In hypopigmented and hyperpigmented mice, I did not find a difference in the expression pattern of neither Versican B nor Collagen I when compared with wild type hearts. These findings demonstrate that melanocytes are not involved in the expression of these two ECM proteins. However, there are other isoforms of Collagens, Versicans and other ECMs that are required for post-natal valve formation. Further studies should try to identify the extracellular environment in the AV valves with 
or without melanocytes. The histological analysis can lead to a better understanding of the role melanocytes may play inside de heart.

Previous studies showed that Versican can control NC cell migration acting as a barrier and negatively regulating their migratory trajectory. Thus, it is possible that this may explain why melanocytes and Versican B share the same area in the AV valves. Additionally, a recent report demonstrated that Versican has a role in melanocyte survival supporting the idea that populating the same region within the AV valve would be favorable for the melanocytes.

Although melanocytes might not contribute directly to valve remodeling, it is important to find their role within the AV valves. One of the most attractive hypothesis is that these pigmented cells provide structural support for the proper functioning of the valves. To identify if the mechanical profile of the AV valves is influenced by the presence or absence of melanocytes, I performed experiments that measured the stiffness coefficient of wild type, hyperpigmented and hypopigmented hearts. The analysis of the tricuspid leaflet showed that areas with melanocytes have a higher stiffness coefficient than areas without them suggesting that melanocytes might indeed have an effect in the biomechanical properties of the valves. This can be explained by the presence of more cells, by some particular components of the melanocytes or by alterations that they may exert on the ECM. The one melanocyte specific characteristic that may underlie this phenomenon is the production of melanin. Melanin is a very non-soluble molecule that forms aggregate with proteins, potentially affecting the hardness of the tissue. To understand exactly the way the pigmented cells are influencing the AV valves, a more detailed histological analysis of the mutant leaflets, including the evaluation of other 
ECM molecules, is required. Additionally, experiments to analyze the hearts of albino mice, which have melanocytes but do not produce melanin, will clarify if it is the melanocytes or the melanin that increase the leaflet stiffness.

The understanding of all steps of valve development will help medicine cure valve diseases. In the United States, doctors perform 99,000 heart valve operations each year (www.texasinstitute.org). Nowadays, there are two kinds of valve replacement: the mechanical valves, which are normally made of plastic, carbon or metal; and the biological valves, which are made from animal tissue or taken from a donated heart. Although the mechanical valves are strong and last a long time, the blood tends to stick to them creating blood clots. Patients with this kind of artificial valve have to take anticoagulants for the rest of their lives. The biological valves present problems as well because they are not as strong as the mechanical valves and they only last up to 10 years. However, patients with this kind of artificial valve do not depend of blood-thinning medicine (www.texasinstitute.org). It is clear that the number of valve replacements each year just in the United States urges for a better solution and/or alternative treatments for valve diseases. The understanding of the molecular and mechanical properties of the valves during its embryonic and post-natal development can lead to the advance of optional treatments. 
VITA

\section{FLAVIA CARNEIRO BRITO}

November 9, 1978

1997- 2001

2003- 2007

2005

2006

2008
Born, Camboriu, Santa Catarina, Brazil

B.S., Biology

Pontificia Universidade do Rio Grande do Sul

Porto Alegre, RS- Brazil

Teaching Assistant

Florida International University

Miami, Florida

Excellence in Teaching Award

Florida International University

Miami, Florida

Student Summer Research Award

Florida International University

Miami, Florida

Dissertation Year Fellowship

Florida International University

Miami, Florida

\section{PUBLICATIONS AND PRESENTATIONS}

Carneiro FR, Moraes CR (1999) Contribution for the study of laterality of the population of Porto Alegre, RS, Brazil. IV Scientific Initiation Meeting in Biological Sciences, Pontificia Universidade Catolica do Rio Grande do Sul, Brazil.

Carneiro FR, Pra D, Lau AH, Knakievicz T, Segura GJ, Erdtmann B (2000) Preliminary analisys of planaria's exposition to complex mistures to determine damage on DNA. V Scientific Initiation Meeting in Biological Sciences, Pontificia Universidade Catolica do Rio Grande do Sul, Brazil.

Segura GJ, Knakievicz T, Pra D, Lau AH, Carneiro FR, Erdtmann B (2000) Biografic study of planaria (Girardia) in Rio Grande do Sul. V Scientific Initiation Meeting in Biological Sciences, Pontificia Universidade Catolica do Rio Grande do Sul, Brazil. 
Carneiro FR, Lau AH, Knakievicz, Pra D, Vargas AMS, Segura GJ (2000) Aprimoramento da Tecnica de Cariotipagem de Planarias. XXI Scientific Initiation Meeting, Universidade Federal do Rio Grande do Sul, Brazil.

Segura GJ, Lau AH, Knakievicz, Pra D, Carneiro FR, Vargas AMS, Erdtmann B (2000) Evolution of triploid cellular lineage in mixoploids planarias. XXI Scientific Initiation Meeting, Universidade Federal do Rio Grande do Sul, Brazil.

Carneiro FR, Pra D, Erdtmann B (2001) Genotoxic evaluation of Guaiba Bay- RS utilizing Comet Test with Planaria. XXXXVII Genetics National Meeting, Sao Paulo, Brazil.

Carneiro FR, Kos L (2005) Wnt Signaling in Murine Cardiac Conduction System Development. Seventh Annual Biology Symposium of Florida International University. Fairchild Tropical Botanic Garden, Miami, USA.

Carneiro FR, Kos L (2005) Wnt7a and Wnt11 in Murine Cardiac Conduction System Development. Graduate Student Association 2005 Annual Scholarly Forum. Florida International University, USA.

Pra D, Lau AH, Knakievicz T, Carneiro FR, Erdtmann B (2005) Environmental genotoxicity assessment of an urban stream using freshwater planarians. Mutat Res. 585:79-85.

Brito FC, Kos L (2006) Melanocytes or Cardiac Neural Crest Cells?!. Graduate Student Association 2006 Annual Scholarly Forum. Florida International University, USA.

Brito FC, Kos L (2006) The origin of melanocytes in the murine heart. The $13^{\text {th }}$ Annual Weinstein Cardiovascular and Development Conference. St. Petersburg, FL, USA.

Brito FC, Kos L (2006) Cardiac and Skin Melanocytes respond to the same environmental signals. The $13^{\text {th }}$ Annual Pan American Society for Pigment Cell Research Conference. Cincinnati, OH, USA.

Brito FC, Kos L (2007) The origin of melanocytes in the murine heart. The $16^{\text {th }}$ Biology Research Symposium. Florida International University, Miami, FL, USA.

Brito FC, Kos L (2007) Collagen I and Versican B expressions in hypo and hyperpigmented cardiac valves. Comparative Immunology Symposium. Florida International University, Miami, FL.

Brito FC and Kos L (2008) Timeline and distribution of melanocytes precursors in the mouse heart. Pigmented Cell Melanoma Res. 21:464-470. 